$\mathrm{DOE} / \mathrm{MC} / 23292--3030$

DE92 001103

\title{
Hydrogen Recovery by Novel Solvent Systems
}

\section{Final Report}

\section{R. Shinnar \\ Z. Ludmer \\ A. Ullmann}

August 1991

Work Performed Under Contract No.: DE-AC21-87MC23292

For

U.S. Department of Energy

Office of Fossil Energy

Morgantown Energy Technology Center

Morgantown, West Virginia

By

The City College of New York

New York, New York






\section{DISCLAIMER}

This report was prepared as an account of work sponsored by an agency of the United States Government. Neither the United States Government nor any agency thereof, nor any of their employees makes any warranty, express or implied, or assumes any legal liability or responsibility for the accuracy, completeness or usefulness of any information, apparatus, product, or process disclosed, or represents that its use would not infringe privately owned rights. Reference herein to any specific commercial product, process, or service by trade name, trademark, manufacturer, or otherwise, does not necessarily constitute or imply its endorsement, recommendation, or favoring by the Unted States Government or any agency thereof. The views and opinions of authors expressed herein do not necessarily state or reflect those of the United States Government or any agency thereof.

This report has been reproduced directly from the best available copy.

Available to DOE and DOE contractors from the Office of Scientific and Technical Information, P.O. Box 62, Oak Ridge, TN 37831; prices available from (615)576-8401, FTS 626-8401.

Available to the public from the National Technical Information Service, U.S. Department of Commerce, 5285 Port Royal Rd., Springfield, VA 22161. 



\title{
Hydrogen Recovery by Novel Solvent Systems
}

Final Report
R. Shinnar
Z. Ludmer
A. Ullmann

Work Performed Under Contract No.: DE-AC21-87MC23292

\author{
For \\ U.S. Department of Energy \\ Office of Fossil Energy \\ Morgantown Energy Technology Center \\ P.O. Box 880 \\ Morgantown, West Virginia 26507-0880
}

By
The City College of New York

Convent Avenue \& 138th Street

New York, New York 10031 
PAGE

EXECUTIVE SUMMARY • . . . . . . . . . . . . . . . . . . 1-11

CHAPTER I. INTRODUCTION . . . . . . . . . . . . . 12

CHAPTER II. REVIEW - EXISTING ACID GAS TREATING
TECHNOLOGY . . . . . . . . . . . . . . 15

II.1 CHEMICAL SOLVENTS. . . . . . . . 15

II.2 PHYSICAL SOLVENTS. . . . . . . . . 19

CHAPTER III. ECONOMIC INCENTIVES FOR BETTER PROCESSES FOR HYDROGEN SEPARATION. . . . . . . . . . 26

CHAPTER IV. PROPERTIES OF SOLVENT MIXTURES NEAR THEIR CRITICAL POINT OF MISCIBILITY. . . . . • . 31

CHAPTER V. DESIGN AND CONSTRUCTION OF THE EXPERIMENTAL TEST FACILITY. • . . . . . . . . . . . 36

CHAPTER VI. EXPERIMENTAL RESULTS . . . . . . . . . . . . 41

VI.1 NONLINEAR EFFECTS OF GAS SOLUBILITY
IN CRITICAL SOLVENTS . . . . . . . . . . . . . . . 11

VI.2 DETAILED RESULTS FOR DIFFERENT SOLVENT SYSTEMS. . . . . . . . . . 51

CHAPTER VII. SOME THEORETICAL CONSIDERATION ON THE
RESULTS. . . . . . . . . . . . . . . . . . . 78

CHAPTER VIII. TECHNICAL IMPLICATIONS OF THE RESULTS. . . . 86 


\section{I.S OBJECTIVES:}

The objective of this work is to develop a novel method for purification of hydrogen from coal-derived synthesis gas. The study involved a search for suitable mixtures of solvents for their ability to separate hydrogen from the coal derived gas stream in significant concentration near their critical point of miscibility. The properties of solvent pairs identified were investigated in more detail to provide data necessary for economic evaluation and process development.

\section{II.S BACKGROUND STATEMENT:}

In hydrogen production, separation of hydrogen from the other constituents of raw syngas is expensive and highly energy intensive. A novel, cheaper, and less energy intensive process could here lead to substantial cost reduction. We propose to do this by finding radically improved solvents for extraction processes. One needs to find solvents with a greater power of solution and higher selectivity that can be regenerated with lower energy consumption.

Previous work suggested that a novel class of solvents should have these desired properties. It was found that mixtures of solvents near their critical point of miscibility exhibit strongly improved solvent properties. Solubility for certain compounds strongly increases near the critical composition point. This is similar to the well-known super critical extraction with fluids at their gas-liquid critical point, but has cunsiderable advantages over it, as there is no need for high pressure.

\section{III.S RESULTS AND ACCOMPLISHMENTS:}

The work was carried out in several phases:

III.S.a DEVELOPMENT OF AN EXPERIMENTAL METHOD TO MEASURE GAS SOLUBILITIES IN A TWO PHASE LIQUID MIXTURE OF SOLVENTS.

The first phase was development of a reliable experimental method that allows measurement of the solubilities of different gases in solvent mixtures, being able to measure the solubility in a two phase liquid simultaneously in each of the phases. This task was completed successfully, and led to reliable and reproducible results. The equipment used and the method are described in the reports. 
While the equipment led to reliable and reproducible results, it had two disadvantages that could not be overcome within the time and financial constraints of the program. One was the fact that measurements were slow. To get reproducibly accurate results required significant time, more than a day for each data point. Furthermore the system needed to be calibrated for each new solvent which was time consuming. Also, we were not able to reach temperatures below $-20^{\circ} \mathrm{C}$ due to equipment constraints. With a large and prolonged effort these problems could have been overcome. We decided to concentrate first on getting results and to prove that our basic approach works. Large scale screening of solvent would then be done in a follow up study. The fact that we could prove experimentally the soundness of our approach and obtain sufficient data to evaluate the idea proved that this decision was justified.

\section{III.S.b EXPERIMENTAL RESULTS}

The experimental results based on screening a number of promising partially miscible solvent pairs can be summarizeü as follows:

\section{1) Increased Solubility}

We had originally claimed, based on our theoretical results, that close to the critical point we would find a maximum (or minimum) of solubility and thereby obtain solvents with increased solvent powex. We did not find such solvent pairs. We found pronounced local maxima (or minima) close to the critical point. There were strong deviations in solubility compared to what one would expect from properly averaging the solubilities in the two individual solvents making up the mixture. While in some cases the solubility was higher than the solvent with the higher solubility alone, the increase was modest. However, the result that close to the critical point the mixture behaves differently from what one would expect by properly averaging, has very useful implications in a different way. It modifies the dependence of solubility on temperature, a result that could have very interesting applications which will be discussed separately. Also the impact on solubility is different for different solutes. Thus such mixtures would have different selectivities. Both effects were experimentally confirmed and will be discussed in more detail in the next two sections.

For $\mathrm{CO}_{2}$ and $\mathrm{H}_{2} \mathrm{~S}$, the main impurities in hydrogen purification for coal derived hydrogen, the increased selectivity and temperature effect are more important than an increase in solubility. For methane removal, the solubility 
is much more crucial. Here we did not find any promising solvent pair and we therefore concentrated on the effects of critical solvent mixtures on $\mathrm{CO}_{2}$ and $\mathrm{H}_{2} \mathrm{~S}$.

\section{Increased Selectivity of Solvent Pairs With A Critical point of Miscibility}

We also predicted based on our theoretical analysis that some solvent pairs will have a better selectivity than the single solvents. This was based on the assumption that the impact of the critical point on solubility will be different for different solutes. If this is so one could hope to find solvent pairs in which there is a significant increase in selectivity.

Regretfully, the same nonlinear effect also can lead to a decrease in selectivity. We found examples of both cases. The most interesting results are summarized in Table S.I and Fig. S.1. We note that the effect is significant and quite large. It not only occurs close to the critical point but also close to the concentration limit for complete miscibility which has similar properties. This opens up new avenues when searching for better solvents. It also allows modification and improvement of presently used solvent systems. For example for NMP, the solvent used in the Purisol Process, a $20 \%$ addition of dodecane improves selectivity by $25 \%$, a dramatic improvement of significant economic value. Much more work is needed here to search for optimal systems. What is important for us is to prove the existence of the effect, and, in this research, this was completely successful. This is also an unanticipated important scientific achievement with wide implications for other systems. A patent is being filed.

\section{3) Temperature sensitivity of The solubility In critical Solvent Mixtures}

We noted before that the impact of the critical point phenomena on solubility should lead to a change in the temperature sensitivity of the solubility. Again the change could be in either direction. Table and Fig. S.2 summarizes the results (solvent mixtures investigated with low solubilities are not reported here).

Again we note that the effect is clearly proven much significant, and as expected can either be positive or negative. This again is an important, totally novel scientific development, as to our best knowledge, it has never been reported before. 
Table S.I Selectivity for hydrogen sulfide with respect to carbon dioxide in pure solvents and in critical solution mixtures at 1 atm gas partial pressure

Solvent

Temperature selectivity

Solubility Ratio $\mathrm{H}_{2} \underline{\mathrm{S}} / \mathrm{CO}_{2}$

Selectivity Ratio Mixture/Pure Solvent

\begin{tabular}{|c|c|c|c|}
\hline Acetonitrile & 15 & 3.50 & 1.203 \\
\hline Water & 15 & 2.796 & 1.506 \\
\hline $\begin{array}{l}\text { Acetonitrile } \\
\text { \& Water }\end{array}$ & 15 & 4.212 & \\
\hline NMP & 78 & 8.711 & 1.582 \\
\hline Dodecane & 78 & 2.561 & 5.383 \\
\hline NMP \& Dodecane & 78 & 13.785 & \\
\hline NMP & 20 & 13.131 & 0.817 \\
\hline $\begin{array}{l}\text { Methyl- } \\
\text { Cyclohexane }\end{array}$ & 20 & 5.517 & 1.946 \\
\hline NMP \& MCH & 20 & 10.733 & \\
\hline NMP & 55 & 11.794 & 0.728 \\
\hline Heptane & 55 & 2.523 & 3.405 \\
\hline NMP \& Heptane & 55 & 8.59 & \\
\hline Methanol & 0 & 4.00 & 2.049 \\
\hline Toluene & 0 & 8.043 & 1.019 \\
\hline $\begin{array}{l}\text { Metnanol } \\
\text { Toluene }\end{array}$ & 0 & 8.197 & \\
\hline
\end{tabular}




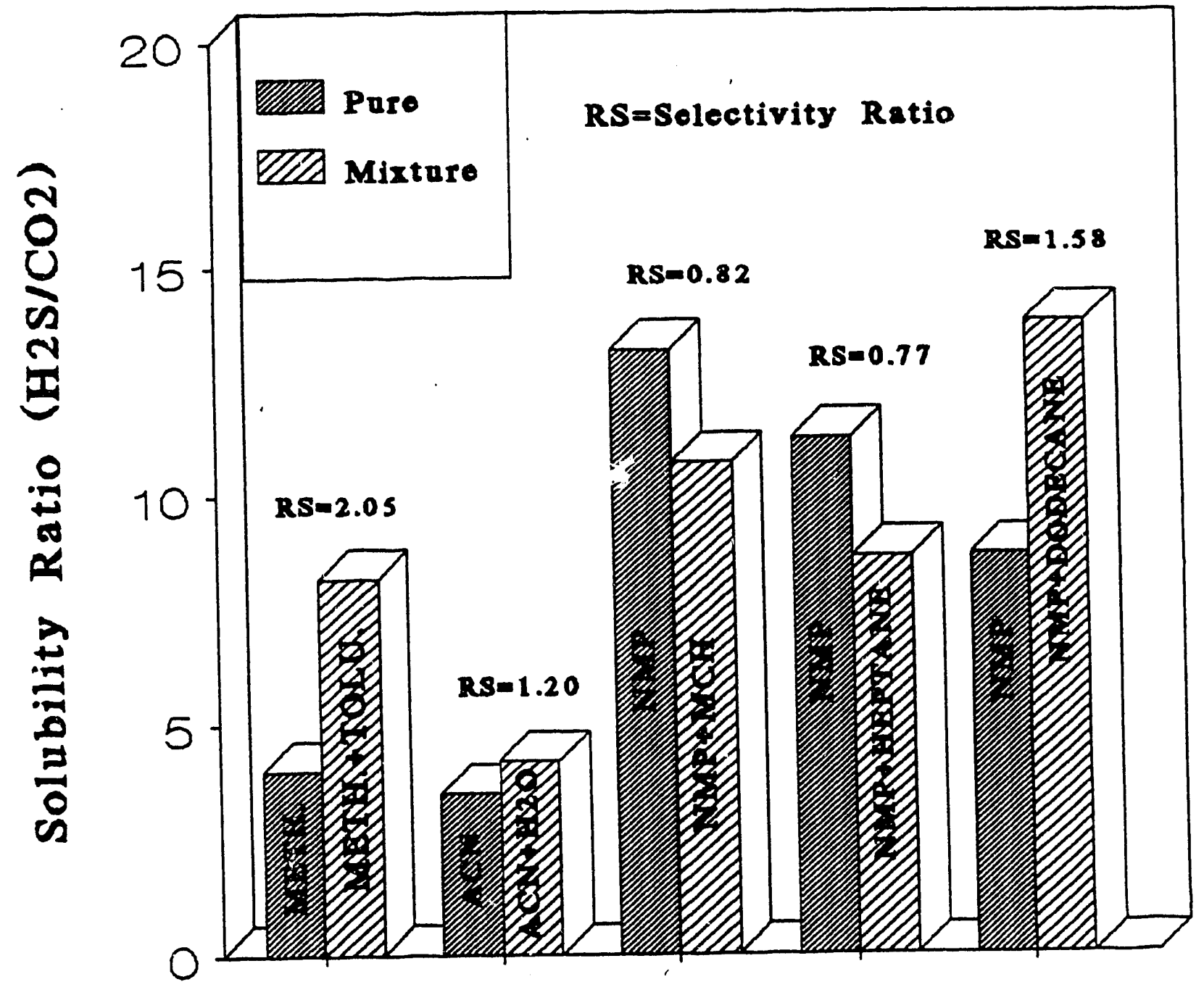

Figure S.1. Selectivity for hydrogen sulfide with respect to carbon
dioxide in pure solvents and in critical solution mixture at 1 atm. gas partial pressure. 
Table S.2 Temperature sensitivity of the solubility in critical solution mixtures. Solvent Solute Temperature (gas) Low, High

Solubility ${ }^{1}$ Solubility

S.R. (mixt.) $\mathrm{T}_{1}-\mathrm{T}_{2}-\mathrm{S}_{1}$ at $T_{1}$, at $T_{2}$ Ratio $S_{1} / S_{2}$ S.R. (pure)

Acetonitrile

$\mathrm{CO}_{2}$

$\begin{array}{ll}-5 & 15\end{array}$
$\mathrm{S}_{1} \mathrm{~S}_{2}$

Acetonitrile

\& Water

$15 \quad 11.56$

8.72

1.33

1.56

8.0

3.87

2.07

Acetonitrile
Acetonitrile

$\mathrm{H}_{2} \mathrm{~S}$

$5 \quad 20$

$33.68 \quad 26.68$

1.26

1.23

\& Water

$21.44 \quad 13.85$

1.55

N-Methyl-pyr-

rolidone(NMP) $\quad \mathrm{CO}_{2}$

35

78

3.65

1.80

2.03

0.70

NMP \&

$1.20 \quad 0.84$

1.43

\section{NMP \\ NMP \&}

$\mathrm{H}_{2} \mathrm{~S}$

35

78

$47.82 \quad 15.68$

3.05

0.57

Dodecane

$20.20 \quad 11.58$

1.74

NMP

NMP \& Methyl-

$\mathrm{CO}_{2}$

3.0

50

$5.50 \quad 2.70$

2.04

1.05

cyclohexane

$5.10 \quad 2.39$

2.13

NMP

NMP \& Methyl-

$\mathrm{H}_{2} \mathrm{~S}$

20

60

$62.80 \quad 23.59$

2.66

1.21

Cyclohexane

$45.08 \quad 13.99$

3.22

NMP
NMP \& Heptane

$\mathrm{CO}_{2}$

20

70

$4.76 \quad 2.05$

$3.25 \quad 1.17$

2.32

2.78

1.20

NMP

NMP \& Heptane

$$
\mathrm{H}_{2} \mathrm{~S}
$$

2.0

70

$62.80 \quad 19.61$

3.20

3.85

1.20

Methanol

Toluene

Methanol \&

$\begin{array}{lll}\mathrm{H}_{2} \mathrm{~S} & -16 & 20\end{array}$

$62.00 \quad 15.90$

$58.20 \quad 18.60$

3.90

0.71

Toluene 
Table S.2 (Cont'd)

\begin{tabular}{|c|c|c|c|c|c|c|c|}
\hline \multirow[t]{2}{*}{ Solvent } & \multirow{2}{*}{$\begin{array}{l}\text { Solute } \\
\text { (gas) }\end{array}$} & \multicolumn{2}{|c|}{ Temperature } & \multicolumn{2}{|c|}{ Solubility } & \multirow{2}{*}{$\begin{array}{l}\text { Solubility } \\
\text { Ratio } S_{1} / s_{2}\end{array}$} & \multirow{2}{*}{$\frac{\text { S.R. (mixt.) }}{\text { S.R. (pure) }}$} \\
\hline & & $\begin{array}{c}\text { Low, } \\
\mathrm{T}_{1}\end{array}$ & $\begin{array}{c}\mathrm{High} \\
\mathrm{T}_{2}\end{array}$ & $\begin{array}{l}\text { at } T_{1}, \\
S_{1}\end{array}$ & $\begin{array}{l}\text { at } T_{2} \\
\underline{S}_{2}\end{array}$ & & \\
\hline \multirow{2}{*}{$\begin{array}{l}\text { Methanol } \\
\text { Methanol \& } \\
\text { Toluene }\end{array}$} & $\mathrm{CO}_{2}$ & -16 & 20 & 12.61 & 4.16 & 3.03 & 0.76 \\
\hline & & & & 7.04 & 3.07 & 2.29 & \\
\hline \multirow{2}{*}{$\begin{array}{l}\text { Lutidine } \\
\text { Lutidine \& } \\
\text { Water }\end{array}$} & $\mathrm{CO}_{2}$ & 5 & 50 & 7.34 & 3.07 & 2.39 & 2.08 \\
\hline & & & & 6.65 & 1.34 & 4.96 & \\
\hline
\end{tabular}

(1) Volume of the gas at standard condition over solute-free solvent volume. 


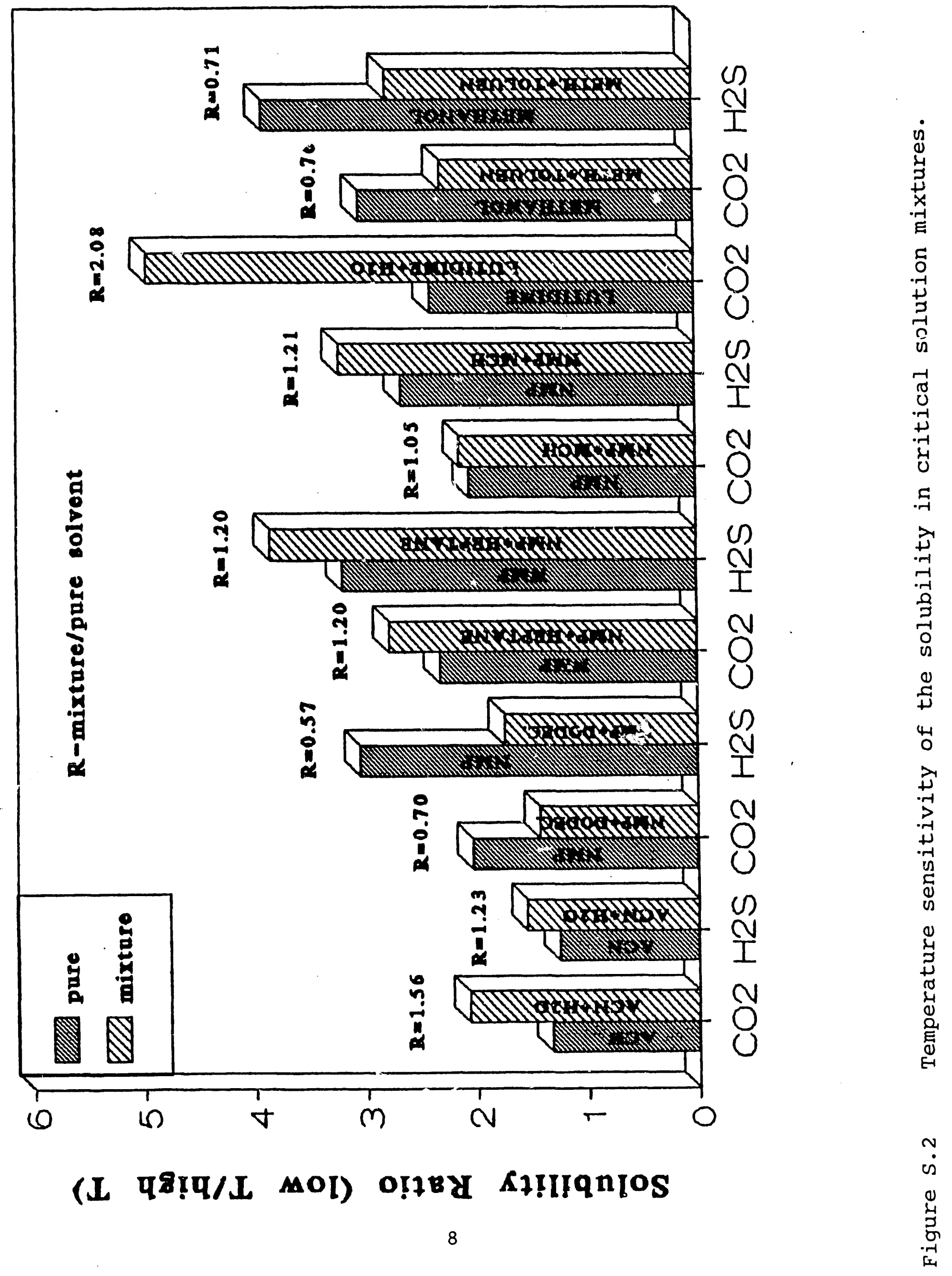


4) Desolubilization of Gases By Mixing of Solvents

One aspect of operating close or across a critical point is that strong changes occur over a narrow temperature/pressure range with small inputs of energy. This is the basis of many processes in supercritical extraction using single fluids. Our work showed that in some cases there is a similar phenomenon here that can be utilized for developing a novel separation process.

This process, explained in detail in the report, is schematically explained in Fig. S.3. Fig. S.3 gives an example of $\mathrm{CO}_{2}$ removal based on the system acetonitrile-water. As the nonlinear effects are different for different gases, such a removal process has a potential for high selectivity.

5) Use of Solvent Mixture with A Lower Critical Point

Solvent mixtures with a lower critical point (in which the mixture separates into two phases above a critical temperature) have a special interest in the sense that here one would expect a stronger impact on the temperature gradient. This was confirmed by our results with a lutidine water mixture shown in Fig. S.4. At a temperature of $5^{\circ} \mathrm{C}$ below the critical point, the critical mixture has a solubility for $\mathrm{CO}_{2}$ practically equal to pure lutidine whereas close to the critical point it is closer to that of water. This interesting effect has strong practical implications and permits further investigation.

\section{IV.S ECONOMIC VALUE OF THE RESEARCH}

In the production of $\mathrm{H}_{2}$ by gasification of coal, removal of $\mathrm{CO}_{2}$ and $\mathrm{H}_{2} \mathrm{~S}$ from the gasifier product is a major item in the total cost (25\% of investment and operating cost). The novel concepis for improved solvents have a potential for reducing the total gas clean up cost by $30 \%$. However, considerable further work in evaluating such solvents is required to realize this potential. 


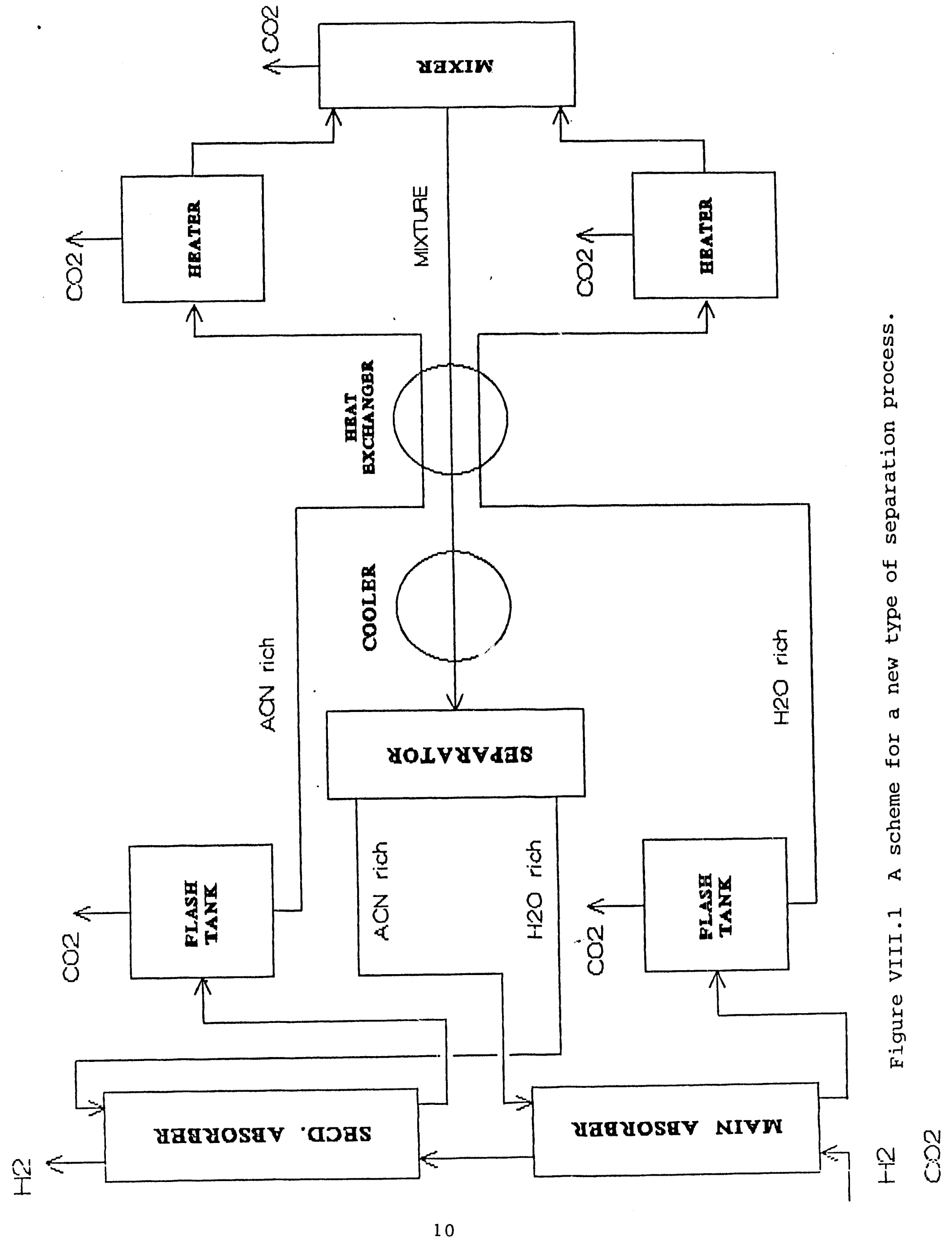




\section{SOLUBILITY OF $\mathrm{CO} 2$ \\ LUTIDINE+WATER}

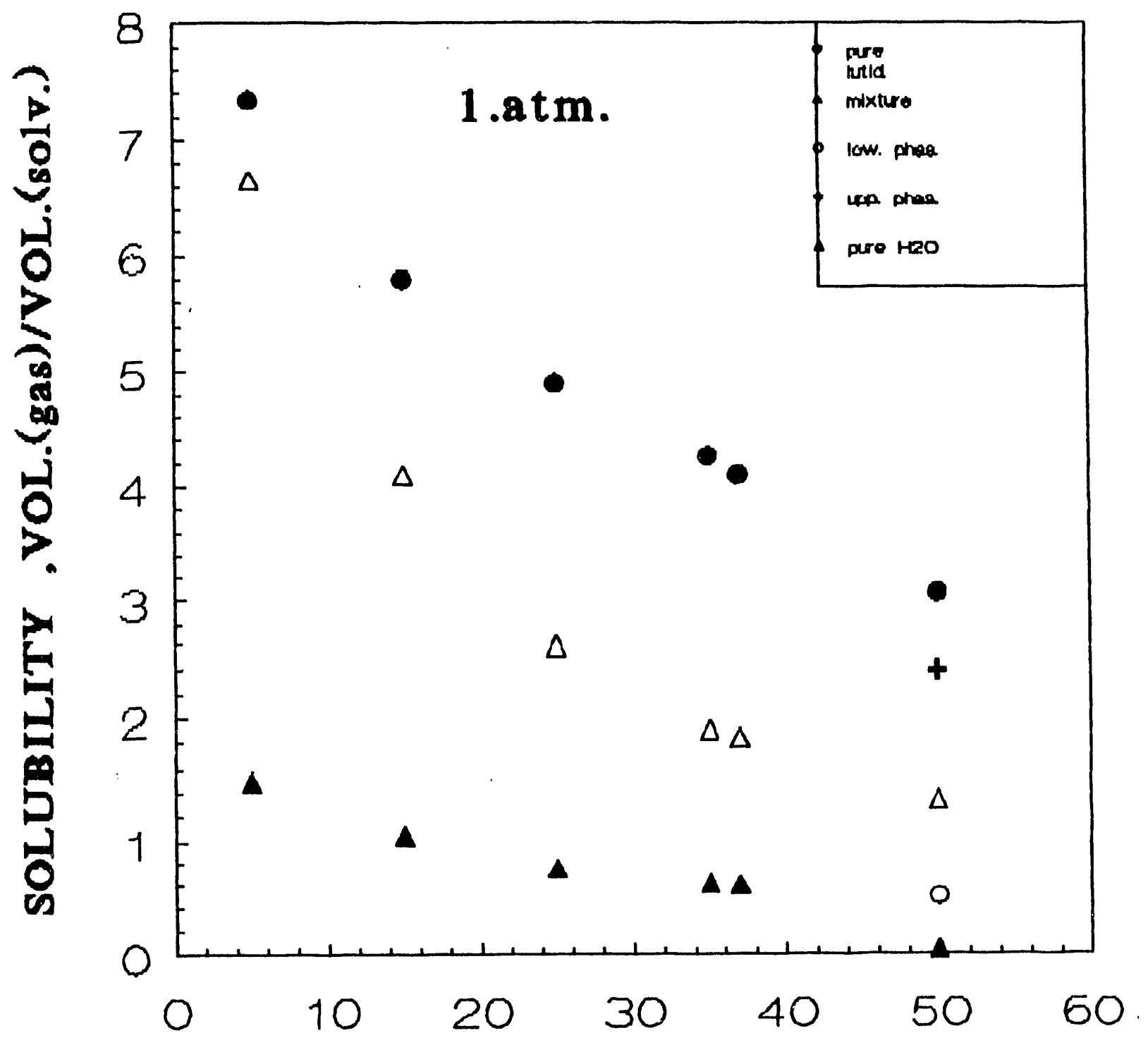

TEMPERATURE , C

Figure S.4 in critical mixture as a function of temperature. 


\section{INTRODUCTION}

Hydrogen from coal is produced by first gasifying the coal to a syngas containing a mixture of $\mathrm{CO}, \mathrm{H}_{2}, \mathrm{CO}_{2}, \mathrm{H}_{2} \mathrm{~S}$ and $\mathrm{CH}_{4}$. The exact composition of that mixture is a function of both coal properties and the gasifier used. Entrained bed gasifiers do not generate any methane, whereas syngas from fluidized bed gasifiers and moving bed gasifiers contain substantial amounts of methane.

The syngas mixture is then shifted and then the $\mathrm{H}_{2}$ is separated from the rest of the gases (see Fig. I.1). Alternatively, the $\mathrm{H}_{2} \mathrm{~S}$, together with some $\mathrm{CO}_{2}$, is removed before the shift, with later removal of the $\mathrm{CO}_{2}$. A detailed review of existing processes as given in section II was published as a separate topical report [Shinnar, 1989], and will only be shortly summarized here.

Basically, there are two available options to separate the $\mathrm{H}_{2}$ from methane, one is based on steam reforming and pressure swing adsorbers using molecular sieves. All components including unreacted methane are passed through a series of packed beds containing molecular sieve adsorbers. All compounds excluding $\mathrm{H}_{2}$ are adsorbed and a very high purity of $\mathrm{H}_{2}$ is obtained. However, only $85 \%$ of the $\mathrm{H}_{2}$ is removed. The rest is fed together with the purge stream to the furnace of the steam reformer (see Fig. I.2).

This method at present is not attractive for producing $\mathrm{H}_{2}$ from coal gasification due to the low hydrogen recovery. The present alternatives are either pure physical solvent processes, separation processes based on chemical binding, or mixed solvents that adsorb both by physical adsorption and chemical binding. [Kohl and Riesenfeld, 1985; Qader, 1985; Whyte et al., 1983; Hochgesand, 1970 ].

The next section gives a review of these processes. The separation of $\mathrm{H}_{2}$ from $\mathrm{H}_{2} \mathrm{~S}$ and $\mathrm{CO}_{2}$ is costly and for present processes contributes about 25.0 to $30.0 \%$ of total process cost both in terms of investment and operatingcost. It is also energy intensive. There is therefore a strong need for better purification processes both for syngas and hydrogen production from coal. In this contract an attempt was made to find better solvents for physical solvent based separation processes. The basic idea underlying this attempt is the use of a solvent mixture with a critical point of miscibility.

Such solvents possess two attractive potential uses:

a) Near the critical point, there are strong nonlinear interactions that lead to maximum and minimum solubility. The impact is different on different solutes. This can lead to improved selectivities and a steeper temperature dependence.

b) Near the critical point small changes in temperature lead to large changes in properties due to phase changes, which gives an additional tool to the process designer. 




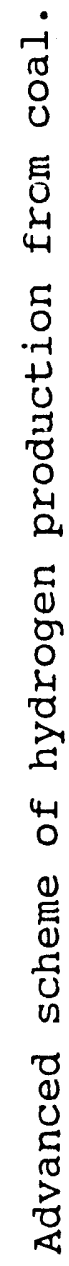






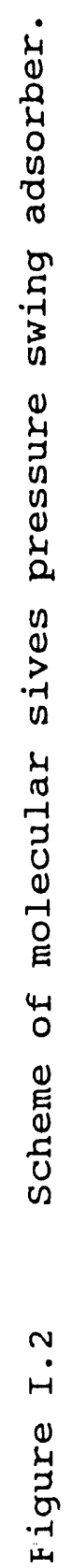


These properties of the critical point of miscibility are similar to the properties of the critical point of phase transition in single solvents, which form the basis of supercritical extraction processes.

The goal of this contract was to investigate if these features apply to gaseous solutes and therefore gas separation processes. our results show that some of these solvent pairs have properties which should make them very interesting for gas separations.

our report is organized in the following way. In section II we give a short review of existing technology. Section III outlines the economic incentives.' section IV explains the theoretical concepts of critical solvents and their potential impact. Section $V$ describes the experimental procedure. Section VI gives the experimental results. section VII outlines a theoretical approach to estimate the direction in which the nonlinearities impact on solubilities of different gases near the critical point. This allows more efficient screening for solvents. section VIII discusses their impact on process design as well as the work needed for bringing the technology to a stage where it can be implemented on a full industrial scale. 
Absorption is probably the most important and most common gaspurification technique. It involves the transfer of substance from the gaseous to the liquid phase through the phase boundary. The absorbed material may dissolve physically in the liquid (physical solvents) or react chemically with it (chemical solvents).

\section{1 CHEMICAL SOLVENTS}

Two choices are available for chemical solvent systems: alkanolamines and alkaline salt solutions.

\section{Alkanolamines for Hydrogen Sulfide and Carbon Dioxide Removal}

Credit for the development of alkanolamines as absorbents for acidic gases goes to R.R. Bottoms [Bottoms, 1936] who in 1930 was granted a patent covering this application.

The two amines which have proved to be of principal interest for gas purification are monoethanolamine (MEA) and diethanolamine (DEA). Triethanolamine (TEA) which was the first to become commercially available, has been displaced largely because of its low capacity, its low reactivity, and its relatively poor stability. Diisopropanolamine (DIPA) [Klein, 1970] is being used in the Adip process and in the sulfinol process. Two other commercial solvents are available, methyldiethanolamine (MDEA) and diglycolamine (DGA).

A comparison of the solvents based on selected physical properties, is shown in Table II.1.

The basic flow scheme for all alkanolamine acid-gasabsorption process systems is shown in Figure II.1. Various modifications, such as water or glycol wash for amine recovery and a split-stream cycle to reduce the steam requirement, are commonly used.

Selective absorption of hydrogen sulfide in the presence of carbon dioxide, especially in cases where the ratio of carbon dioxide to hydrogen sulfide is very high, has become the subject of considerable interest, particularly in the purification of nonhydrogen gases such as coke-oven gas, the products from coal gasification processes, and claus plant tail gas. The early work of Kohl [Kohl, 1951] has shown that MDEA can absorb hydrogen sulfide reasonably selectively under proper operating conditions involving short contact times. Additional information on selective hydrogen sulfide absorption with MDEA or MDEA-based solutions [Crow and Baumann, 1974; Blane and Elgue, 1981; Sigmund et al., 1981] indicate that, with proper design, selective solvents can yield hydrogen sulfide concentrations as low as 4 ppmv in the treated gas while permitting a major fraction of the carbon dioxide to pass through unabsorbed. 

Absorption.

A prime requirement for absorptive solution to be used in regenerative $\mathrm{CO}_{2}$ and $\mathrm{H}_{2} \mathrm{~S}$ removal processes is that any compounds formed by reactions between the acid gas and the solution must be readily dissociated. This precludes the use of alkaline salts with weak acids. Typically, the processes employ an aqueous solution of a salt containing sodium or potassium as the cation with an anion so selected that the resulting solution is buffered to a $\mathrm{pH}$ of about 9 to 11. Sodium and potassium carbonate solutions have been used extensively for the absorption of $\mathrm{CO}_{2}$ and $\mathrm{H}_{2} \mathrm{~S}$ from gas streams because of their low cost and ready' avaifability.

A process that has gained broad acceptance for acid gas removal is the Benfield Process. This process was developed by the U.S. Bureau of Mines, at Bruceton, Pennsylvania, by Benson, Field, and co-workers in the early 1950's [Benson et al., 1954, 1956]. Upon leaving the Bureau of Mines, Benson and Field formed the Benfield Corporation which was later acquired by Union Carbide Corp. The Benfield hot potassium carbonate process employs conventional packed or trayed towers for countercurrent contact of gas and liquid. Figure II.2 shows a process flow diagram of the simplest configuration, a single-stage design. Research and development work by the Benfield Corporation and Union Carbide has significantly improved the economics and extended the applicability of the original process. The addition of proprietary activators to enhance the reaction kinetics and to alter the vapor-liquid equilibrium relationship has led to reduced tower size, a greater degree of purification, and improved thermal efficiency. various flow schemes were developed such as the Benfield Hipure Process, which produces very high purity product gases [Benson and Parrish, 1974].

Since hydrogen sulfide is absorbed much more rapidly in potassium carbonate solution than carbon dioxide, it would be expected that the process could be made at least partially selective for hydrogen sulfide. Lowering the absorption temperature would decrease the rate of carbon dioxide absorption without effect on the hydrogen sulfide absorption rate, thus resulting in increased selectivity. Rib et al [Rib, 1983], showed by operating a two stage Benfield system, that under operating conditions investigated, over $90 \%$ of the $\mathrm{H}_{2} \mathrm{~S}$ and $40 \%$ of $\mathrm{CO}_{2}$ could be removed, with about $70 \%$ of the $\mathrm{CO}_{2}$ retained in the product gas.

In general, chemical absorption systems suffer from a number of economic disadvantages in separation of feed gas containing high levels of $\mathrm{CO}_{2}$. The conventional processes such as alkanolamine and hot potassium are too energy intensives and have high maintenance costs due to the corrosive nature of the system and solvent degradation. 
Table İ. 1

Property

Mol. weight

Specific Gravity, $20 / 20^{\circ} \mathrm{C}$

Boiling Point, ${ }^{\circ} \mathrm{C}$

$\begin{array}{rl}760 \mathrm{mmHg} & 171 \\ 50 \mathrm{mmHg} & 100 \\ 10 \mathrm{mmHg} & 69\end{array}$

Vapor Pressure, minh at $20^{\circ} \mathrm{C}$

0.36

Freezing Point, ${ }^{\circ} \mathrm{C} \quad 10.50$

Solubility in water $\%$ by weight, $20^{\circ} \mathrm{C}$

Absolute viscosity, cps at $20^{\circ} \mathrm{C}$

24.10

$380\left(30^{\circ} \mathrm{C}\right) \quad 1,013$

$\begin{array}{ll}1.0919 & 1.1258 \\ 30 / 20^{0} & \end{array}$

decoinp.

187

150

0.01

28.00

0.01

21.20

$-21.00$

Complete Complete 87.00

Complete

Heat of Vaporization, Btu/lb at 1 atm.

355

$288(23 \mathrm{~mm}) 230$ $\left(168.5^{\circ} \mathrm{C}\right)$

MDEA *

119.17

1.0418

247.2

164

128

0.01

0.01

0.01

$45 / 20^{\circ}$

1.0550

244

Complete

101 $198\left(45^{\circ} \mathrm{C}\right)$ $26\left(24^{\circ} \mathrm{C}\right)$

Approximate cost, $\$ / 1 b$

0.47

0.48

0.49

0.97

0.44

0.68

* Data of Union Carbide Chemicals Company

** Data of Texaco Chemical Company, Inc. 


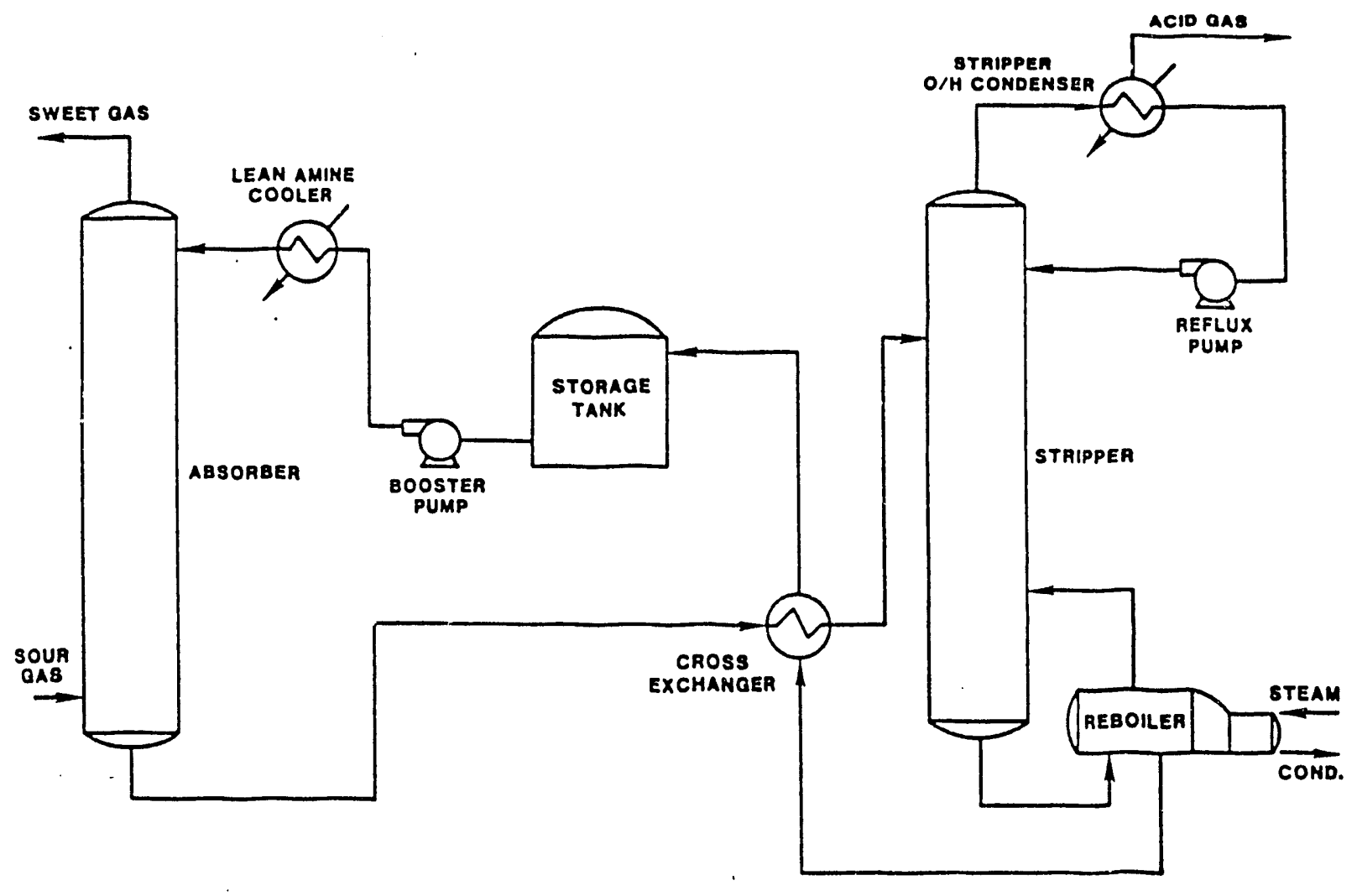

Figure II.1 Process flow sheet for common alkanolamine sweetening plant. 


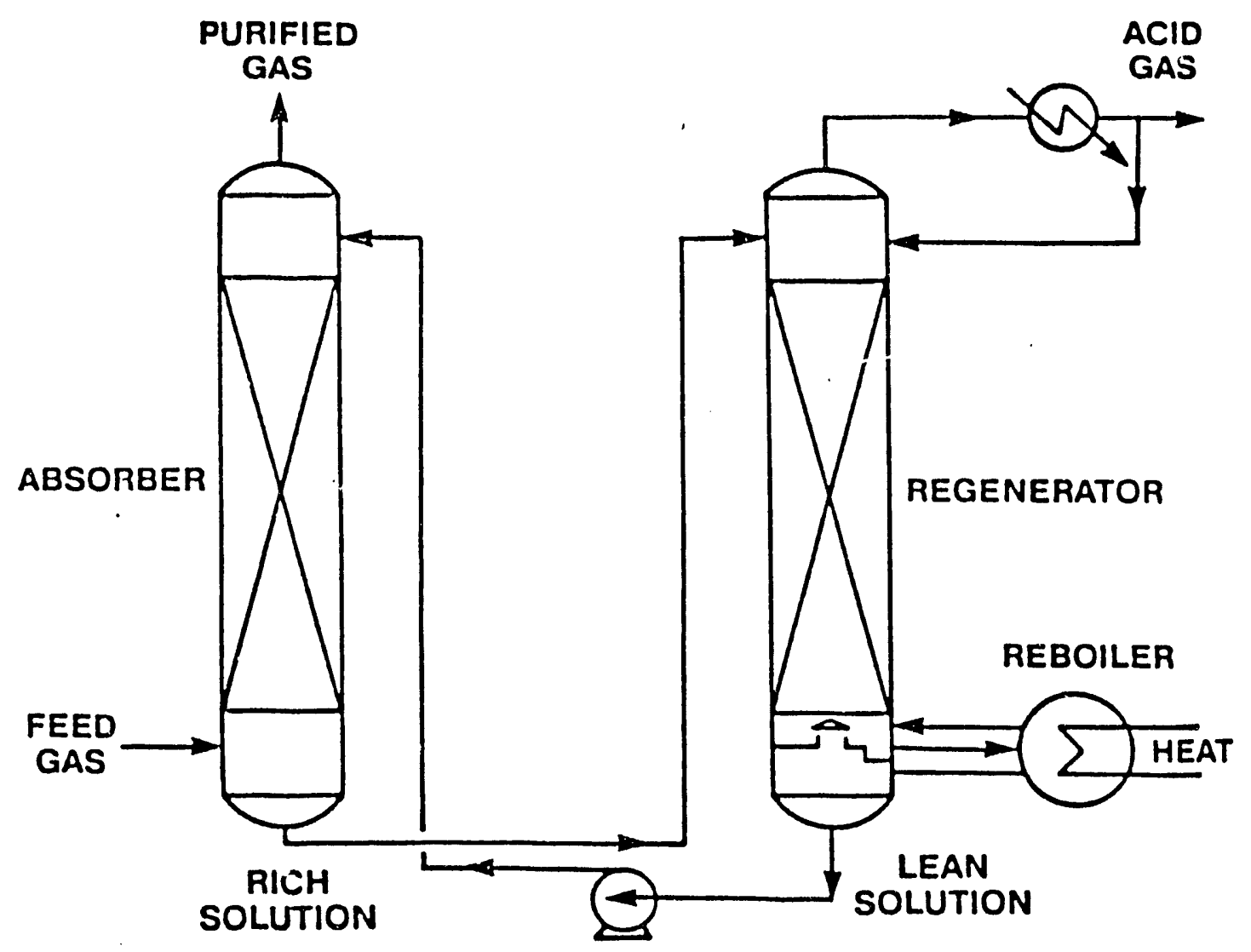

TYPICAL APPLICATIONS

Natural Gas

SNG

Ethylene Oxide

Figure II.2 Benfield single-stage absorber. 


\section{2 PHYSICAL SOLVENTS}

To overcome the economic disadvantages of heat-regenerable reactive solvent processes several processes have been developed which are based on the use of essentially anhydrous organic solvents which physically dissolve the acid gases and can be stripped by reducing the acid-gas partial pressure. Today, the commercially proven physical solvent processes and their solvents are:

$\begin{array}{lll}\text { Estasolvan } & - & \text { tributyl phosphate or TBP } \\ \text { Fluor Solvent } & - & \text { propylene carbonate or PC } \\ \text { Purisol } & - & \text { N-methyl-pyrrolidone or NMP } \\ \text { Rectisol } & - & \begin{array}{l}\text { methanol } \\ \text { dimethyl ether of polyethylene glycol or } \\ \text { Selexol }\end{array} \\ \text { Sepasolv-MPF } & -\quad \begin{array}{l}\text { Selexol } \\ \text { mixture of polyethylent glycol dialkyl } \\ \text { ether or Sepasolv }\end{array}\end{array}$
listed.

In Table II.2, the physical properties of the solvents are

of the solvents, methanol is relatively high in vapor pressure at normal process conditions and reguires deep refrigeration or special recovery methods to prevent high sclvent losses and therefore will be discussed separately.

In their simplest form, physical solvent processes require little more than an absorber, atmospheric flush vessel, and recycle pump. No steam or other heat source is required. When the absorbed gases are desorbed from the solution by flushing at atmospheric pressure, the lean solution contains acid gas in an amount corresponding to equilibrium at 1 atm acid-gas partial. pressure; and this therefore, represents the theoretical minimum partial pressure of acid gas in the purified-gas stream. To obtain a higher degree of purification, vacuum or inert gas stripping or heating of the solvent may be employed. Other process modifications are being used to minimize loss of valuable gas components, provide a relatively low temperature of operation, and otherwise improve process economics.

Most organic solvents have an appreciably higher solubility for hydrogen sulfide than for carbon dioxide, (see Table II.3) and a certain degree of selective $\mathrm{H}_{2} \mathrm{~S}$ removal can be attained. This feature is of significance when the ratio of $\mathrm{CO}_{2}$ to $\mathrm{H}_{2} \mathrm{~S}$ in the crude gas is so high that the acid gases cannot be processed in a standard Claus unit. By removing essentially all of the $\mathrm{H}_{2} \mathrm{~S}$ and only a portion of the carbon dioxide, this ratio can be lowered sufficiently to permit normal processing in a claus plant.

The operation of a typical solvent process is illustrated in the schematic flow diagram shown in Figure II.3. This example incorporates three possible modes of solvent regeneration, i.e., simple flashing, inert gas stripping, and heat regeneration. In addition, a split-stream cycle is shown (broken line) which can be used for bulk removal of acid gases with partially stripped solvent, followed by final purification with completely regenerated solvent. 
Lets now summarize the commercially proven physical solvent processes:

The Fluor solvent Process

The Fluor Solvent Process, which is licensed by the Fluor Corporation of Los Angeles, was first described (Kohl, 1.960) in 1960. Although several solvents have been covered by patents, only propylene carbonate has so far been used commercially. In 1975, the process was reported to be in use in ten commercial installations (Anon; 1975).

\section{The Purisol process}

This process which was developed by Lurgi Gesellschaft fur warme and. Chemotechnik m.b.h. of Frankfurt, West Germany, is presently being used in four commercial installations, two treating natural gas and two in hydrogen plant service (Anon, 1975). Discussion of the basic features of the process and of its application have been presented in several papers (Hochgesand, 1970; Bevon and Roszkowski, 1969). The solvent used in the Purisol process is NMP, which has an exceptionally high solubility for $\mathrm{H}_{2} \mathrm{~S}$; thus, it is particularly suitable for selective $\mathrm{H}_{2} \mathrm{~S}$ absorption in the presence of $\mathrm{CO}_{2}$.

\section{The Selexol Frocess}

This process, which was developed by Allied Chemical Corporation and, since 1982, is licensed by the North Company, has been described quite extensively in the literature (Sweng 1970; Valentine, 1974; Sweng, 1976; Judd, 1978). It is used widely for bulk removal of $\mathrm{CO}_{2}$ from natural and synthesis gases and for selective sulfur removal from a variety of gas streams. In 1984, about 40 plants were either in operation or under construction worldwide.

\section{The Estasolvan Process}

Disclosed jointly by Institut Francaise du Petrole of France and Friedrich Uhde, G.m.b.H. of West Geimany (Franckowiak, 1970), the process was ciemonstrated in two pilot plants, but so far no commercial applications have been reported. The solvent used in the Estasolvan process, TBP, is reported to have high capacity for acid gases and good selectivity for hydrogen sulfide with respect to carbon dioxide (Franckowiak, 1970).

\section{The Sepasolv MPE Process}

This process, which was developed by BASF of West Germany, is quite similar to the selexol process, both with respect to the solvent used and its mode of operation (Walfer, 1980, 1982). It was initially developed primarily for the selective removal of $\mathrm{H}_{2} \mathrm{~S}$ 
Table'II.2 Miscellaneous Comparative Data of Solvents




Table II.3

Solubility of hydrogen sulfide in solvents relative to carbon dioxide at $25^{\circ} \mathrm{C}$.

\section{Solvent}

$\begin{array}{lcc}\text { Selexol } & - & 8.93 \\ \text { PC } & - & 3.29 \\ \text { NMP } & - & 10.20 \\ \text { Sepasolve } & - & 6.86 \\ \text { TMP } & - & 5.6 \\ \left.\text { Methanol (at } 25^{\circ} \mathrm{C}\right) & - & 7.06\end{array}$




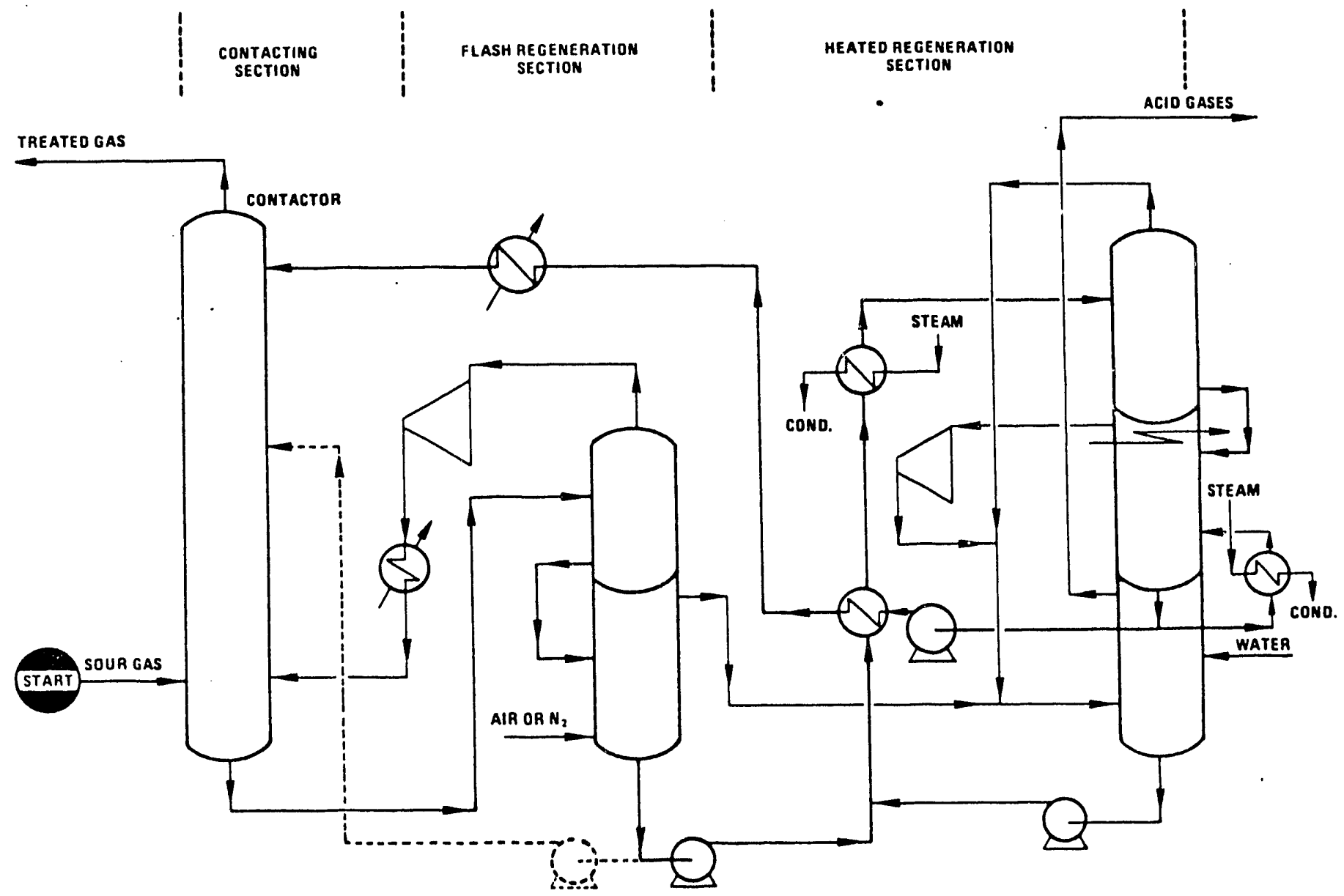

Figure II.3 Typical physical solvent process flow diagram. 
from natural gas, but reportedly is also suitable for $\mathrm{CO}_{2}$ removal from synthesis gases.

In contrast to the other solvent processes described above, the Sulfinol and Amisol processes employ a mixture of a chemical and physical solvents as the absorptive medium and are, in many respects, comparable to the chemical solvent processes described in Section II.1. However, the presence of the physical solvent enhances the solution capacity appreciably over that of the conventional chemical solution. The solvent consists of DIPA, Sulfolane, and water. The Sulfinol process is licensed by Shell International Research M.j N.V., The Hague, The Netherlands and Shell Development Co., Houston. 'The process has found wide application in the treatment of natural, refinery, and synthesis gases. In 1975, over 100 commercial units were reported to be in operation or under construction (Anon., 1975).

The Amisol process disclosed by Bratzler and Doerges (Bratzler, 1974) is similar to the sulfinol process in that it uses a combination of physical and chemical solvents for acid gas removal. The solvent consists of methanol with an undisclosed addition and MEA or DEA.

Another branch of the physical solvent processes are the Low Temperature Gas-Purification Processes. In these processes the crude gas is first precooled and some of the impurities are removed by condensation. Final purification is attained by absorption of the remaining impurities in methanol or liquid carbon dioxide.

\section{The Rectisol Process}

In this process, which was developed in Germany by Lurgi Gasellschaft fur Warmetechnik, removal of $\mathrm{CO}_{2}, \mathrm{H}_{2} \mathrm{~S}$, organic sulfur compounds, hydrogen cyanide, and benzene from synthesis gases is accomplished by physical absorption in methanol at low temperatures $\left(-32^{\circ} \mathrm{F}\right)$. Advantage is taken of the high solubility of these compounds especially $\mathrm{CO}_{2}$ and $\mathrm{H}_{2} \mathrm{~S}$ in methanol at low temperatures (see Tables II.2 and II.3). The principal advantages claimed for the process are (a) considerably lower energy consumption than is required in chemical solvent processes, (b) satisfactory removal of all undesirable impurities in a single process and (c) production of product gas with very low water content (Hoogendoorz, 1957).

The basic flow scheme of the Rectisol process for the treatment of synthesis gas produced by coal gasification is shown in Figure II.4. The main disadvantages of the process are (a) its complex flow scheme, and (b) relatively high vaporization losses of the solvent, caused by the appreciable vapor pressure of methanol even at low temperatures. If $\mathrm{H}_{2} \mathrm{~S}$ has to be removed from the feedgas, but $\mathrm{CO}_{2}$ may remain in the purified gas, selexol, sepasolv, and NMP are more suitable than methanol. 
This process (Hise, 1982), is a joint development of CNG Research Corporation, the U.S. Department of Energy, and Helipump Corporation. The process, which is still in the developmental stage, is proposed for acid gas removal from coal-derived gases available at pressures above 300 psig and containing high concentrations of $\mathrm{CO}_{2}$, typically in excess of 25 mole percent. The $\mathrm{CO}_{2}$ is condensed at a temperature near its triple point $\left(-69^{\circ} \mathrm{F}\right)$ and subsequently used as the solvent for the removal of $\mathrm{H}_{2} \mathrm{~S}, \mathrm{CO}_{2}$ and other impurities such as $\mathrm{COS}, \mathrm{CS}_{2}, \mathrm{HCN}$, and mercaptans. A simplified flow diagram of the process is shown in Figure II. 5.

The advantages claimed for the process are complete removal of all sulfur compounds and trace impurities, production of a gas stream rich in $\mathrm{H}_{2} \mathrm{~S}$, production of pure $\mathrm{CO}_{2}$, low solvent flow rates, and low energy consumption. 




Figure II.4 Schematic flow diagram of basic Rectisol process. 
C-1 $\mathrm{CO}_{2}$ Absorber-Condenser

$\mathrm{C}-2 \mathrm{H}_{2} \mathrm{~S}$ And Troce Impurities Absorber

F-1 Flosher

C-3 Triple Point Crystallizer

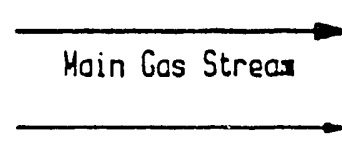

Other Strecas


T

$\mathrm{CO}_{2}(\mathrm{~s})$

Sluiried in Solvent (1)

Refrigerant-

Abscrbent

$c-1$

F-1

Purified Cos

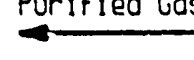

Crude Cas
$\mathrm{CO}_{\text {,-solvent (1) }}$
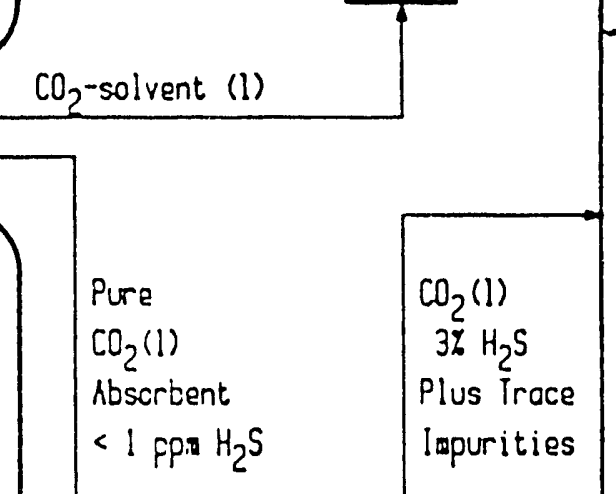

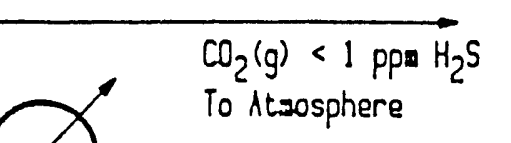

To Atsosphere

1

$30: \mathrm{CO}_{2}(\mathrm{~g})$

Plus Troce Impurities

To Clous Plant

$\mathrm{CO}_{2}(\mathrm{~g})<1 \mathrm{pp} \mathrm{H}_{2} \mathrm{~S}$
$\mathrm{To}$ Atzosphere

$\mathrm{C}-3$ g. $\mathrm{CO}_{2}(\mathrm{~g})<1$ ppa
To Atsosphere



Recovery

1 inecovery

\section{Pover}

Recovery

Sour Yater

Figure II.5 Simplified flow diagram of CNG acid gas removal process. 
The investment cost for separating $\mathrm{H}_{2}$ from $\mathrm{H}_{2} \mathrm{~S}$ and $\mathrm{CO}_{2}$ in a plant based on an entrained bed coal gasifier (no need for $\mathrm{CH}_{4}$ removal), varies between one-third to one-fourth of total investment. This includes incremental offsites and utility consumption which are also significant. A summary is given in Table III.1. If the cost of gasification itself is reduced in the future, either by a better gasifier or by cheaper oxygen, then the fraction of cost incurred by the separation process is going to increase. Further cost reduction, therefore, requires paying equal attention to gas separation and looking for new ways to reduce the cost. Let us, therefore, briefly summarize what these costs depend on. There are several major items.

1) The investment in the extraction contactors is a function of the solvent flow rate needed. High solubility of the gas is therefore essential.

2) The stripping of the gas from the solvent has a high energy consumption, especially for chemical solvents, and is costly.

3) To minimize solvent losses, one needs either a high-boiling solvent or a refrigeration system. The methanol losses in the Great Plains Plant are so high that the plant produces its own methanol in a small methanol plant.

One way to reduce these costs significantly is to find improved solvents, and most improvements in recent years have been due to the development of better solvents. This work continues the trend, introducing a totally new class of solvents. Now, what are the crucial properties of a solvent that could lead to a significant cost reduction?

A) The three compounds, $\mathrm{H}_{2} \mathrm{~S}, \mathrm{CO}_{2}$ and $\mathrm{CH}_{4}$ have to be removed separately. At least the gas stream coming from the $\mathrm{H}_{2} \mathrm{~S}$ removal must contain a much higher ratio of $\mathrm{H}_{2} \mathrm{~S}$ to $\mathrm{CO}_{2}$ than the syngas itself. Otherwise, the feed is not suitable for a claus plant, which requires at least $20 \% \mathrm{H}_{2} \mathrm{~S}$ in the feed, and one would have to choose a more expensive process to convert the $\mathrm{H}_{2} \mathrm{~S}$ to sulfur. Thus, the Great Plains SNG plant used a stretford process, due to the low $\mathrm{H}_{2} \mathrm{~S}$ content of the gas, which is not only expensive but causes operating problems. The solvents must therefore be selective, and one should be able to adjust this selectivity.

B) There should be a high gradient of solubility with temperature. This would significantly reduce the expense of stripping the solvent from the gas. We will later note that some of the solvents identified in this research lead to modifications of the present scheme which could lead to further cost reductions. 




0
0



$\theta$

$\theta$


40
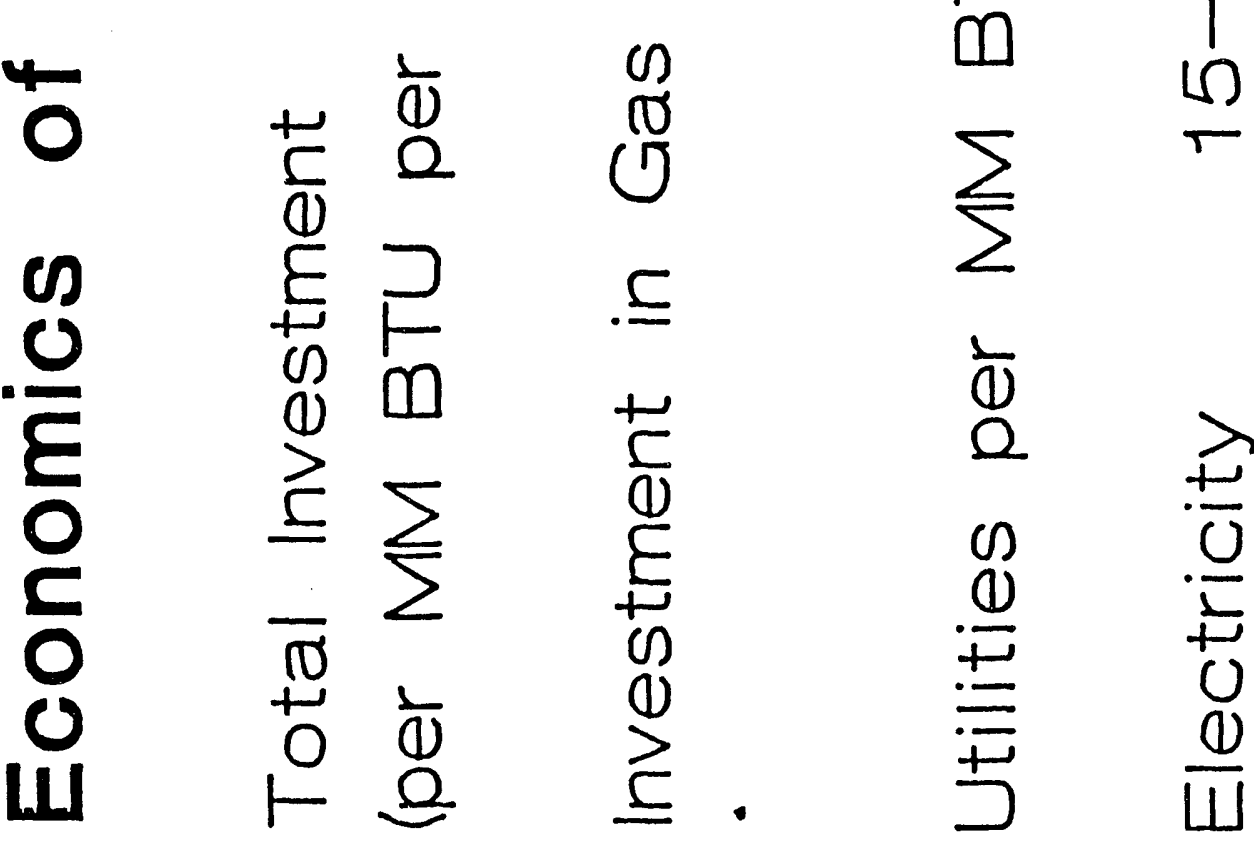

O
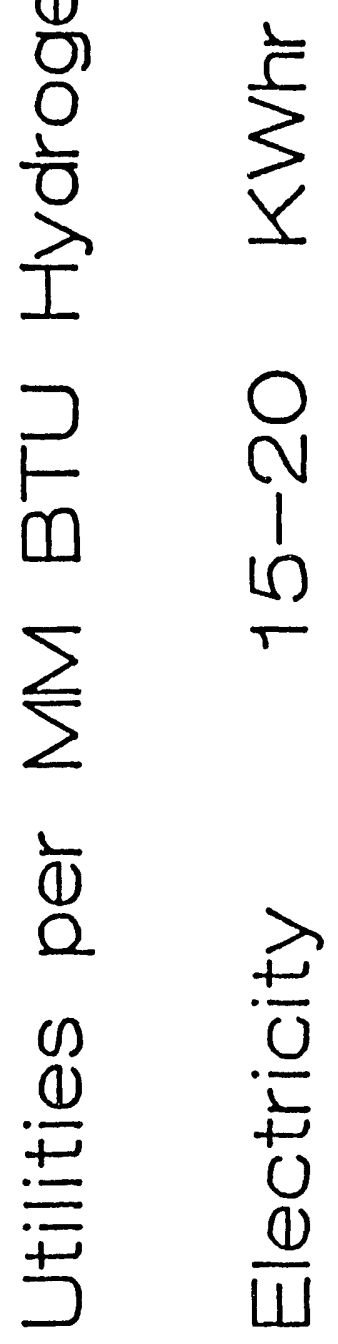

눙

O



으

م

○)

1 吾

0

$\forall$

음

.

$+0$

ช :

艾

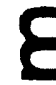

0
0
0
U.

0

唔

雚完

$\varepsilon \quad$.

(ర)

(1) है

茂 
IV. PROPERTIES OF SOLVENT MIXTURES NEAR THEIR CRITICAL POINT OF MISCIBILITY.

a) Introduction

Let us consider a binary mixture of solvents which has a critical point of miscibility. The meaning of such a critical point can be explored by a phase diagram (see Fig. IV.1).

This figure describes the concentrations of components $A$ and $B$ as a function of temperature. The region marked "one phase" represents conditions of complete miscibility of components $A$ and $B$, whereas regions marked "two phase" correspond to separation into two phases. When the phase diagram shows a maximum (Fig. IV.1a), it is called an upper critical solution temperature (UCST), whereas a minimum (Fig. IV.1b) corresponds to a lower critical solution temperature (LCST).

A single fluid also has a vapor-liquid critical point. Above the critical temperature, there is only one phase independent of pressure. At that singular point the interaction between the two phases is very strong. In the last twenty years it has been found that near this critical point there are some very interesting thermodynamic effects, [Paulaitis, et al., 1983a, b]. The solubility of many compounds has a distinct maximum near this critical point and the selectivity of the liquid for dissolving different compounds is also strongly increased. This has led to a whole variety of new separation processes called supercritical extraction, some of which have been commercialized. The main drawback in using supercritical fluids is the necessity of working under relatively high pressures [Penninger, et al. 1985]. There are only a few suitable solvents which have critical points at low pressures and temperatures.

The idea has been postulated (Ludmer et al., 1987) that binary solvent mixtures near their critical point of miscibility have very similar properties to those at the critical point of the liquid-gas equilibrium of a single fluid. If so, they should have unique properties for separation processes. The advantage of such solvents over conventional supercritical extraction is that there are a large number of such binary solvents available with critical points of miscibility at low temperatures, and the effect is independent of pressure. Thus, we can tailor make a solvent for a specific application.

\section{b) Selectivity}

CST mixtures close to their critical point should also be selective [Ludmer, Shinnar, Yakhot, 1987]. The solubility $\left(n_{i}\right)$ of a solute in a binary mixture close to its immiscibility critical point was shown to have the following form:

$$
\left(n_{i}\right)-\exp \left(\alpha_{i}^{2} \delta^{2} / 4 T^{2}\right)
$$



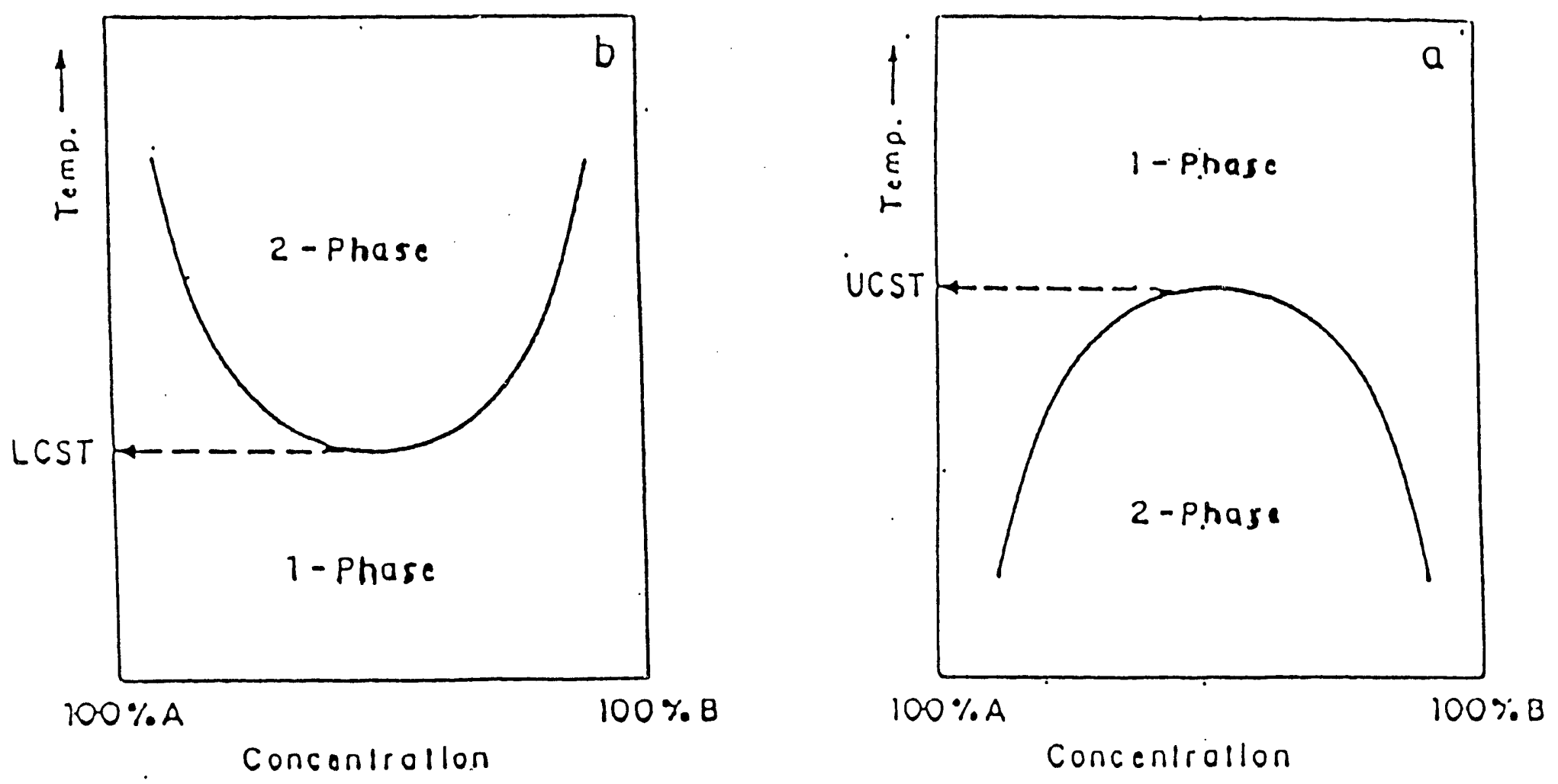

Figure IV.1 Coexistence curve of immiscible binary mixture. 
where $\delta^{2}$ - the square of the order parameter is defined as

$$
\begin{gathered}
\delta^{2}=\tau^{3 v-\gamma} f\left(C / \tau^{\beta}\right) \\
\tau=\left(T-T_{c}\right) / T_{c} \\
C=X-X_{c}
\end{gathered}
$$

$x_{c}$ - denotes the critical composition

$$
\alpha_{i}=\frac{\delta \varphi_{i}(X, P, T)}{\delta X_{i}}
$$

$\alpha_{i}$ represents the change in the chemical potential due to fluctuations in solvent composition.

It has been shown previously that in the vicinity of the critical point the critical exponents have the following values:

$$
\gamma \sim 1.23, \quad v \sim 0.63, \beta \sim 0.33
$$

The scaling function in Eq. (2) can be expanded as follows:

$$
f(x)=1-a x^{2}+\ldots \ldots
$$

By substituting expressions $(2,4)$ into (1), one obtains the following equation:

$$
n_{i} \sim \exp \left[\left(\tau^{3 v-\gamma}-a c^{2} \tau^{3 v-\gamma-2 \beta}\right) \alpha_{i}^{2} / 4 T^{2}\right]
$$

From Eq. (5) it is clear that at the critical point (c=0), the solubility has a maximum value.

Figures IV.2 to IV.4 are schematic presentations of solubilities as predicted by expression (5). Fig. IV.2 describes the solubility of two solutes far away from the critical point. The next two figures describe the solubilities close to the CST. Fig. IV.3 deals with a hypothetical example of two solute molecules having close $\alpha$ values, and Fig. IV. 4 with solutes having different $\alpha$ values. One can see that Eq. (5) predicts that far away from the CST there should not be any maximum in solubility, however, close to the critical point a maximum is expected. Fig. IV.3 shows that even for close $\alpha$ values, in the vicinity of the critical point the system is selective. For solutes with different values of $\alpha$, the selectivity is expected to be pronounced (see Fig. IV.4).

The effect of temperature is best explained using equations 2 and 5. The solubility function has one minimum value at $T=T_{c}$ and another minimum at $\tau<1$. Between those two minima a maximum in solubility as a function of temperature is expected. This maximum is not at the critical point but close.

Let us now look at what available evidence and theory predict for the solubility of a gas in a solvent mixture as a function of composition. If one uses a mixture of two solvents, then solubility of a solute is not simply an average of the amount 

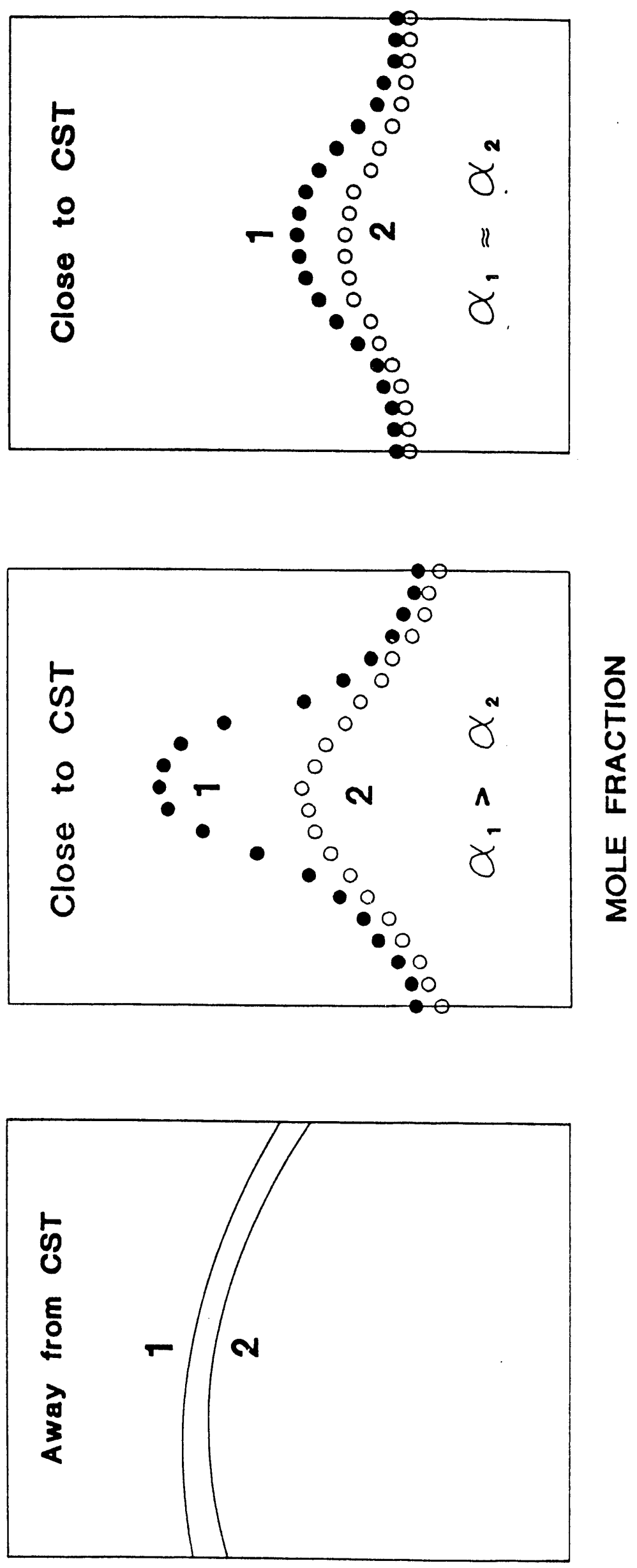

OD

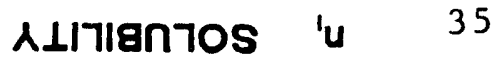


dissolved in each solvent. If $H$ is the Henry constant defined by

$$
H_{i}=p_{i} / x_{i}
$$

where $p_{i}$ is the partial pressure of the gas compound in equilibrium with the solution and $x_{i}$ the molar fraction of the dissolved gas in the mixed solution, then the solubility of the gas in an ideal mixture and low gas concentration can be computed [O'Connell, 1971] from

$$
1 \mathrm{nH}_{3, \mathrm{~m}}=\mathrm{x}_{1} \operatorname{lnH}_{3,1}+\mathrm{x}_{2} \mathrm{InH}_{3,2}
$$

Where 3 denotes the dissolved gas, $I$ and 2 the solvents, and $m$ the mixture. $\mathrm{H}_{3,1}$ and $\mathrm{H}_{3,2}$ are the Henry constants in the pure solvents. Equation (7)' is derived by computing the thermodynamic potential in an ideal mixture of two solvents with no interactions. Obviously, a CST mixture has strong interactions, which can be indicated by either positive (higher solubility) or negative (decreased solubility compared to Eq. (7)). Consider now a case where the interactions are zero. We assume that the solvent mixture is based on one solvent for which $\mathrm{H}$ is large and one for which $\mathrm{H}$ j.s small (good solvent). We plot such a hypothetical case in Fig. IV.5, as a function of composition. We also give in Fig. IV.5 another average based on a linear mass balance. Assume that we mix two volume fractions, $Y_{1}$ and $Y_{2}$, of the pure solvents at the dissolved gas partial pressure $\mathrm{p}_{3}$, (with $\mathrm{s}_{3,1}$ and $\mathrm{s}_{3,2}$ the volumetric solubilities of the gas in the pure solvents). If there is no interaction due to the mixing, the average solubility would be

$$
S_{3, m}=Y_{1} S_{3,1}+Y_{2} S_{3,2}
$$

We note that in an ideal mixture (Eq. 7) the solubility is strongly reduced compared to the linear average of Eq. (8).

We should point out that there is no thermodynamic basis for eq. (8). From a process point of view, however, it is very important to know how much the actual solubility deviates from eq. (8).

Assume now that we have the good solvent (index 1) saturated with a gas and mix it with the poor solvent (index 2) to form a mixture that has the composition of the CST. But we do it at a temperature above the CST. If tile mixture obeys eq. (7), a large fraction of the dissolved gas would be released. However, the problem is how do we recover the pure solvent 1 . In a mixture with a CST one can do this by simply cooling the mixture below the CST. If one cools it sufficiently below, one obtains almost two pure solvents. All one needs is a mixture with a CST at a temperature such that the heating and cooling can be done without a significant energy expenditure.

We could not find any published data that would support the ideas presented here. There are very few data for gas solubilities in solvent mixture, and almost none for mixtures with a critical point. The existing data almost all deal with solvents for which the difference in $\mathrm{H}$ is less than a factor of 2 . Therefore, any of the ideas discussed in section IV required experimental verification, which was one of the major goals of this contract. 
our results confirmed the theoretical expectation. Before discussing them, we will discuss, in the next section, the experimental methods used for this task and the building of an experimental test facility. 


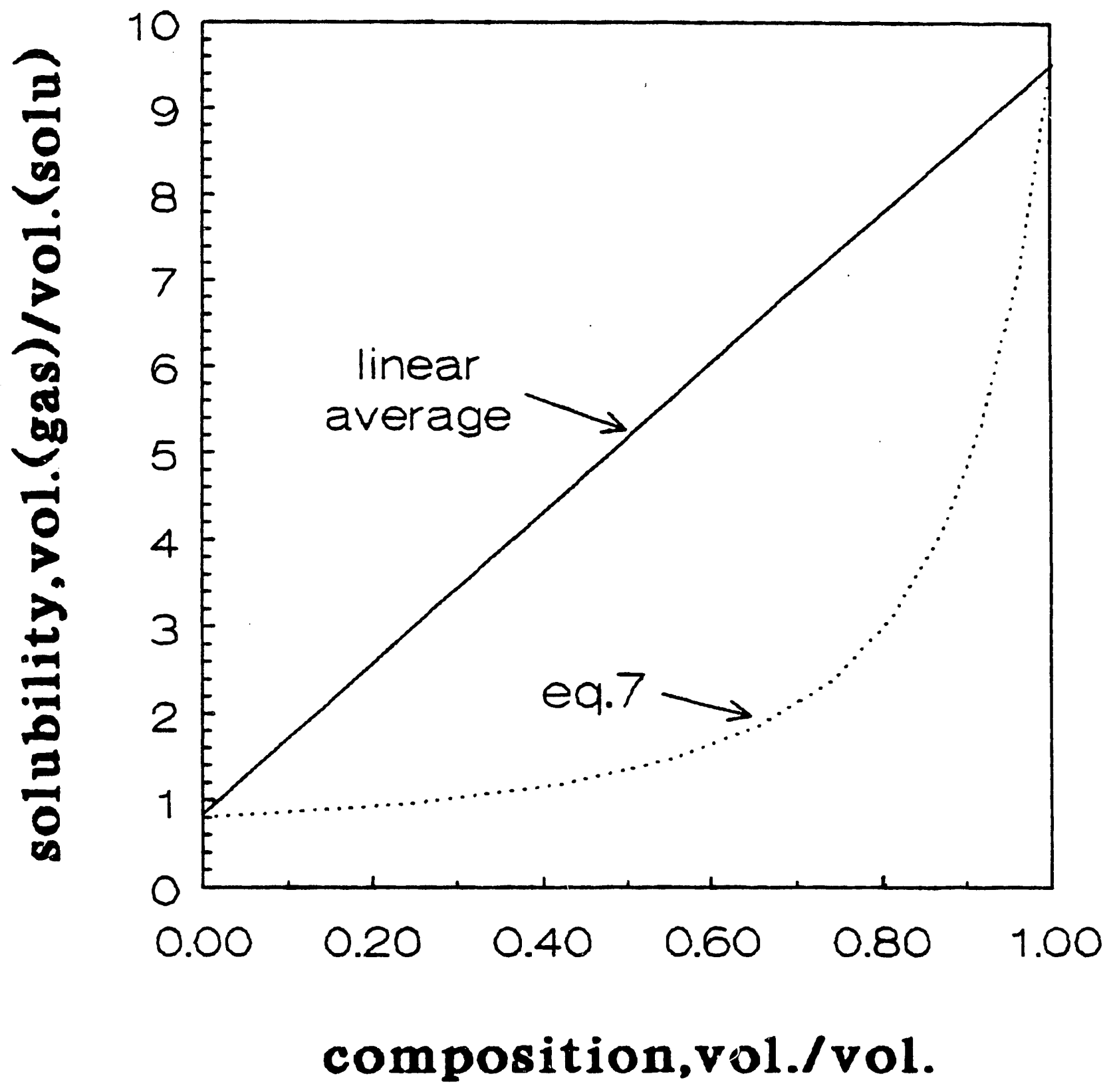

Figure IV.5 Hypothetical solubility in solvent mixture containing one solvent with large $H$ and the second with small $\mathrm{H}$. 
The experimental test facility consists of a mixing chamber equipped with two vertical glass windows, which allow visual observation of the interior, and a magnetic gas recirculating pump, both immersed in a liquid thermostated bath. The temperature of the bath is maintained constant within $+0.1^{\circ} \mathrm{C}$ by means of a temperature controlled heater and two immersion coolers (see Figure V.1). The kinetics of gas solubility are followed with a pressure transducer.

The magnetic recirculating pump serves both for gas mixing and to recirculate the vapors through the 4 -port gas sampling valve. A liquid pump continuously recirculates the liquid phase through a 4-port liquid sampling valve. The rotation of the sampling valve causes a stream of helium to inject a sample of $1 \mu l$ into the gas chromatograph (G.C.) for chemical analysis. By means of a 6-port valve, one can either sample the upper or the lower phases of the demixed liquid mixture.

It shculd be pointed out that the continuous circulation enables one to follow the kinetics of degassing and of gas solubility. The small sampling volume consumed ( $1 \mu l$ ) per injection was shown to have a negligible effect on the equilibrium in the mixing chamber.

Chemical analyses of the gas solubilities in the pure and mixed solvents were performed by means of "Carle" gas-chromatograph equipped with a "Spectra Physics" integrator. The G.C. was also used to determine the solvent compositions in the two-phase region of the critical mixtures. However, low vapor pressure liquids such as NMP couldn't be detected by the G.C. Thus, the liquid phase compositions of systems containing these solvents were deterined by light absorption spectroscopy method. A "Perkin Elmer" UV/VIS spectrophotometer, hooked up to PC computer, was used for this purpose.

During the run-in period, various modifications and improvements were introduced. Gas solubilities obtained with our test facility were compared with literature values. Figure V.2 compares our data for $\mathrm{CO}_{2}$ solubility in methanol with those of Ohgaki, et al, 1976.

The construction of the test facility can therefore be considered successful, at least in the sense that it allows us to start the preliminary screening of solvents. Our test facility was indeed a versatile unit with excellent chemical analytical capabilities.

This in itself is a significant achievement as there are no reported results in the literature for gas solubility equilibria over a two phase system, and no experimental method was available till now in the open literature.

While the equipment gave reproducible and reliable experimental results over a wide range of operating conditions, it still had several drawbacks, which need to be corrected in future studies. These were: 


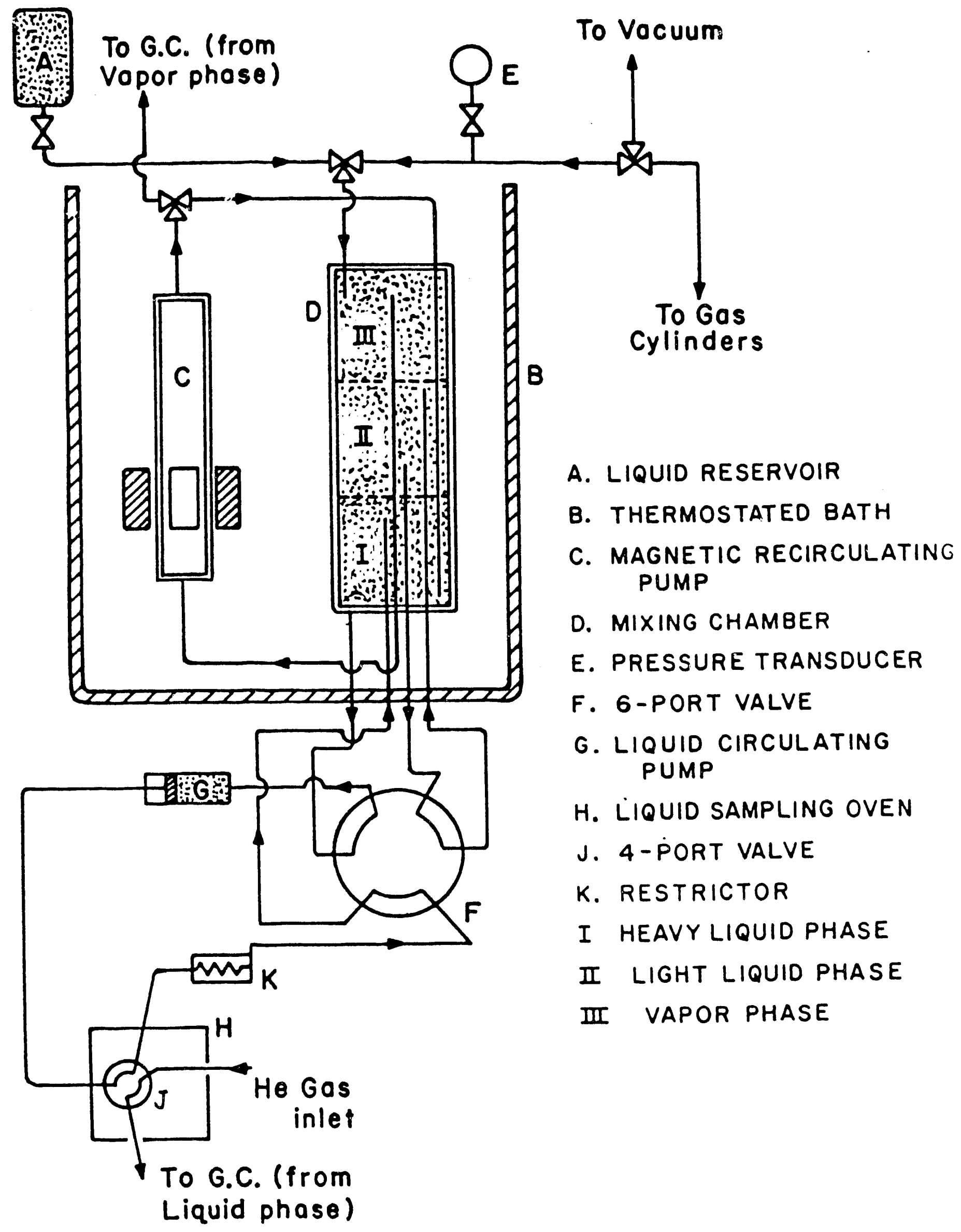

Figure V.I Schematic drawing of the gas solubility facility. 


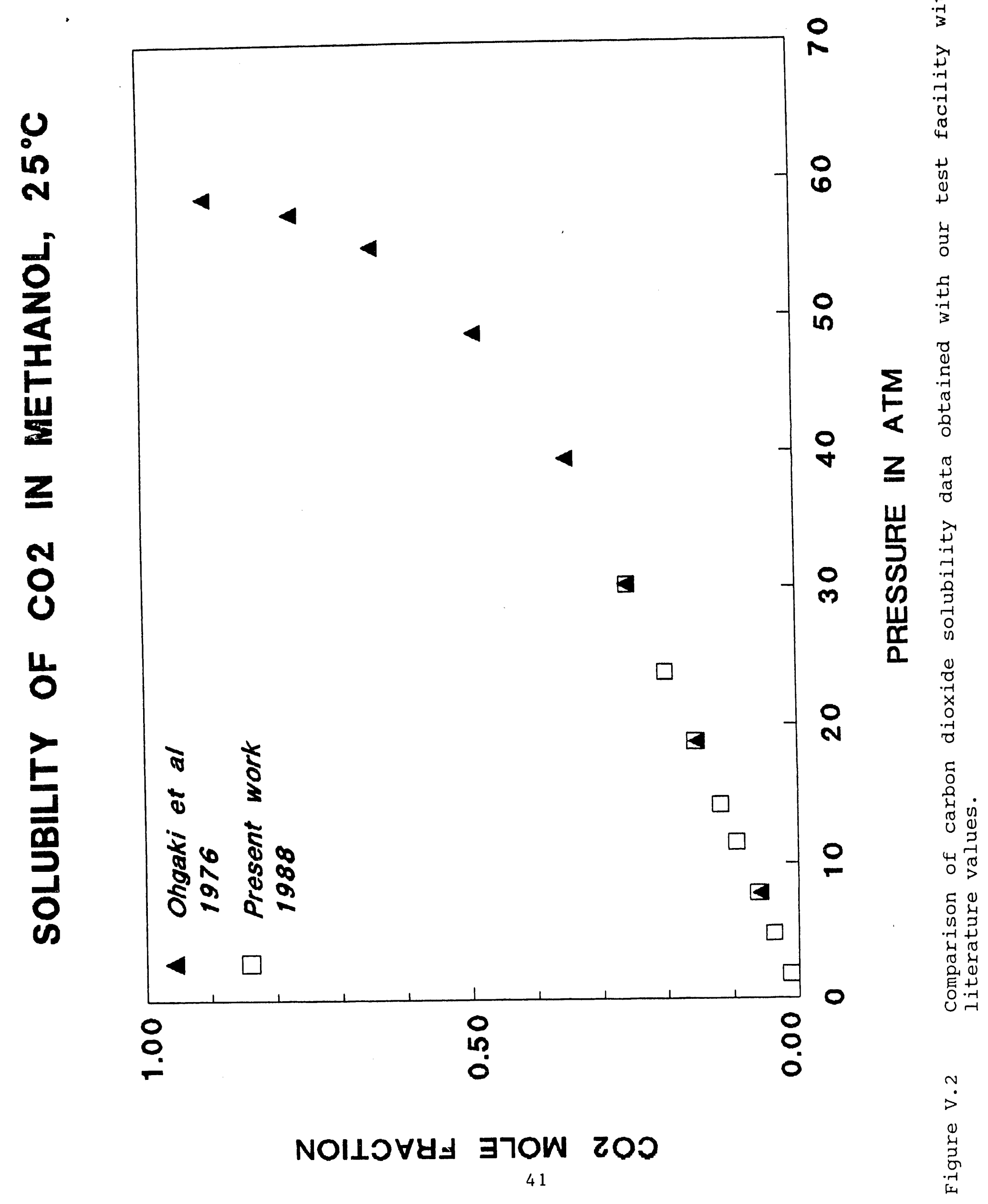


a) The equipment as actually built did not function for temperatures below $-20^{\circ} \mathrm{C}$. Solving this involves no inherent problems. It requires redesign of the cooling unit, and the temperature control. Some of the fittings, packings and valves also did not function well at low temperatures and proper substitutes need to be found.

b) $\mathrm{H}_{2} \mathrm{~S}$ attacked all packings and corroded some of the fittings and valves. This despite the fact that the manufacturers promised that their equipment functions well in the presence of $\mathrm{H}_{2} \mathrm{~S}$. This is a known problem. These difficulties did not prevent us from getting measurements but considerably slowed down our work.

There was another difficulty that we underestimated. While our equipment allowed us accurate measurements, the measurements took significant time and did not allow fast screenings of a large number of solvent pairs over a wide range of conditions. We are not sure that this is a problem that can easily be solved without. a major effort. The best way of solving it for industrial purposes is building multiple parallel equipment served by one operator. 
VI. 1 Nonlinear Effects of Gas Solubility In Critical solvents

In Section IV we discussed the dependence of gas solubility on concentration, for mixtures of solvents. Two equations were proposed (see section IV). One was based on an ideal solution

$$
\operatorname{lnH}_{3, M}=x_{1} \operatorname{lnH}_{3,1}+x_{2} \operatorname{lnH}_{3,2}
$$

and the other was based on a linear average

$$
S_{3, M}=Y_{1} S_{3,1}+Y_{2} S_{3,2}
$$

In order to test these equations, one needs data for mixtures in which the solubilities of the gas in each of the components strongly differs. As water is a poor solvent for both $\mathrm{H}_{2} \mathrm{~S}$ and $\mathrm{CO}_{2}$ compared to some organic solvents, critical mixtures of water with an organic solvents should be a good test for the theory. In Fig. VI.l we gave the solubility of $\mathrm{CO}_{2}$ in a critical mixture of lutidine water as a function of temperature. The mixture has a lower critical point at $37^{\circ} \mathrm{C}$ and the critical mixture contains $33 \%$ lutidine by volume (or a mole fraction of 0.07 ). We also gave the expected solubility in terms of eq. (7) as well as the linear volume average given by eq. (8). We note that at all points the solubility exceeds that predicted by eq. (7). Close to the critical temperature the solubility is approximately equal to the prediction based on a linear average, whereas at $5^{\circ}$, it almost doubles and despite the large difference between water and lutidine it is almost equal to that of pure lutidine.

As the deviation from eq. (7) is a very strong function of temperature near the critical point, there is a strong indication that this is a critical point phenomenon. The phenomenon has some interesting technological implications due to the enhanced temperature dependence.

In Fig. VI.2 we plot the same solubility data in comparison with the pure solvents, and we note that the temperature dependence of the mixture is much larger than of the components. Here, we also gave the solubility of the two phases above the critical point. We will come back to this later.

The results in the lutidine water mixture present the strongest nonlinear effect measured by us. The nonlinear effects are the critical point of the potential usefulness of such mixtures. Therefore, we start our discussion by summarizing all of our results related to this effect. In Table VI.l we give the solubility of $\mathrm{CO}_{2}$ and $\mathrm{H}_{2} \mathrm{~S}$ in different critical mixtures, at different temperatures. We also give the ratio of this solubility to that predicted by eq. (7) (Raoult's law) and eq. (8) (linear volumetric average). In addition we give the ratio of the solubility in the critical mixture to that in each of the two pure solvents.

All solubilities are given by volume of gas at standard conditions per volume of gas-free solvent or solvent mixture at 1 
Let us first look at the extremes. There are several points where the solubility in the mixture exceeds the best of the two solvents, marked with one star in the table and one point marked with \# where the solubility in the mixture is lower than in either of the two pure solvents at the same temperature. In none of these cases is the excess very large, so we don't deal here with supersolvents, but the effects are significant and as we will later show, potentially useful.

But if we search for steeper temperature dependence of solubility and, even more important; better selectivity, it is not important for the mixture to have greatly improved solvent power, all that is important is that the nonlinear effects are strong, different for different compounds, and vary with temperature.

The effect that the impact of the nonlinear effects in such solvent mixtures varies for different solutes is probably the most important for using such mixtures as solvents. It gives us a powerful tool to control selectivity. The nonlinear effects on solubility are not limited to the critical point composition. In Table VI.2 we give data for mixture compositions which lies at the coexistence curve in two phase regions of a critical mixture. Again, we compare it with the Raoult's law (eq. 7) and the linear average. We again note significant deviations in either direction. The direction and magnitude of the deviation may differ from that of the one phase critical mixture itself.

What is technically important is that small additions of a second solvent can often lead to dramatical improvements in selectivity. An example is the NMP dodecane mixture where the NMP rich phase with $20 \%$ dodecane improves selectivity for $\mathrm{H}_{2} \mathrm{~S}$ by $35 \%$ with only a small loss in solvent power which is a dramatic improvement of significant economic value.

There are two important aspects of these nonlinear composition and temperature effects on solubility. The most important one is that these effects are not equal for different compounds. To look at the effects more closely we give in Table VI.3 and Figure VI.3 the selectivity results for $\mathrm{CO}_{2}$ and $\mathrm{H}_{2} \mathrm{~S}$ in the different solvent pairs. In Table VI.3, we also give, for each point, both the selectivity as well as the ratio of selectivity to that in each of the pure solvents. We define here the selectivity in terms of the ratio mole $\mathrm{H}_{2} \mathrm{~S}$ to mole $\mathrm{CO}_{2}$ adsorbed, as this parameter is the most relevant for hydrogen purification from syngas. We note that the mixture can have strong improvements over the basic solvent up to a factor of 1.6 .

In some cases, such as the case of tile NMP (Nmethylpyrolidone)-heptane mixture, the selectivity is strongly reduced as the solution has a stronger positive effect on $\mathrm{CO}_{2}$ as compared to $\mathrm{H}_{2} \mathrm{~S}$. Regretfully we were not able to find a reliable theoretical predictor for the direction of this effect for different materials. By comparing Table VI.1 and Table VI.3, we note that in most cases the increase in selectivity is due to 


\section{SOLUBILITY OF $\mathrm{CO} 2$ \\ LUTIDINE+WATER}

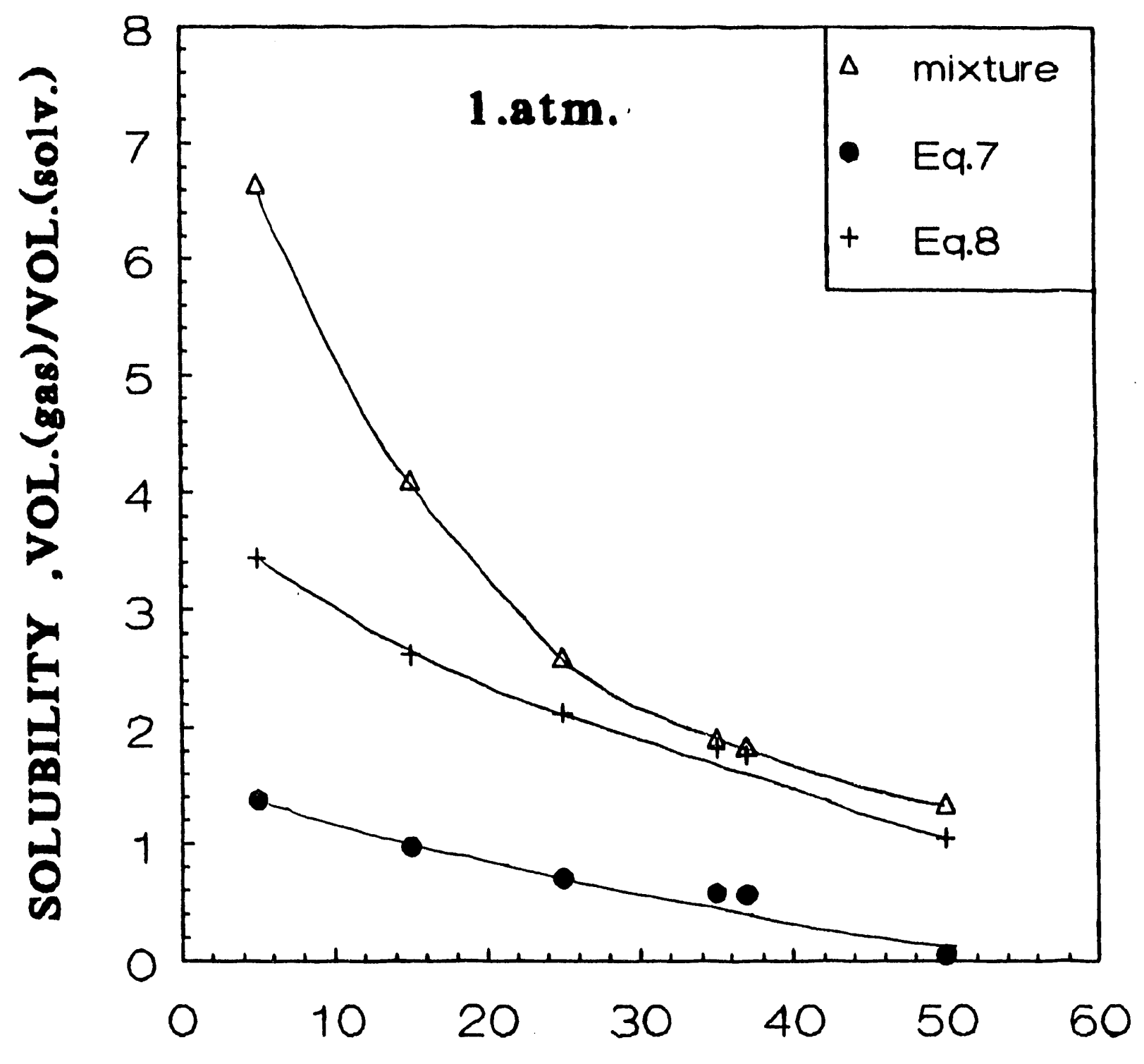

TEMPERATURE ,C

Figure VI.1 Solubility of carbon dioxide in critical mixture of lutidine water as function of temperature compared to calculated solubility by eq. (7) (ideal solution) and eq. (8) (linear average). 


\section{SOLUBILITY OF CO2 \\ LUTIDINE+WATER}

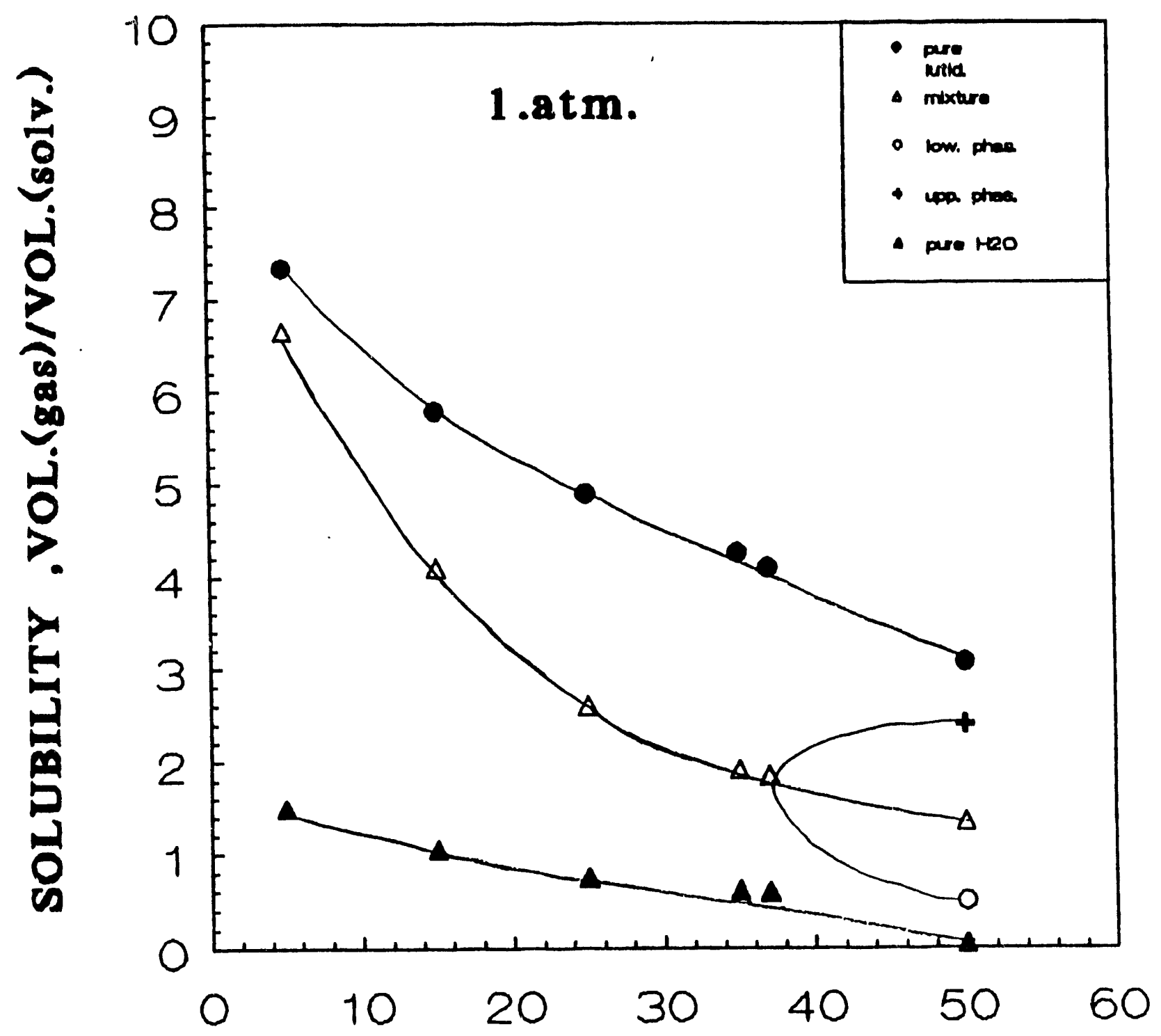

TEMPERATURE ,C

Figure VI.2 Solubility of carbon dioxide in pure lutidine, pure water and in critical mixture as a function of temperature. 
Table VI. 1

Solubility of carbon dioxide and hydrogen sulfide (at 1 atm partial pressure) in the one phase region.

\section{Solubility Ratio}

\begin{tabular}{|c|c|c|c|c|c|c|c|}
\hline $\begin{array}{l}\text { Solvents } \\
\text { System }\end{array}$ & $\begin{array}{l}\text { Solute } \\
\text { (gas) }\end{array}$ & $\begin{array}{l}\text { Temp. } \\
{ }^{0} \mathrm{C}\end{array}$ & Solub.' & $\begin{array}{l}\text { Mixture/ } \\
\text { good } \\
\text { Solvent } \\
\end{array}$ & $\begin{array}{l}\text { Mixture/ } \\
\text { poor } \\
\text { Solvent }\end{array}$ & $\begin{array}{r}\text { Mixture/ } \\
\text { Raoult's } \\
\end{array}$ & $\begin{array}{l}\text { Mixture/ } \\
\text { Avg. } 3 \\
\end{array}$ \\
\hline $\begin{array}{l}\text { Acetonitrile } \\
\text { (good solv.) } \\
+ \\
\text { Water } \\
\text { (poor solv.) }\end{array}$ & $\mathrm{CO}_{2}$ & $\begin{array}{l}10 \\
15 \\
20 \\
25\end{array}$ & $\begin{array}{l}4.40 \\
3.87 \\
3.54 \\
3.21\end{array}$ & $\begin{array}{l}0.464 \\
0.444 \\
0.426 \\
0.401\end{array}$ & $\begin{array}{l}3.451 \\
3.686 \\
3.933 \\
4.280\end{array}$ & $\begin{array}{l}1.973 \\
2.026 \\
2.082 \\
2.169\end{array}$ & $\begin{array}{l}0.701 \\
0.676 \\
0.654 \\
0.629\end{array}$ \\
\hline$(0.609)^{4}$ & $\mathrm{H}_{2} \mathrm{~S}$ & $\begin{array}{l}15 \\
20 \\
45 \\
60\end{array}$ & $\begin{array}{r}16.30 \\
13.85 \\
7.81 \\
5.23\end{array}$ & $\begin{array}{l}0.534 \\
0.519 \\
0.462 \\
0.400\end{array}$ & $\begin{array}{l}5.552 \\
5.368 \\
5.049 \\
4.144\end{array}$ & $\begin{array}{l}2.876 \\
2.778 \\
2.543 \\
2.117\end{array}$ & $\begin{array}{l}0.826 \\
0.803 \\
0.717 \\
0.619\end{array}$ \\
\hline $\begin{array}{l}\text { NMP } \\
(\text { good solv. })\end{array}$ & $\mathrm{CO}_{2}$ & $\begin{array}{l}55 \\
65 \\
70\end{array}$ & $\begin{array}{l}1.75 \\
1.33 \\
1.17\end{array}$ & $\begin{array}{l}0.665 \\
0.607 \\
0.571\end{array}$ & $\begin{array}{l}1.281 \\
1.215 \\
1.219\end{array}$ & $\begin{array}{l}0.985 \\
0.916 \\
0.892\end{array}$ & $\begin{array}{l}0.968 \\
0.900 \\
0.873\end{array}$ \\
\hline$(0.349)^{4}$ & $\mathrm{H}_{2} \mathrm{~S}$ & $\begin{array}{l}50 \\
55 \\
65 \\
70\end{array}$ & $\begin{array}{r}17.09 \\
15.13 \\
11.20 \\
9.24\end{array}$ & $\begin{array}{l}0.508 \\
0.511 \\
0.519 \\
0.471\end{array}$ & $\begin{array}{l}4.547 \\
4.437 \\
3.626 \\
3.568\end{array}$ & $\begin{array}{l}1.866 \\
1.831 \\
1.626 \\
1.535\end{array}$ & $\begin{array}{l}1.205 \\
1.205 \\
1.174 \\
1.083\end{array}$ \\
\hline $\begin{array}{l}\text { NMP } \\
\text { (good } s\end{array}$ & $\mathrm{CO}_{2}$ & 78 & 0.84 & 0.467 & 1.024 & 0.832 & 0.720 \\
\hline
\end{tabular}

Dodecane

(poor solv.)

\begin{tabular}{lccccccc}
$(0.297)^{4}$ & $\mathrm{H}_{2} \mathrm{~S}$ & 78 & 11.58 & 0.739 & 5.514 & 2.305 & 1.888 \\
\hline NMP & & 18 & 4.40 & 0.894 & 2.018 & 1.401 & 1.330 \\
(good solv.) & & 20 & 4.20 & 0.878 & 1.974 & 1.372 & 1.304 \\
& & 30 & 3.50 & 0.854 & 1.938 & 1.338 & 1.272 \\
Methyl- & $\mathrm{CO}_{2}$ & 40 & 2.99 & 0.859 & 1.879 & 1.352 & 1.262 \\
Cyclohexane & & 50 & 2.39 & 0.885 & 1.833 & 1.317 & 1.272 \\
& & 60 & 1.90 & 0.805 & 1.753 & 1.228 & 1.181 \\
$(0.4118)^{4}$ & & 70 & 1.42 & 0.703 & 1.632 & 1.107 & 1.057
\end{tabular}

${ }^{1}$ Volume of the gas at standard condition over solute-free solvent volume.

${ }^{2}$ Ideal mixture (eq. 7)

${ }^{3}$ Volumetric average (eq. 8).

${ }^{4}$ Volume fraction of the good solvent. 
Table VI.1 (Continued)

Solubility Ratio

\begin{tabular}{|c|c|c|c|c|c|c|c|}
\hline \multirow[t]{2}{*}{$\begin{array}{l}\text { Solvents } \\
\text { System }\end{array}$} & $\begin{array}{l}\text { Solute } \\
\text { (gas) }\end{array}$ & $\begin{array}{l}\text { Temp. } \\
{ }^{0} \mathrm{C}\end{array}$ & Solub. 1 & $\begin{array}{l}\text { Mixture/ } \\
\text { good } \\
\text { Solvent }\end{array}$ & $\begin{array}{l}\text { Mixture/ } \\
\text { poor } \\
\text { Solvent }\end{array}$ & \multicolumn{2}{|c|}{ Mixture/ Mixture/ } \\
\hline & $\mathrm{H}_{2} \mathrm{~S}$ & $\begin{array}{l}10 \\
20 \\
30 \\
40 \\
50 \\
60 \\
70\end{array}$ & $\begin{array}{l}53.55 \\
45.08 \\
33.52 \\
24.58 \\
18.52 \\
13.99 \\
11.00\end{array}$ & $\begin{array}{l}0.729 \\
0.717 \\
0.638 \\
0.598 \\
0.593 \\
0.593 \\
0.564\end{array}$ & $\begin{array}{l}3.688 \\
3.840 \\
3.520 \\
3.208 \\
3.046 \\
3.937 \\
3.013\end{array}$ & $\begin{array}{l}2.031 \\
2.009 \\
1.774 \\
1.598 \\
1.515 \\
1.461 \\
1.430\end{array}$ & $\begin{array}{l}1.380 \\
1.376 \\
1.175 \\
1.147 \\
1.127 \\
1.118 \\
1.081\end{array}$ \\
\hline $\begin{array}{l}\text { Lutidine } \\
\text { (good solv.) } \\
\quad+ \\
\text { Water } \\
\text { (poor solv.) }\end{array}$ & $\mathrm{CO}_{2}$ & $\begin{array}{l}5 \\
15 \\
25 \\
35 \\
37\end{array}$ & $\begin{array}{l}6.65 \\
4.10 \\
2.60 \\
1.91 \\
1.84\end{array}$ & $\begin{array}{l}0.906 \\
0.707 \\
0.531 \\
0.448 \\
0.450\end{array}$ & $\begin{array}{l}4.433 \\
3.905 \\
3.476 \\
3.131 \\
3.075\end{array}$ & $\begin{array}{l}4.833 \\
4.214 \\
3.704 \\
3.322 \\
3.265\end{array}$ & $\begin{array}{l}1.933 \\
1.562 \\
1.223 \\
1.048 \\
1.047\end{array}$ \\
\hline
\end{tabular}

$(0.332)^{4}$

Methanol

(good solv.) $+$

Toluene

(poor solv.)

$(0.233)^{4}$

\section{$-16$}

$-10$

$\mathrm{CO}_{2}$

$\begin{array}{cc} & \\ & -16 \\ \mathrm{H}_{2} \mathrm{~S} & -10 \\ & 0 \\ & 20\end{array}$

7.04

5.95

4.88

3.07

62.0

42.0

28.0

15.9
0.558

0.593

1.341

1.322

0.697

0.738

0.976

1.200

1.429

1.371
1.308

0.877

1.039

1.152

1.333

1.172
1.036

1.050

1.011

1.027

1.086

0.840

1.024

1.163

1.354

1.213

1 Volume of the gas at standard condition over solute-free solvent volume.

2 Ideal mixture (eq. 7).

3 Volumetric average (eq. 8).

4 Volume fraction of the good solvent 
Table VI.2

Solubility of carbon dioxide and hydrogen sulfide in critical mixtures (at 1 atm partial pressure) in the two phase region.

\section{Solubility Ratio}

\begin{tabular}{|c|c|c|c|c|c|c|c|}
\hline $\begin{array}{l}\text { Solvents } \\
\text { system }\end{array}$ & Phase & $\begin{array}{l}\text { Temp. } \\
{ }^{0} \mathrm{C}\end{array}$ & Solub.' & $\begin{array}{l}\text { Mixture/ } \\
\text { good } \\
\text { solvent } \\
\end{array}$ & $\begin{array}{l}\text { Mixture/ } \\
\text { poor } \\
\text { Solvent } \\
\end{array}$ & \multicolumn{2}{|c|}{$\begin{array}{l}\text { Mixture/ Mixture/ } \\
\text { Raoult's } \text { Avg. }^{2} \\
\end{array}$} \\
\hline $\begin{array}{l}\text { Acetonitrile } \\
\text { (good solv.) } \\
\quad+ \\
\text { Water } \\
\text { (poor solv.) }\end{array}$ & $\begin{array}{l}\mathrm{ACN} \\
\text { rich }\end{array}$ & $\begin{array}{r}-5 \\
0 \\
3 \\
5\end{array}$ & $\begin{array}{r}11.84 \\
8.76 \\
7.25 \\
5.48\end{array}$ & $\begin{array}{l}1.024 \\
0.826 \\
0.706 \\
0.545\end{array}$ & $\begin{array}{l}6.072 \\
5.078 \\
4.560 \\
3.651\end{array}$ & $\begin{array}{l}2.349 \\
2.246 \\
2.287 \\
2.148\end{array}$ & $\begin{array}{l}1.206 \\
1.029 \\
0.944 \\
0.817\end{array}$ \\
\hline \multirow[t]{2}{*}{$+\mathrm{CO}_{2}$ (gas) } & $\begin{array}{l}\text { Water } \\
\text { rich }\end{array}$ & $\begin{array}{r}-5 \\
0 \\
3 \\
5\end{array}$ & $\begin{array}{l}3.21 \\
3.44 \\
3.92 \\
5.33\end{array}$ & $\begin{array}{l}0.277 \\
0.324 \\
0.382 \\
0.530\end{array}$ & $\begin{array}{l}1.644 \\
1.992 \\
2.465 \\
3.553\end{array}$ & $\begin{array}{l}1.367 \\
1.555 \\
1.790 \\
2.141\end{array}$ & $\begin{array}{l}0.598 \\
0.630 \\
0.684 \\
0.804\end{array}$ \\
\hline & Average & $\begin{array}{r}-5 \\
C \\
3 \\
5\end{array}$ & $\begin{array}{l}8.00 \\
6.40 \\
5.78 \\
5.41\end{array}$ & $\begin{array}{l}0.692 \\
0.604 \\
0.563 \\
0.538\end{array}$ & $\begin{array}{l}4.103 \\
3.710 \\
3.635 \\
3.607\end{array}$ & $\begin{array}{l}2.548 \\
2.974 \\
2.189 \\
2.147\end{array}$ & $\begin{array}{l}1.025 \\
0.898 \\
0.841 \\
0.807\end{array}$ \\
\hline$+\mathrm{H}_{2} \mathrm{~S}$ (gas) & $\begin{array}{l}\text { ACN rich } \\
\text { Water rich } \\
\text { Average }\end{array}$ & $\begin{array}{l}5 \\
5 \\
5\end{array}$ & $\begin{array}{r}28.90 \\
8.95 \\
21.44\end{array}$ & \multicolumn{2}{|c|}{0.858} & \multicolumn{2}{|c|}{$\begin{array}{lr} & 2.5551 .101 \\
31 & 0.577 \\
17 & 0.972\end{array}$} \\
\hline $\begin{array}{l}\text { NMP } \\
\stackrel{(\text { good solv. ) }}{+}\end{array}$ & $\begin{array}{l}\text { NMP } \\
\text { rich }\end{array}$ & $\begin{array}{l}20 \\
40 \\
45\end{array}$ & $\begin{array}{l}57.29 \\
31.71 \\
25.73\end{array}$ & $\begin{array}{l}0.912 \\
0.713 \\
0.683\end{array}$ & $\begin{array}{l}8.896 \\
6.865 \\
6.141\end{array}$ & $\begin{array}{l}1.672 \\
1.524 \\
1.709\end{array}$ & $\begin{array}{l}1.160 \\
1.051 \\
1.158\end{array}$ \\
\hline \multirow{2}{*}{$\begin{array}{l}\text { Heptane } \\
\text { (poor solv.) } \\
+\mathrm{H}_{2} \mathrm{~S} \text { (gas) }\end{array}$} & $\begin{array}{l}\text { Heptane } \\
\text { rich }\end{array}$ & $\begin{array}{l}20 \\
40 \\
45\end{array}$ & $\begin{array}{l}15.07 \\
14.00 \\
14.74\end{array}$ & $\begin{array}{l}0.240 \\
0.315 \\
0.391\end{array}$ & $\begin{array}{l}2.340 \\
3.030 \\
3.518\end{array}$ & $\begin{array}{l}1.803 \\
1.882 \\
1.950\end{array}$ & $\begin{array}{l}1.231 \\
1.204 \\
1.261\end{array}$ \\
\hline & Average & $\begin{array}{l}20 \\
40 \\
45\end{array}$ & $\begin{array}{l}35.55 \\
23.09 \\
20.74\end{array}$ & $\begin{array}{l}0.566 \\
0.519 \\
0.550\end{array}$ & $\begin{array}{l}5.52 \\
4.998 \\
4.950\end{array}$ & $\begin{array}{l}2.305 \\
2.027 \\
2.044\end{array}$ & $\begin{array}{l}1.361 \\
1.247 \\
1.306\end{array}$ \\
\hline \multirow[t]{3}{*}{$+\mathrm{CO}_{2}$ (gas) } & $\begin{array}{l}\text { NMP } \\
\text { rich }\end{array}$ & $\begin{array}{l}20 \\
40 \\
50\end{array}$ & $\begin{array}{l}4.28 \\
2.85 \\
2.18\end{array}$ & $\begin{array}{l}0.898 \\
0.847 \\
0.764\end{array}$ & $\begin{array}{l}1.760 \\
1.620 \\
1.463\end{array}$ & $\begin{array}{l}1.013 \\
1.013 \\
1.033\end{array}$ & $\begin{array}{l}0.990 \\
0.994 \\
1.014\end{array}$ \\
\hline & $\begin{array}{l}\text { Heptane } \\
\text { rich }\end{array}$ & $\begin{array}{l}20 \\
40 \\
50\end{array}$ & $\begin{array}{l}2.56 \\
2.16 \\
1.87\end{array}$ & $\begin{array}{l}0.538 \\
0.642 \\
0.654\end{array}$ & $\begin{array}{l}1.055 \\
1.230 \\
1.252\end{array}$ & $\begin{array}{l}1.010 \\
1.117 \\
1.020\end{array}$ & $\begin{array}{l}0.986 \\
1.102 \\
1.003\end{array}$ \\
\hline & Average & $\begin{array}{l}20 \\
40 \\
50\end{array}$ & $\begin{array}{l}3.25 \\
2.43 \\
1.99\end{array}$ & $\begin{array}{l}0.682 \\
0.722 \\
0.697\end{array}$ & $\begin{array}{l}1.337 \\
1.381 \\
1.336\end{array}$ & $\begin{array}{l}1.028 \\
1.068 \\
1.030\end{array}$ & $\begin{array}{l}1.002 \\
1.047 \\
1.012\end{array}$ \\
\hline
\end{tabular}

1 Volume of the gas at standard condition over solute-free solvent volume.

2 Ideal mixture (eq. 7)

3 Volumetric average (eq. 8). 
Table VI.2 (cont'd)

Solubility Ratio

\begin{tabular}{|c|c|c|c|c|c|c|c|}
\hline $\begin{array}{l}\text { Solvents } \\
\text { System }\end{array}$ & Phase & $\begin{array}{l}\text { Temp. } \\
{ }^{0} \mathrm{C}\end{array}$ & Solub. ${ }^{1}$ & $\begin{array}{l}\text { Mixture/ } \\
\text { good } \\
\text { solvent }\end{array}$ & $\begin{array}{l}\text { Mixture/ } \\
\text { poor } \\
\text { Solvent } \\
\end{array}$ & $\begin{array}{r}\text { Mixture/ M } \\
\text { Raoult's }{ }^{2}\end{array}$ & $\begin{array}{l}\text { xture/ } \\
\text { Avg. } 3 \\
\end{array}$ \\
\hline${ }_{(\text {good solv.) }}^{\text {NMP }}$ & $\begin{array}{l}\text { NMP } \\
\text { rich }\end{array}$ & $\begin{array}{l}20 \\
35\end{array}$ & $\begin{array}{l}3.12 \\
2.09\end{array}$ & $\begin{array}{l}0.652 \\
0.572\end{array}$ & $\begin{array}{l}2.940 \\
2.173\end{array}$ & $\begin{array}{l}0.735 \\
0.635\end{array}$ & $\begin{array}{l}0.713 \\
0.623\end{array}$ \\
\hline $\begin{array}{l}\text { Dodecane } \\
\text { (poor solv.) }\end{array}$ & & $\begin{array}{l}45 \\
65\end{array}$ & $\begin{array}{l}1.53 \\
1.18\end{array}$ & $\begin{array}{l}0.553 \\
0.538\end{array}$ & $\begin{array}{l}1.776 \\
1.426\end{array}$ & $\begin{array}{l}0.628 \\
0.658\end{array}$ & $\begin{array}{l}0.603 \\
0.651\end{array}$ \\
\hline \multirow[t]{2}{*}{$+\mathrm{CO}_{2}$ (gas) } & $\begin{array}{l}\text { Dodecane } \\
\text { rich }\end{array}$ & $\begin{array}{l}20 \\
35 \\
45 \\
65\end{array}$ & $\begin{array}{l}1.06 \\
0.97 \\
0.89 \\
0.83\end{array}$ & $\begin{array}{l}0.222 \\
0.265 \\
0.321 \\
0.379\end{array}$ & $\begin{array}{l}1.000 \\
1.007 \\
1.031 \\
1.005\end{array}$ & $\begin{array}{l}0.855 \\
0.876 \\
0.909 \\
0.863\end{array}$ & $\begin{array}{l}0.815 \\
0.856 \\
0.903 \\
0.855\end{array}$ \\
\hline & Average & $\begin{array}{l}20 \\
35 \\
45 \\
65\end{array}$ & $\begin{array}{l}1.49 \\
1.20 \\
1.02 \\
0.91\end{array}$ & $\begin{array}{l}0.312 \\
0.329 \\
0.369 \\
0.414\end{array}$ & $\begin{array}{l}1.406 \\
1.250 \\
1.186 \\
1.096\end{array}$ & $\begin{array}{l}0.738 \\
0.710 \\
0.732 \\
0.743\end{array}$ & $\begin{array}{l}0.688 \\
0.682 \\
0.716 \\
0.736\end{array}$ \\
\hline \multirow[t]{3}{*}{$+\mathrm{H}_{2} \mathrm{~S}$ (gas) } & $\begin{array}{l}\text { NMP } \\
\text { rich }\end{array}$ & $\begin{array}{l}20 \\
35 \\
50 \\
65\end{array}$ & $\begin{array}{l}55.60 \\
44.50 \\
32.24 \\
19.94\end{array}$ & $\begin{array}{l}0.885 \\
0.931 \\
0.856 \\
0.924\end{array}$ & $\begin{array}{l}8.633 \\
8.768 \\
7.694 \\
6.453\end{array}$ & $\begin{array}{l}1.226 \\
1.340 \\
1.187 \\
1.388\end{array}$ & $\begin{array}{l}0.982 \\
1.042 \\
0.957 \\
1.149\end{array}$ \\
\hline & $\begin{array}{l}\text { Dodecane } \\
\text { rich }\end{array}$ & $\begin{array}{l}20 \\
35 \\
50 \\
65\end{array}$ & $\begin{array}{r}9.02 \\
9.49 \\
10.03 \\
11.27\end{array}$ & $\begin{array}{l}0.144 \\
0.198 \\
0.266 \\
0.522\end{array}$ & $\begin{array}{l}1.400 \\
1.870 \\
2.394 \\
3.647\end{array}$ & $\begin{array}{l}1.153 \\
1.490 \\
1.896 \\
2.621\end{array}$ & $\begin{array}{l}0.898 \\
1.215 \\
1.584 \\
2.232\end{array}$ \\
\hline & Average & $\begin{array}{l}20 \\
35 \\
50 \\
65\end{array}$ & $\begin{array}{l}22.94 \\
20.20 \\
17.96 \\
14.08\end{array}$ & $\begin{array}{l}0.365 \\
0.422 \\
0.422 \\
0.653\end{array}$ & $\begin{array}{l}3.562 \\
3.981 \\
3.981 \\
4.558\end{array}$ & $\begin{array}{l}1.451 \\
1.597 \\
1.721 \\
2.003\end{array}$ & $\begin{array}{l}0.990 \\
1.137 \\
1.271 \\
1.692\end{array}$ \\
\hline $\begin{array}{l}\text { NMP } \\
(\text { good solv. })\end{array}$ & $\begin{array}{l}\text { NMP } \\
\text { rich }\end{array}$ & $\begin{array}{l}10 \\
15\end{array}$ & $\begin{array}{l}5.56 \\
5.03\end{array}$ & $\begin{array}{l}1.01 \\
0.978\end{array}$ & $\begin{array}{l}2.269 \\
2.206\end{array}$ & $\begin{array}{l}1.304 \\
1.315\end{array}$ & $\begin{array}{l}1.245 \\
1.253\end{array}$ \\
\hline $\begin{array}{l}\text { Methyl- } \\
\text { cyclohexane } \\
\text { (poor solv.) }\end{array}$ & & $\begin{array}{l}10 \\
15\end{array}$ & $\begin{array}{l}3.67 \\
3.50\end{array}$ & $\begin{array}{l}0.667 \\
0.680\end{array}$ & $\begin{array}{l}1.498 \\
1.534\end{array}$ & $\begin{array}{l}1.380 \\
1.300\end{array}$ & $\begin{array}{l}1.334 \\
1.246\end{array}$ \\
\hline$+\mathrm{CO}_{2}$ (gas) & & $\begin{array}{l}10 \\
15\end{array}$ & $\begin{array}{l}5.10 \\
4.66\end{array}$ & $\begin{array}{l}0.927 \\
0.906\end{array}$ & $\begin{array}{l}2.080 \\
2.042\end{array}$ & $\begin{array}{l}1.451 \\
1.419\end{array}$ & $\begin{array}{l}1.375 \\
1.346\end{array}$ \\
\hline $\begin{array}{l}\text { Lutidine } \\
\text { (good solv.) }\end{array}$ & $\begin{array}{l}\text { Lutidine } \\
\text { rich }\end{array}$ & 50 & 2.41 & 0.786 & 48.28 & 28.40 & 1.207 \\
\hline+ & $\begin{array}{l}\text { Water } \\
\text { rich }\end{array}$ & 50 & 0.5 & 0.163 & 10.00 & 10.00 & 1.553 \\
\hline $\begin{array}{l}\text { Water } \\
+\mathrm{CO}_{2} \text { (gas) }\end{array}$ & Average & 50 & 1.35 & 0.438 & 26.90 & 24.45 & 1.278 \\
\hline
\end{tabular}

1 Volume of the gas at standard condition over solute-free solvent volume. Ideal mixture eq. 7)

Volumetric average (eq. 8). 
Table VI.3

Selectivity of hydrogen sulfide in respect to carbon dioxide in critical mixtures (at 1 atm partial pressure) in the one phase region.

\section{Selectivity Ratio}

\begin{tabular}{|c|c|c|c|c|c|c|}
\hline $\begin{array}{l}\text { Solvents } \\
\text { System }\end{array}$ & $\begin{array}{l}\text { Temp. } \\
{ }^{\circ} \mathrm{C} \\
\end{array}$ & selec. ${ }^{1}$ & $\begin{array}{l}\text { Mixture/ } \\
\text { good } \\
\text { solvent }\end{array}$ & $\begin{array}{l}\text { Mixture/ } \\
\text { poor } \\
\text { Solvent }\end{array}$ & $\begin{array}{r}\text { Mixture/ M } \\
\text { Raoult's } \\
\end{array}$ & $\begin{array}{l}\text { xture/ } \\
\text { Avg. } 3 \\
\end{array}$ \\
\hline $\begin{array}{l}\text { Acetonitrile } \\
\text { (good solvent) }+ \\
\text { Water (poor solvent) }\end{array}$ & $\begin{array}{l}5 \\
15 \\
20\end{array}$ & $\begin{array}{l}3.963 \\
4.212 \\
3.912\end{array}$ & $\begin{array}{l}1.182 \\
1.203 \\
1.219\end{array}$ & $\begin{array}{l}1.501 \\
1.506 \\
1.365\end{array}$ & $\begin{array}{l}1.406 \\
1.420 \\
1.334\end{array}$ & $\begin{array}{l}1.205 \\
1.221 \\
1.227\end{array}$ \\
\hline $\begin{array}{l}\text { NMP (good solvent) }+ \\
\text { Heptane } \\
\text { (poor solvent) }\end{array}$ & $\begin{array}{l}55 \\
65 \\
70\end{array}$ & $\begin{array}{l}8.670 \\
8.489 \\
7.897\end{array}$ & $\begin{array}{l}0.770 \\
0.862 \\
0.825\end{array}$ & $\begin{array}{l}3.473 \\
3.008 \\
2.927\end{array}$ & $\begin{array}{l}1.865 \\
1.789 \\
1.720\end{array}$ & $\begin{array}{l}1.021 \\
1.315 \\
1.241\end{array}$ \\
\hline $\begin{array}{l}\text { NMP (good solvent) }+ \\
\text { Dodecane } \\
\text { (poor solvent) }\end{array}$ & 78 & 13.786 & 1.582 & 5.383 & 3.022 & 2.623 \\
\hline
\end{tabular}

\begin{tabular}{lrrrrrr} 
NMP (good solvent) & 20 & 10.733 & 0.817 & 1.946 & 1.464 & 1.055 \\
+ & 30 & 9.577 & 0.748 & 1.816 & 1.326 & 0.924 \\
$\begin{array}{l}\text { Methyl-cyclohexane } \\
\text { (poor solvent) }\end{array}$ & 50 & 7.749 & 0.670 & 1.662 & 1.151 & 0.886 \\
& 60 & 7.363 & 0.736 & 1.676 & 1.189 & 0.946 \\
& 70 & 7.746 & 0.802 & 1.846 & 1.292 & 1.023 \\
\hline & & & & & & \\
Methanol & -16 & 8.593 & 1.748 & 0.7752 & 1.299 & 1.013 \\
(good solvent) + & -10 & 8.471 & 2.025 & 0.871 & 1.419 & 1.132 \\
$\begin{array}{l}\text { Toluene } \\
\text { (poor solvent) }\end{array}$ & 0 & 8.197 & 2.049 & 1.019 & 1.471 & 1.247 \\
& 20 & 7.101 & 1.858 & 1.336 & 1.618 & 1.444
\end{tabular}

1 Ratio- mole $\mathrm{H}_{2} \mathrm{~S}$ to mole $\mathrm{CO}_{2}$ absorbed

2 Ideal mixture (eq. 7)

3 Volumetric average (eq. 8) 


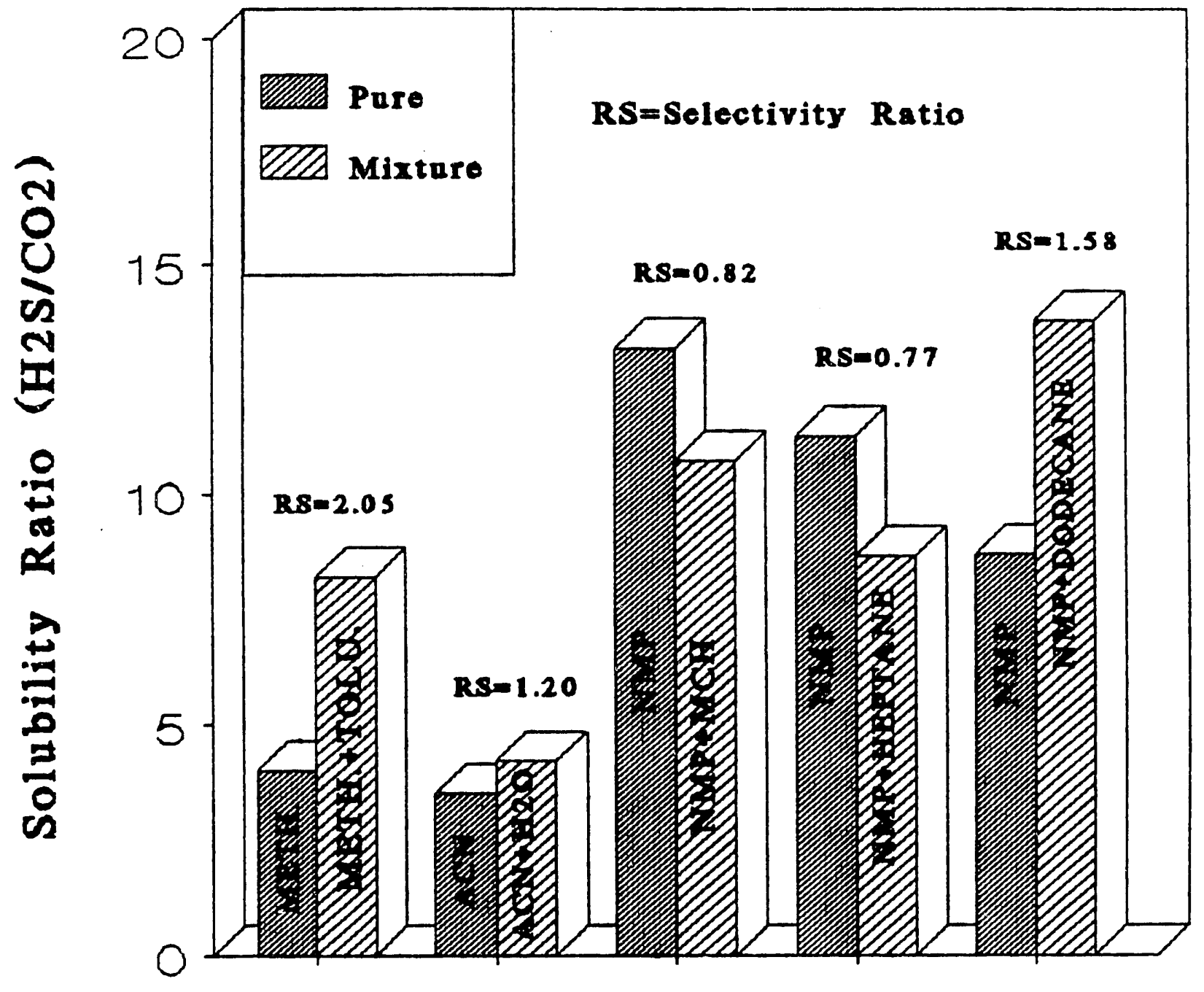

Figure VI.3 Selectivity of hydrogen sulfide with respect to carbon dioxide (at 1 atm. partial pressure) in the one-phase region. 
reduction of solubility for one of the compounds.

Table VI.3 also gives the selectivity that could be obtained if both solutes followed Raoult's law (eq. 7) or both solutes followed eq. (8) (linear volumetric average). Eq. (7) can lead to increases in selectivity, if the less powerful of the two solvents has a better selectivity. But in our case the best improvements are in mixtures which are far from following eq. (7).

Tables VI.1 - VI.3 summarize the most important part of our results. They clearly show that by adding a solvent forming a critical mixture one can modify a solvent such that its temperature dependence of solubility increases and its selectivity improves without sacrificing too much of the solvent power. This provides an important tool for the process designer.

In the next section we will discuss in more detail the different solvent systems involved.

\section{2 Detailed Results For Different Solvent Systems}

The solvent systems involved as well as their properties are given in Table VI.4. We note that the degree of emphasis varied from solvent to solvent. This was due to several reasons.

a) Our whole approach was developed successively and in different stages of our work we looked at different aspects. This was also due to the fact that our main goal was not solely scientific results but rather binding effects and results which would lead to cheaper hydrogen separation.

b) The fact that our method required a large effort for each data point and the experimental difficulties with each new system prevented us from getting a complete set of data for each solvent. Still, as we show in the next section, we were able to achieve our main goals. The data show that this is an approach that can be very useful in practice (patents have resulted). The work also led to novel results of scientific importance in understanding the solubility of gases in solvents. Let us now discuss the different results.

Fig. VI.4 - VI.7 give the results for the systems, methanolhexane, water-butoxyethanol, ethylacetoacetate-heptane and heptaneo-toluidine. At this time we were looking at higher pressures. The high solubility of $\mathrm{CO}_{2}$ in the mixture has had a strong impact on the critical points. All of these solvent mixtures aside from heptane-toluidine show significant nonlinear effects. They showed no strong advantages in terms of solvent power and we therefore looked at other systems.

One of the systems studied most extensively was acetonitrile water, which is a good solvent with good solubility for $\mathrm{H}_{2} \mathrm{~S}$ and reasonable selectivity. 
Table VI.4 Physical properties of the solvents

\begin{tabular}{|c|c|c|c|c|}
\hline Solvent & $\begin{array}{l}\text { Molecular } \\
\text { weight, } \mathrm{g} / \mathrm{mole}\end{array}$ & $\begin{array}{l}\text { Specific } \\
\text { Gravity, } \mathrm{g} / \mathrm{cm}^{3}\end{array}$ & $\begin{array}{l}\text { Boiling } \\
\text { Pt. }{ }^{0} \mathrm{C}\end{array}$ & $\begin{array}{l}\text { Freezing } \\
\text { Pt. }{ }^{0} \mathrm{C}\end{array}$ \\
\hline Acetonitrile & 41.05 & 0.786 & 82 & -48 \\
\hline Water & 18.08 & 1.000 & 100 & 0 \\
\hline $\begin{array}{l}\text { N-methyl } \\
\text { Pyrrolidone }\end{array}$ & 99.13 & 1.033 & $82 / 10 \mathrm{~mm}$ & -24 \\
\hline Dodecane & 170.34 & 0.75 & 216.2 & -12 \\
\hline Heptane & 100.21 & 0.684 & 98 & -91 \\
\hline $\begin{array}{l}\text { Methyl } \\
\text { cyclohexane }\end{array}$ & 98.19 & 0.770 & 101 & -126 \\
\hline $2,6-1$ utidine & 107.16 & 0.92 & 143 & -6 \\
\hline Methanol & 32.04 & 0.791 & 64.6 & -98 \\
\hline Hexane & 86.18 & 0.659 & 69 & -95 \\
\hline Toluene & 92.14 & 0.867 & 111 & -93 \\
\hline o-toluidine & 107.16 & 1.004 & 200 & -28 \\
\hline $\begin{array}{l}\text { Ethyl } \\
\text { acetoacetate }\end{array}$ & 130.14 & 1.021 & 181 & -43 \\
\hline Butoxyethanol & 118.18 & 0.903 & $171 / 743 n$ &  \\
\hline
\end{tabular}




\section{SOLUBILITY OF CO2 IN \\ METHANOL-HEXANE}



Figure VI.4 Solubility of carbon dioxide at the CST forming a binary composition. 


\section{Solubility of $\mathrm{CO} 2$ in H2O-butoxyethanol}

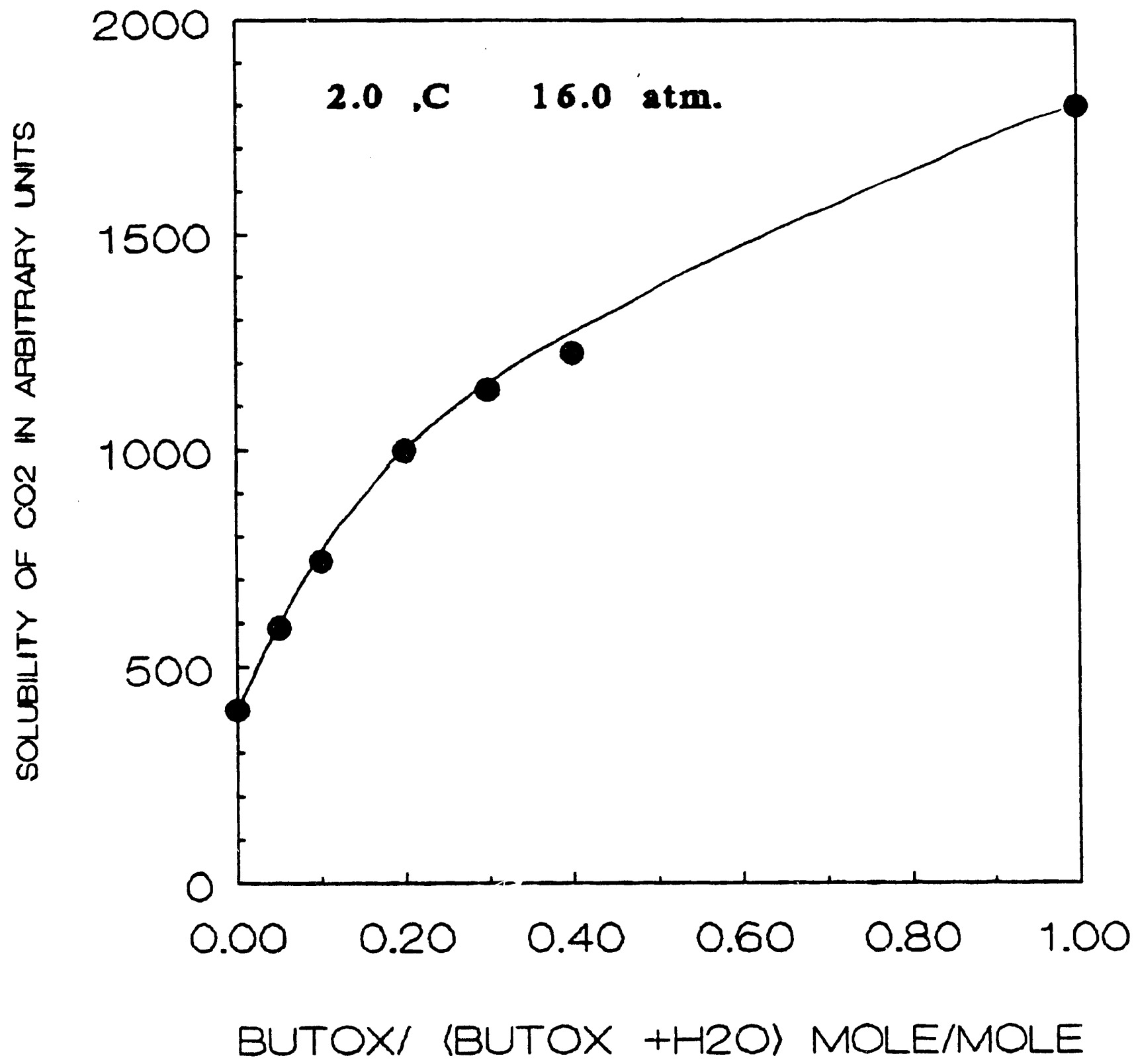

Figure VI.5 Solubility of carbon dioxide at the CST forming a binary
mixture water/butoxiethanol as a function of the mixture composition. 


\section{SOLUBILITY OF CO2 IN HEPTANE-ETHYL ACETOACETATE}

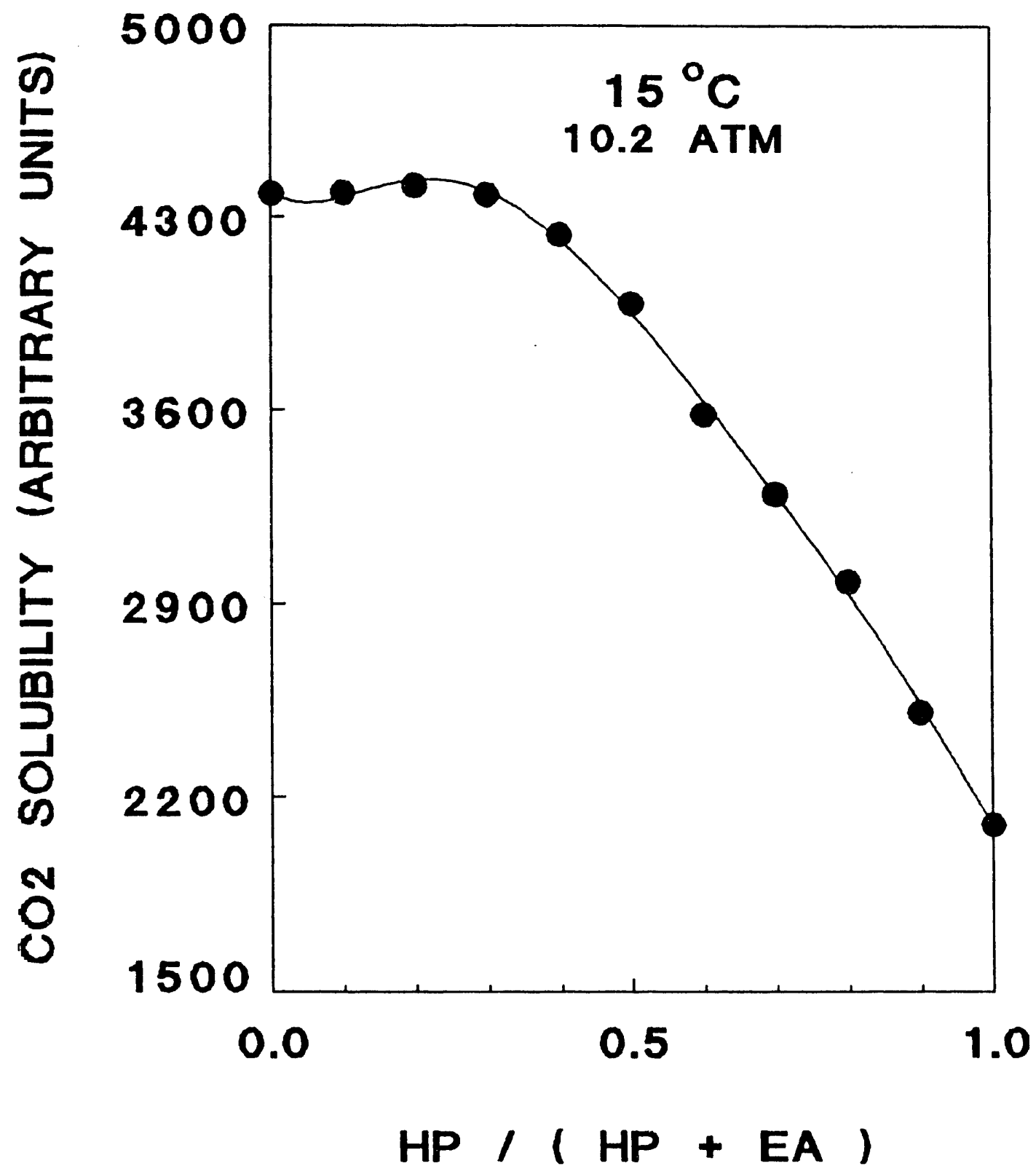

Figure VI.6 Solubility of carbon dioxide at the CST forming a binary mixture heptane/ethyl-acetoacetate as a function of the mixture composition. 


\section{SOLUBILITY OF CO2 IN HEPTANE-TOLUIDINE}

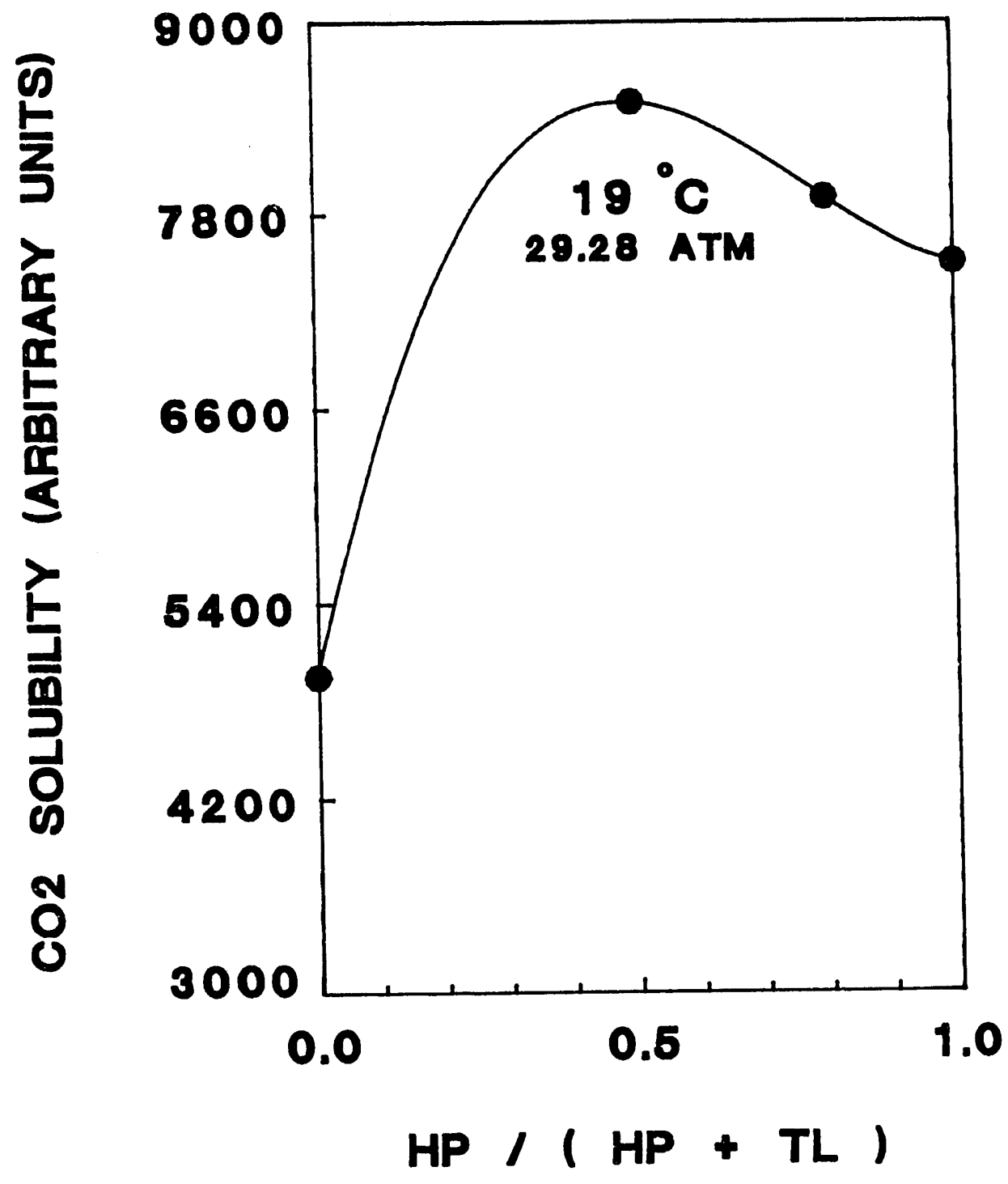

Figure VI.7 Solubility of carbon dioxide at the cST forming a binary
mixture heptane/o-toluidine as a function of the mixture composition. 
The results for acetonitrile-water are summarized in Figures VI.8 -VI.12, where we deal with different aspects of the problems. Fig. VI.8 gives the solubility of $\mathrm{CO}_{2}$ as a function of temperature for a critical mixture. The $\mathrm{CO}_{2}$ partial pressure is 1 atm. Below the critical point two phases are found (see Figure VI.9) and we give the solubility in both phases, as well as the computed volumetric two phase average. We note that at low temperatures the average approaches that of the pure solvent whereas at the critical point is below the linear average (see Table VI.2). This leads to a strong temperature effect which will be discussed in the next section.

Fig. VI.10 gives similar results at a higher pressure of $\mathrm{CO}_{2}$ (15 atm). The results are similar only the critical temperature increases to $35^{\circ} \mathrm{C}$. Fig. VI.11 gives the results for $\mathrm{H}_{2} \mathrm{~S}$ at 1 atm.

If we look at Table VI.1 and VI. 2 we see that for this mixture in all points above the critical point the solubility is below the linear average and above the value predicted by Raoult's law. On the other hand, very interestingly, below the critical point the solubility in the acetonitrile rich phase is above the linear average. The effect is also apparent for $\mathrm{H}_{2} \mathrm{~S}$. Here, small additions of water lead to a dramatic improvement in selectivity (a $60 \%$ increase).

While this mixture does not have the composition of the CST it has some critical property, as at this temperature any small change in composition or drop in temperature will lead to formation of two phases. It therefore has some properties of critical phenomena and here the improvament in selectivity is greater than for the critical solvent mixture above the critical point (see Fig. VI.12). These large improvements in selectivity by small additions of a second solvent could be our most important finding, that justifies our whole effort.

There is another interesting aspect of working in the region where there are two phases. If we use both phases and look at the average then the temperature dependence becomes much higher than customary in solvents. We will discuss this later.

While the work with the acetonitrile system proves and illuminates some of the important advantages of such systems, this solvent is not recommended for hydrogen separation as the selectivity is less than that achieved by other solvents. However, it could be very attractive for cases where only $\mathrm{CO}_{2}$ is removed, such as in Fisher-Tropsch. Here the solubility in a water acetonitrile mixture with $20 \%$ water has a higher solubility for $\mathrm{CO}_{2}$ at $0^{\circ} \mathrm{C}$ than methanol at $-10^{\circ} \mathrm{C}$. This could be attractive. In addition the presence of water should reduce the solubility of hydrocarbons, which is important in some applications. 


\section{Solubility of $\mathrm{CO} 2$}

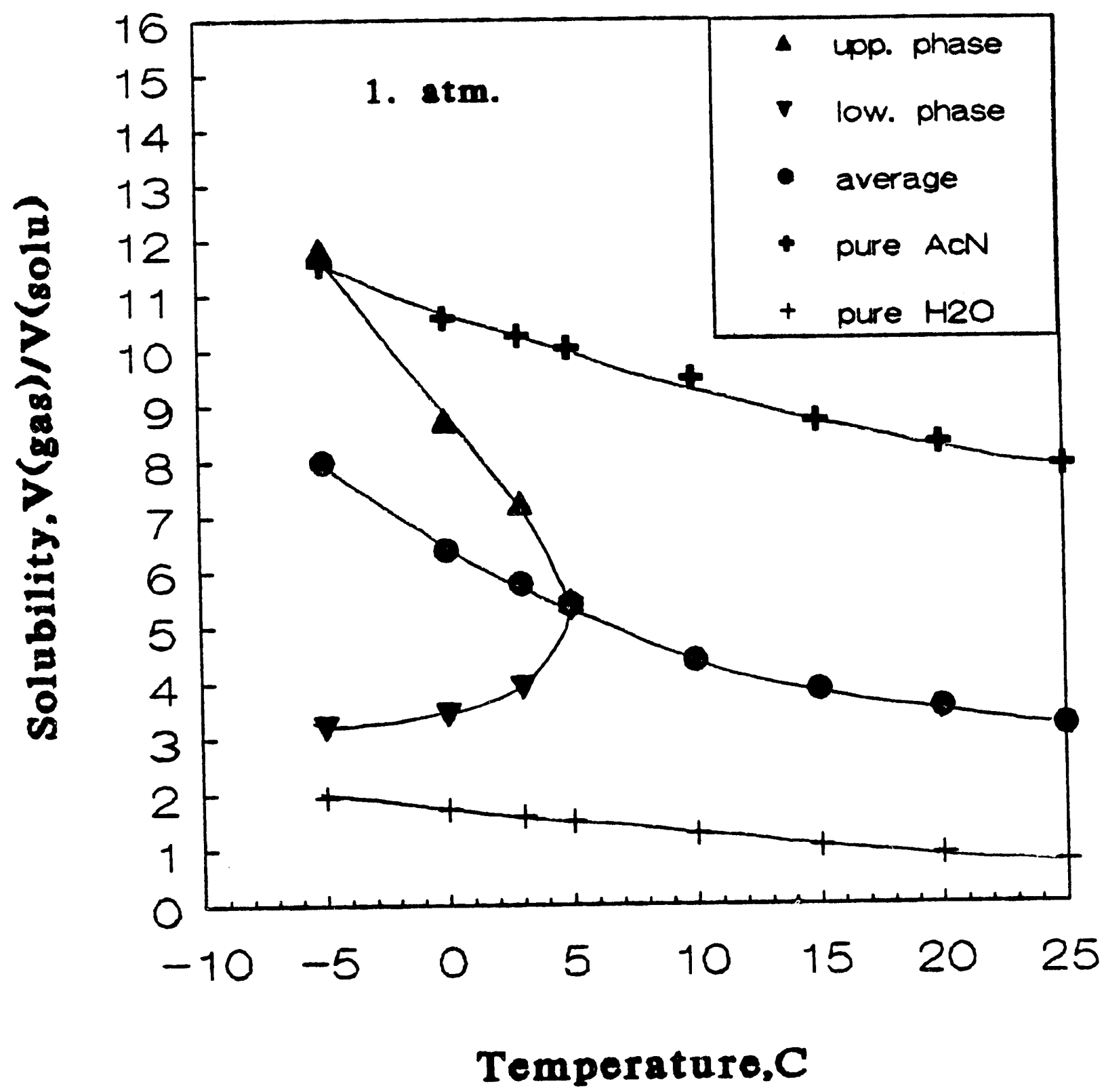

Figure VI.8 Solubility of carbon dioxide in pure acetonitrile, pure water and in critical mixture as a function of temperature. 


\section{Coexistence Curve $\mathrm{ACN} / \mathrm{H} 2 \mathrm{O}$}

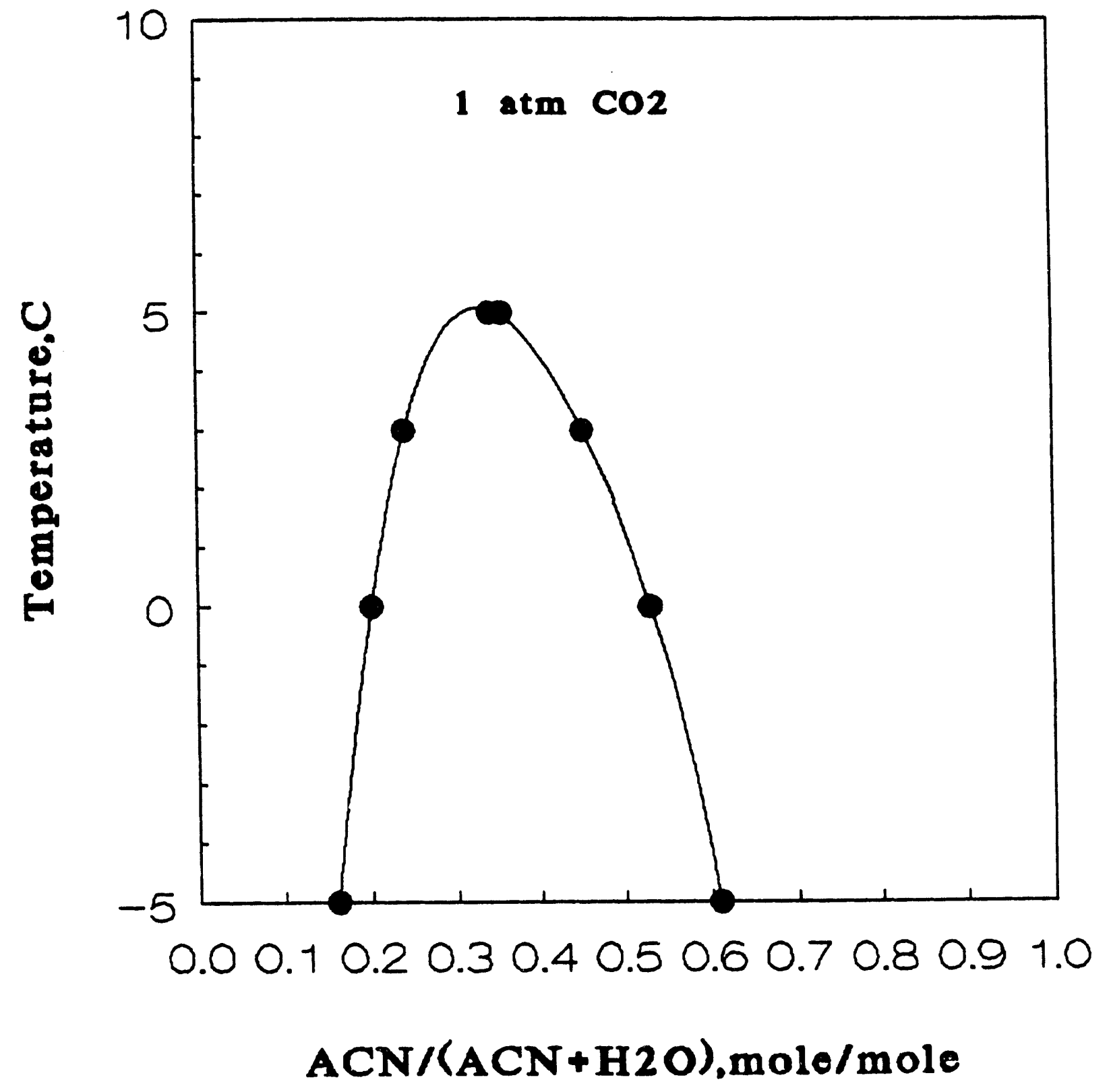

Figure VI.9 Coexistence curve of the acetonitrile/water system. 61 


\section{SOLUBILITY of $\mathrm{CO} 2$ \\ in $\mathrm{ACN}+\mathrm{H} 2 \mathrm{O}$}

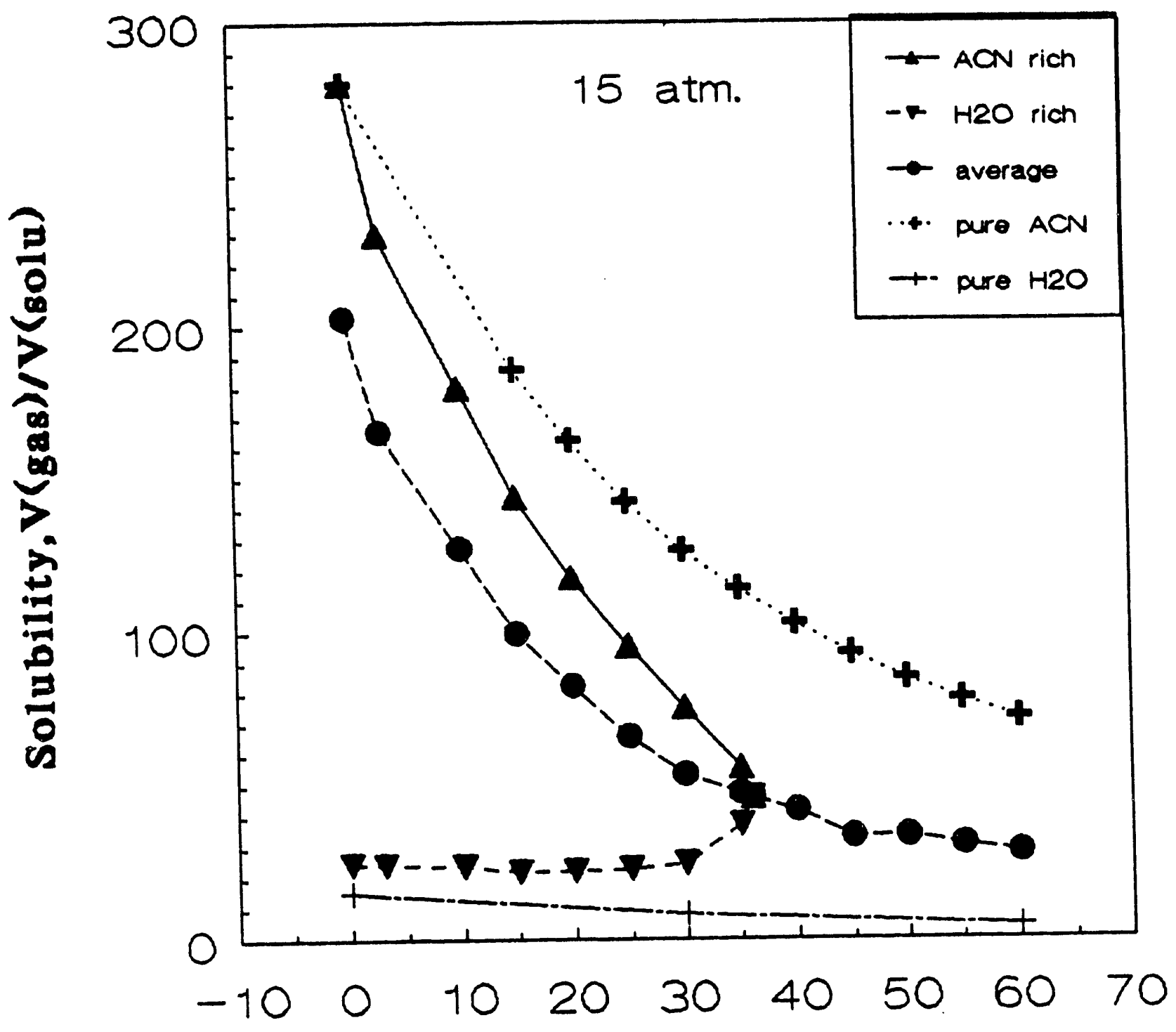

\section{Temperature,C}

Figure VI.10 Solubility of carion dioxide in pure acetonitrile, pure water and in critical mixture as a function of temperature (at 15 atm. partial pressure). 


\section{Solubility of $\mathrm{H} 2 \mathrm{~S}$ in $\mathrm{ACN}+\mathrm{H} 2 \mathrm{O}$}

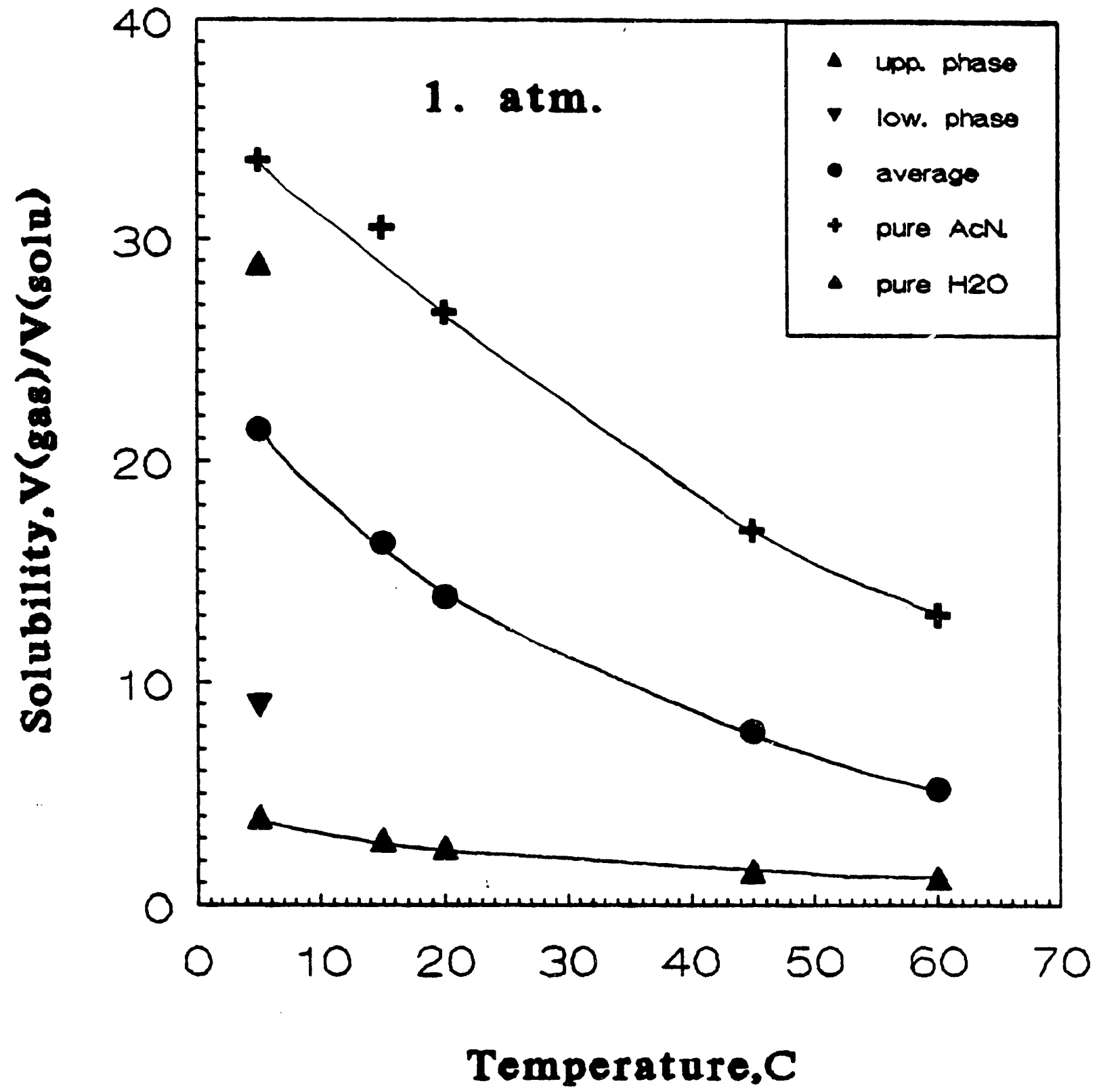

Figure VI.11 Solubility of hydrogen sulfide in pure acetonitrile, pure water, and in critical mixture as a function of temperature. 


\section{Selectivity}

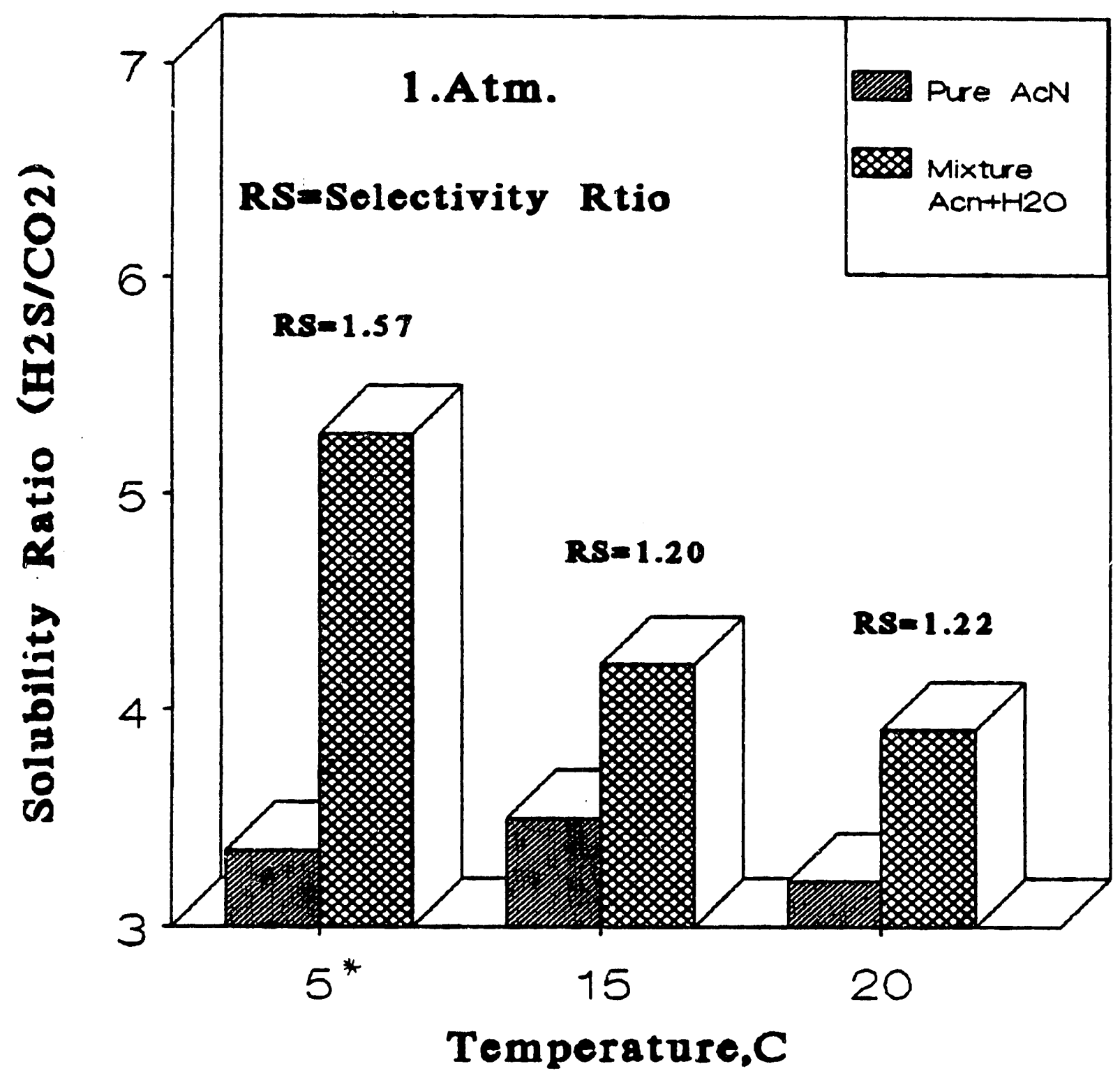

Figure VI.12 Selectivity of hydrogen sulfide with respect to carbon dioxide in acetonitrile-water critical mixture (* below the CST). 
NMP is a commercially used solvent (Purisol). It has a high selectivity for $\mathrm{H}_{2} \mathrm{~S}$ as compared to $\mathrm{CO}_{2}$. Three solvents forming a critical mixture with NMP were tested. Only one showed a significant positive effect on selectivity. The two others reduced selectivity. The detailed results are given in Table VI.1-3 and in Fig. VI.13 - VI.22.

What is especially significant in the NMP-dodecane system is that by relatively small additions of a second solvent forming a critical solution, the selectivity could be increased by $35 \%$ (Fig. VI.16). This is similar to the effect discussed with acetonitrile but here it is of direct applicability as it is not just an example proving the theory but a directly useful result, which is part of our patent application. Dodecane also has the advantage of being high boiling and therefore having a very low vapor pressure.

VI. 2C

METHANOL - TOLUENE

Methanol is also a solvent used in actual practice in the Rectisol Process. Here the critical point is very low and was not reachable in our equipment. The results for $\mathrm{CO}_{2}$ and $\mathrm{H}_{2} \mathrm{~S}$ solubilities are given in Figures VI.23 - 24. Here we deal with a single phase. Again, we were able to show a significant increase in selectivity by addition of toluene (see Fig. VI.25). What is especially interesting here is that at $20^{\circ} \mathrm{C}$ the solubility of $\mathrm{CO}_{2}$ is below that predicted by Raoult's law, whereas that of $\mathrm{H}_{2} \mathrm{~S}$ is above the pure solvent. This is of great theoretical interest, but here this also might have direct practical value. It is promising as it confirms the theoretical expectation and therefore justifies a search for solvents which might have even much better properties, and gives guidelines as to what solvents to look for.

\section{VI.2d LUTIDINE-WATER}

Lutidine water presents an interesting system for solvent removal of $\mathrm{CO}_{2}$ and we discussed it before. It has the same solvent power at $5^{\circ} \mathrm{C}$ as methanol at lower temperatures and a much lower vapor pressure. And the solubility of $\mathrm{CO}_{2}$ at $5^{\circ} \mathrm{C}$ is almost unafrected by diluting it with $60 \%$ water due to strong nonlinearities. On the other hand the temperature dependence is increased, which is important. This is a very interesting solvent and we wanted to get more extensive data; however, the solvent affected the packings and gaskets in our equipment. It would have required significant modifications and considerable work to get the equipment to work properly with lutidine. With the little inherent difficulties our timetable and the remaining budget did not allow for the modifications. But the result itself is a very interesting major accomplishment which needs to be followed up. The results are given in Fig. VI.2. 


\section{Coexistence Curve M-Pyrrol and Dodecane}

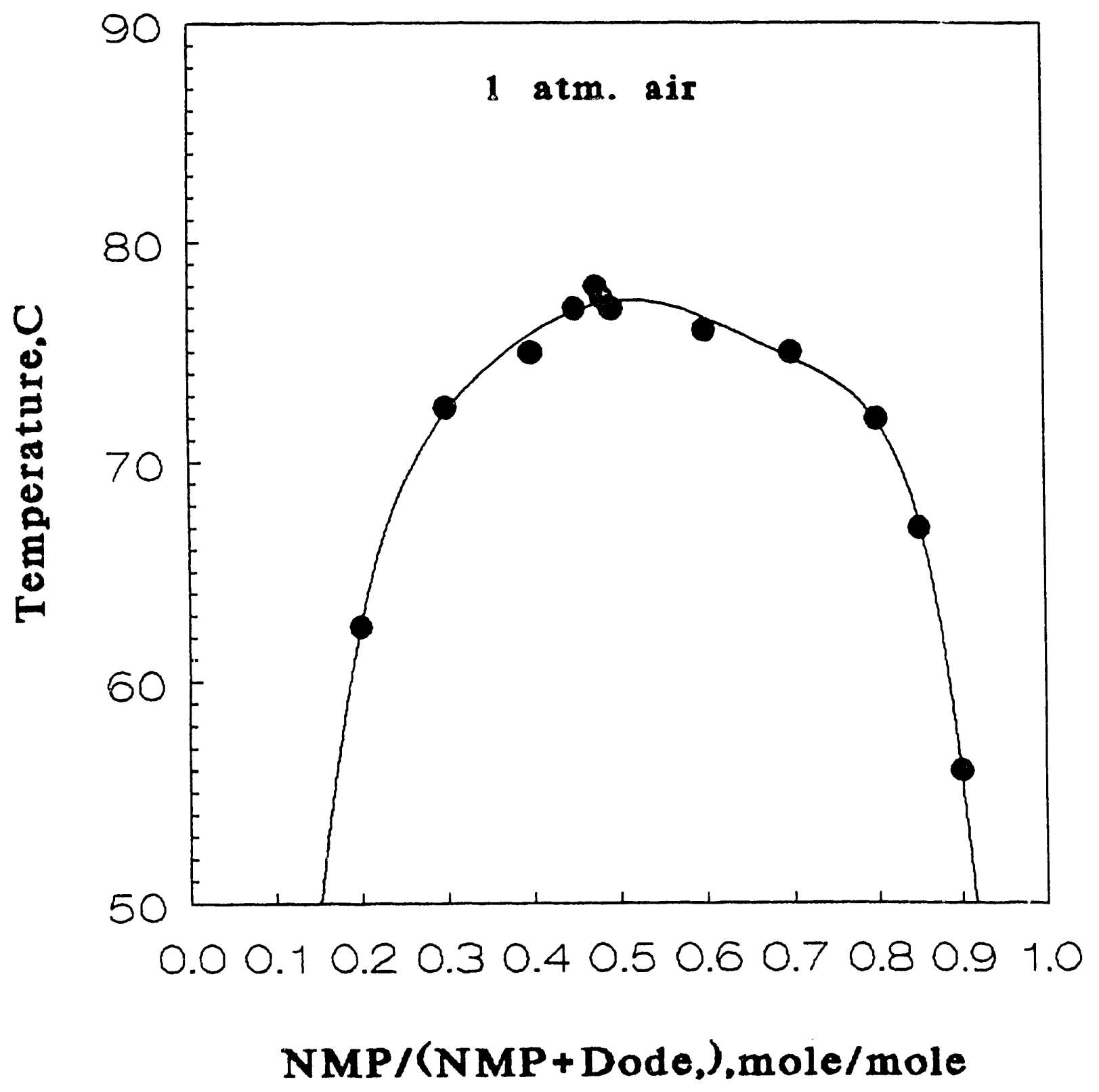

Figure VI.13 Coexistence curve of the N-methylpyrrolidone-dodecane system. 


\section{Solubility of $\mathrm{CO} 2$ in M-Pyrol/Dodecane}



Figure VI.14 Solubility of carbon dioxide in pure NMP, pure dodecane, and in critical mixture as a function of temperature. 


\section{Solubility of $\mathrm{H} 2 \mathrm{~S}$ in M-Pyrol/Dodecane}

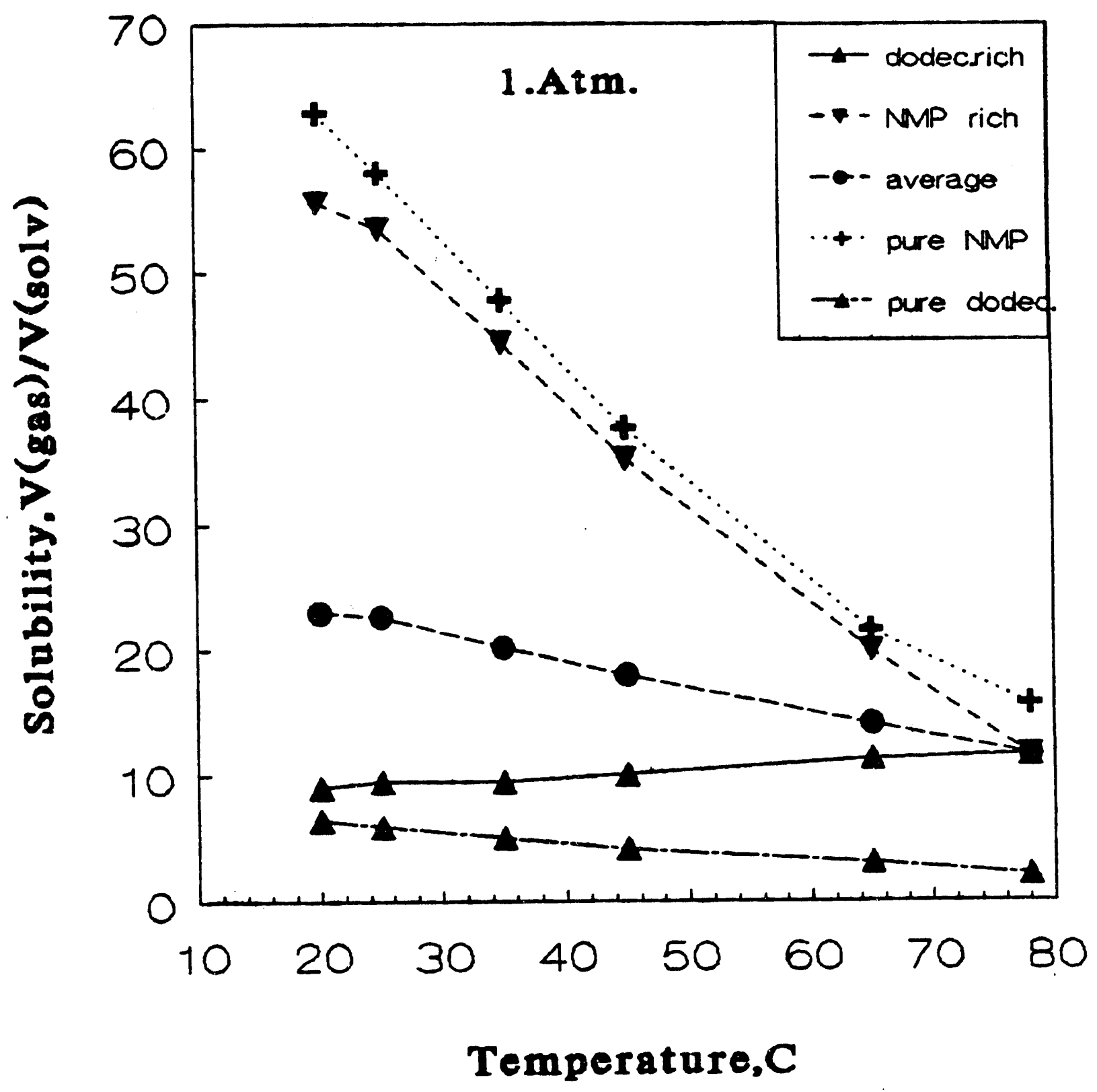

Figure VI.15 Solubility of hydrogen sulfide in pure NMP, pure dodecane, and in critical mixture as a function of temperature. 


\section{$\underline{\text { Selectivity }}$}

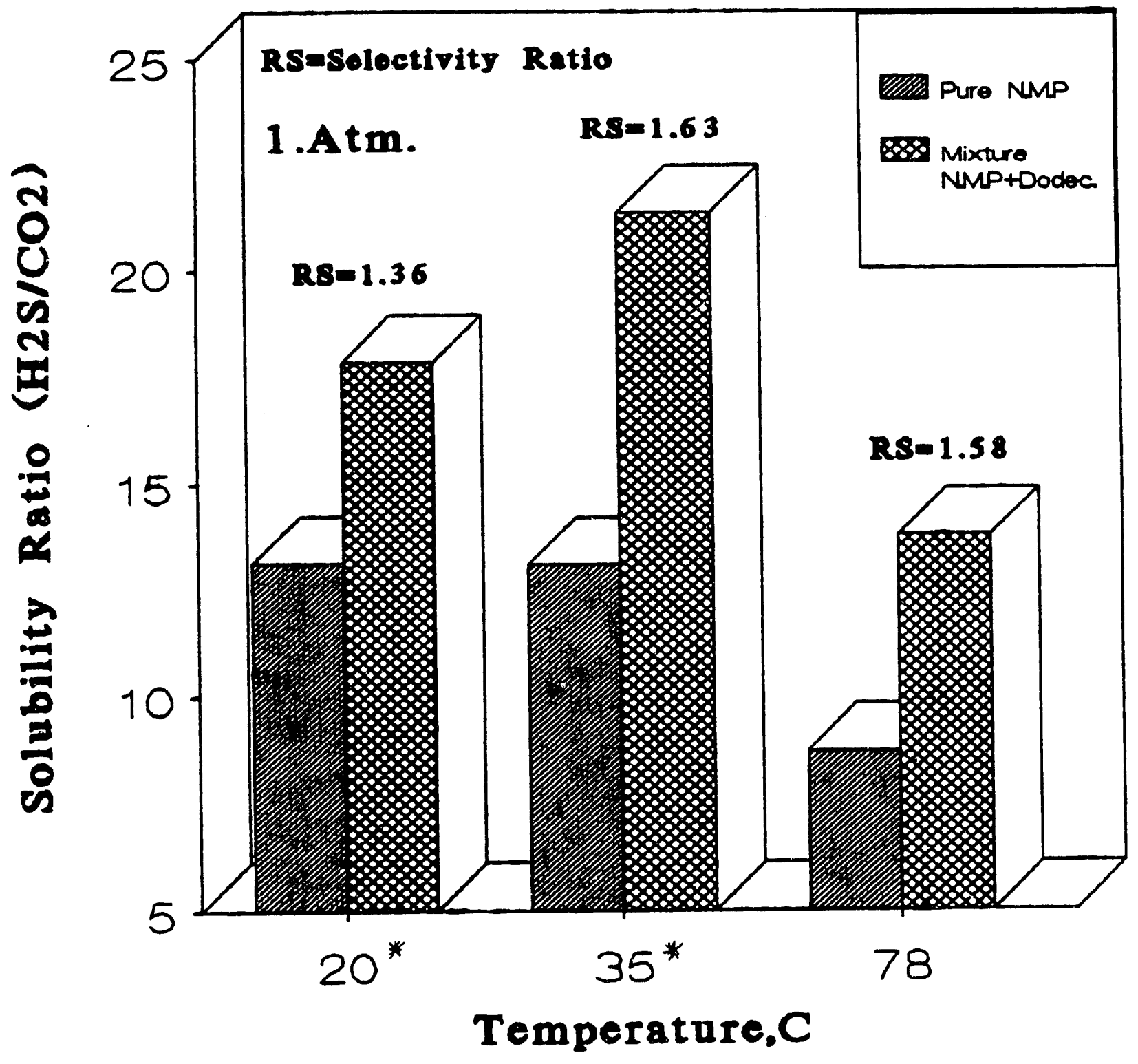

Figure VI.16 Selectivity of hydrogen sulfide with respect to carbon dioxide in NMP-dodecane critical mixture. (* below the CST). 


\section{Coexistence Curve M-Pyrol/Heptane}

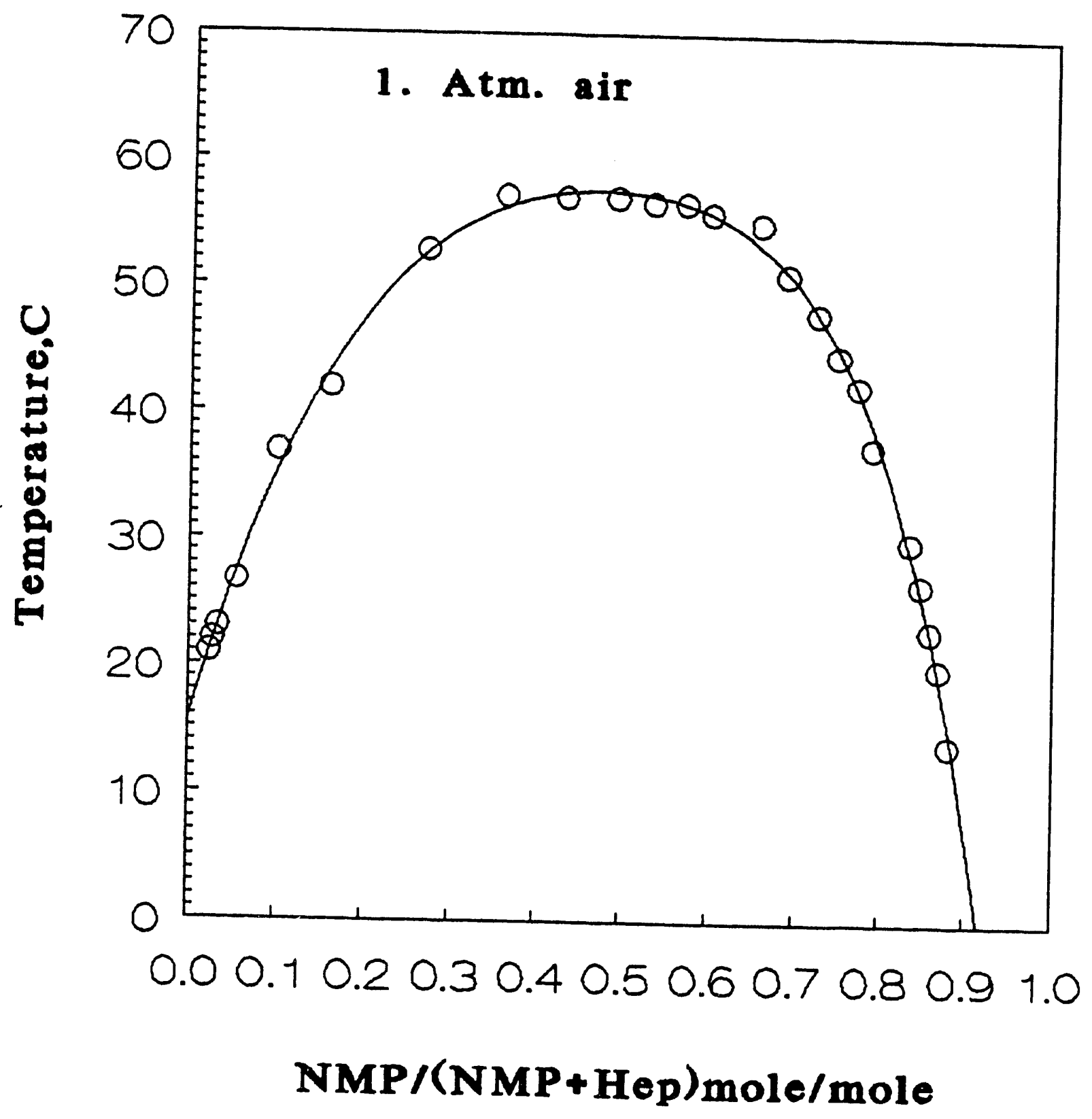

Figure VI.17 Coexistence curve of the NMP-heptane system. 


\section{Solubility of $\mathrm{CO} 2$ in M-Pyrol/Heptane}

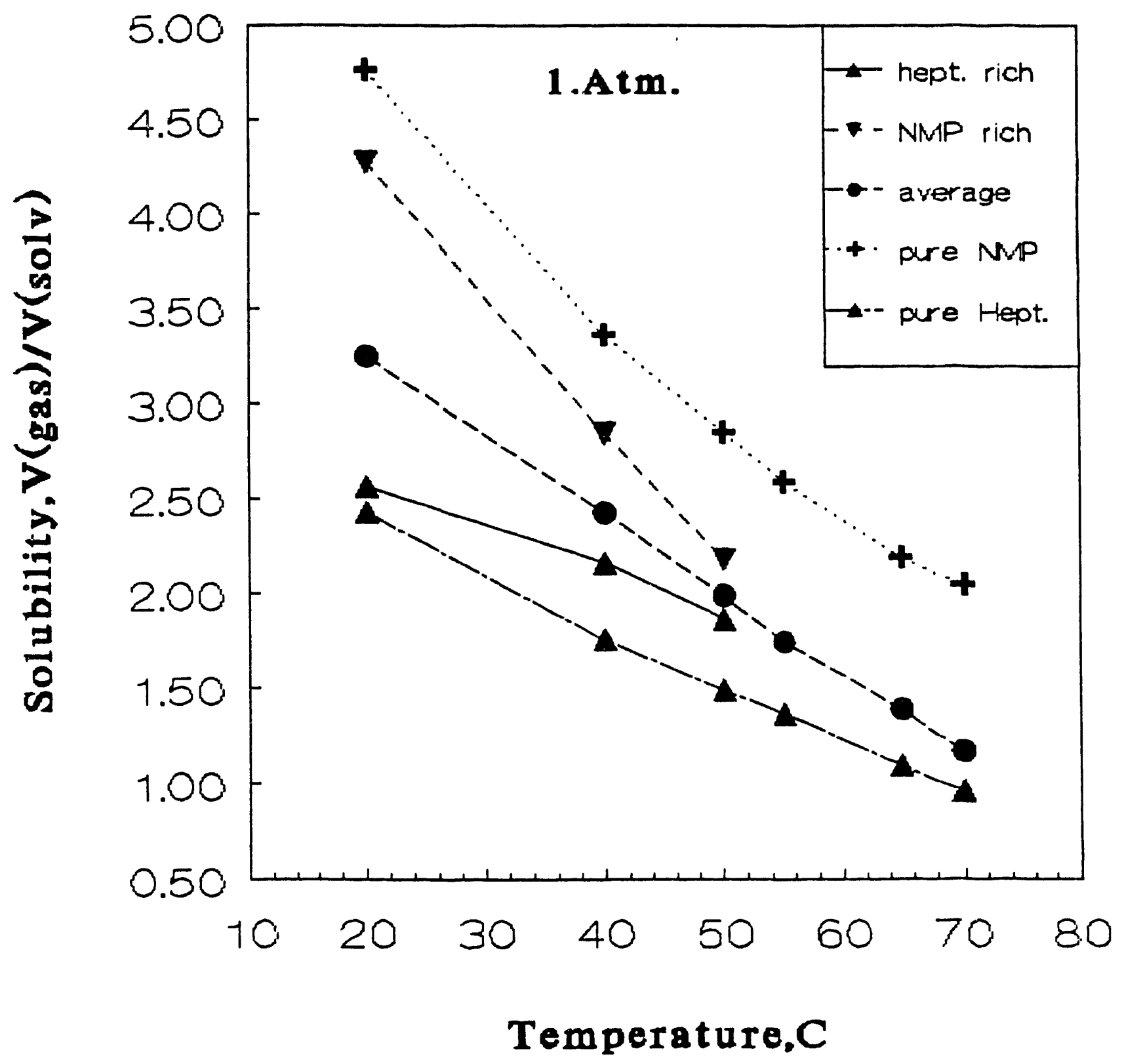

Figure VI.18 Solubility of carbon dioxide in pure NMP, pure heptane, and in critical mixture as a function of temperature. 


\section{Solubility of $\mathrm{H} 2 \mathrm{~S}$ in M-Pyrol/Heptane}

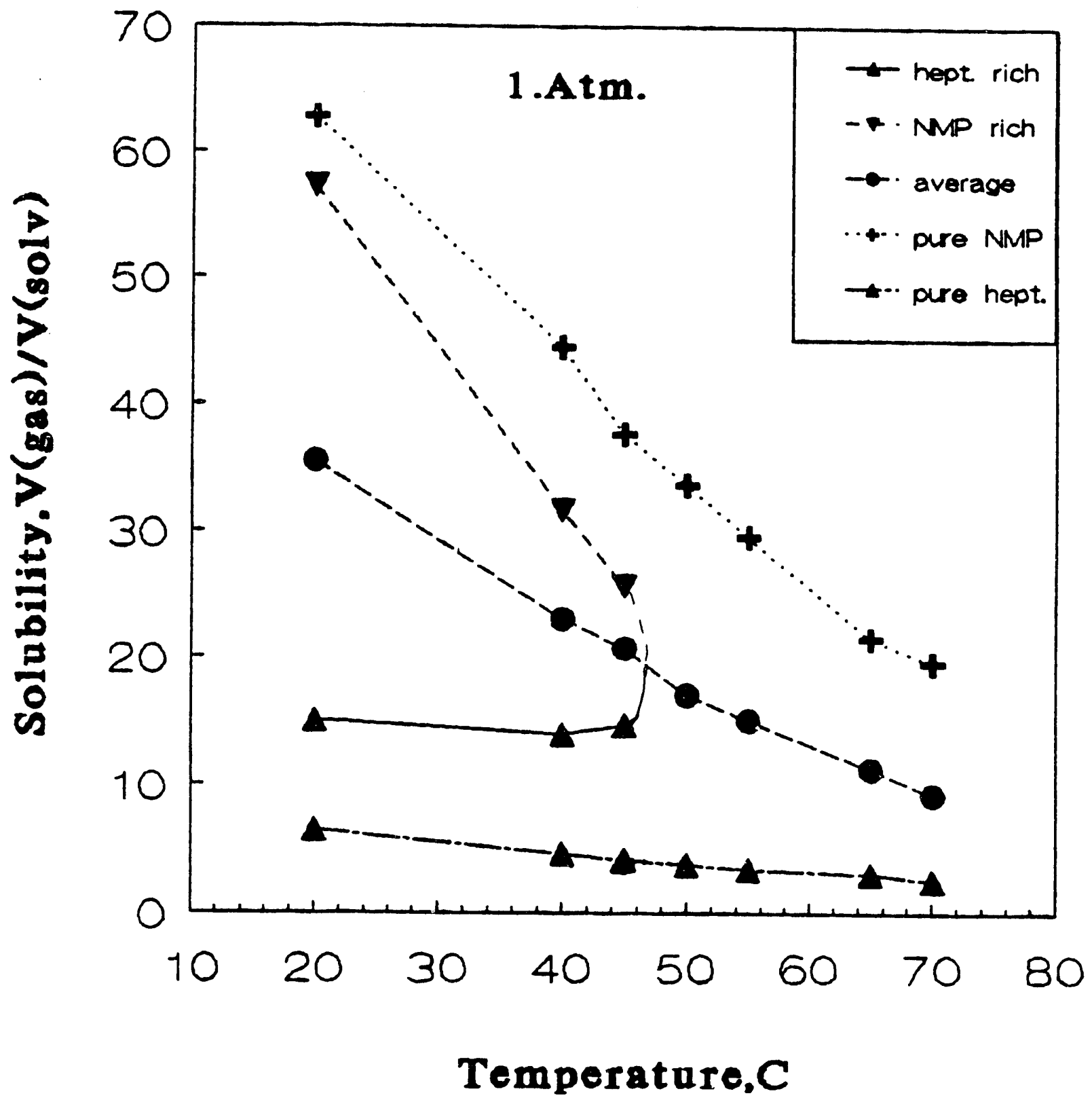

Figure VI.19 Solubility of hydrogen sulfide in pure NMP, pure heptane, and in critical mixture as a function of temperature. 


\section{$\frac{\text { Coexistense Curve }}{\text { M-Pyrol/M-Cyclohexane }}$}

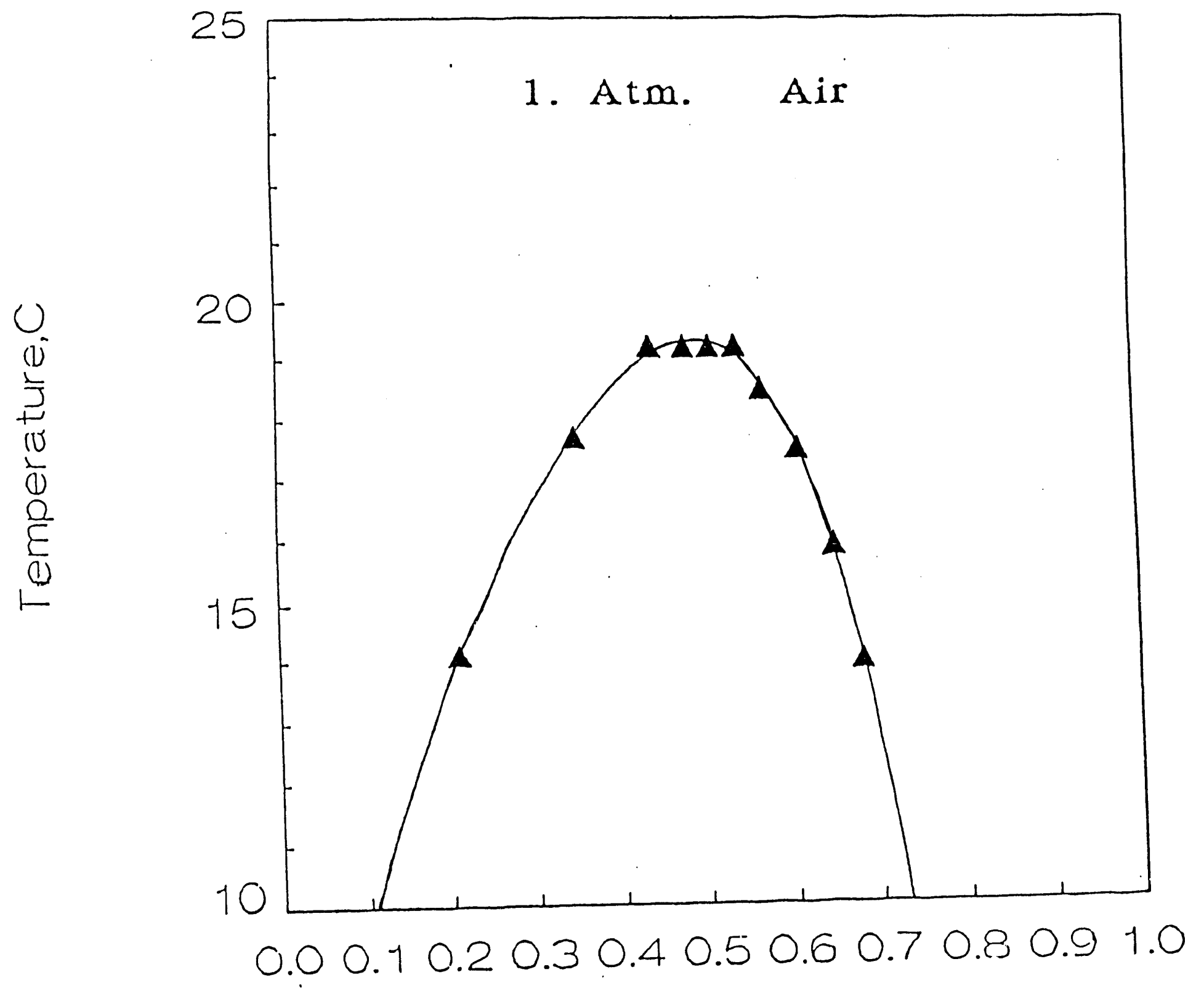

NMP/(NMP+MI-C-hexanelmole/rnole

Figure VI.20 Coexistence curve of NMP-methylcyclohexane. 


\section{Solubility of $\mathrm{CO} 2$ in $\mathrm{NMP} / \mathrm{MCH}$}

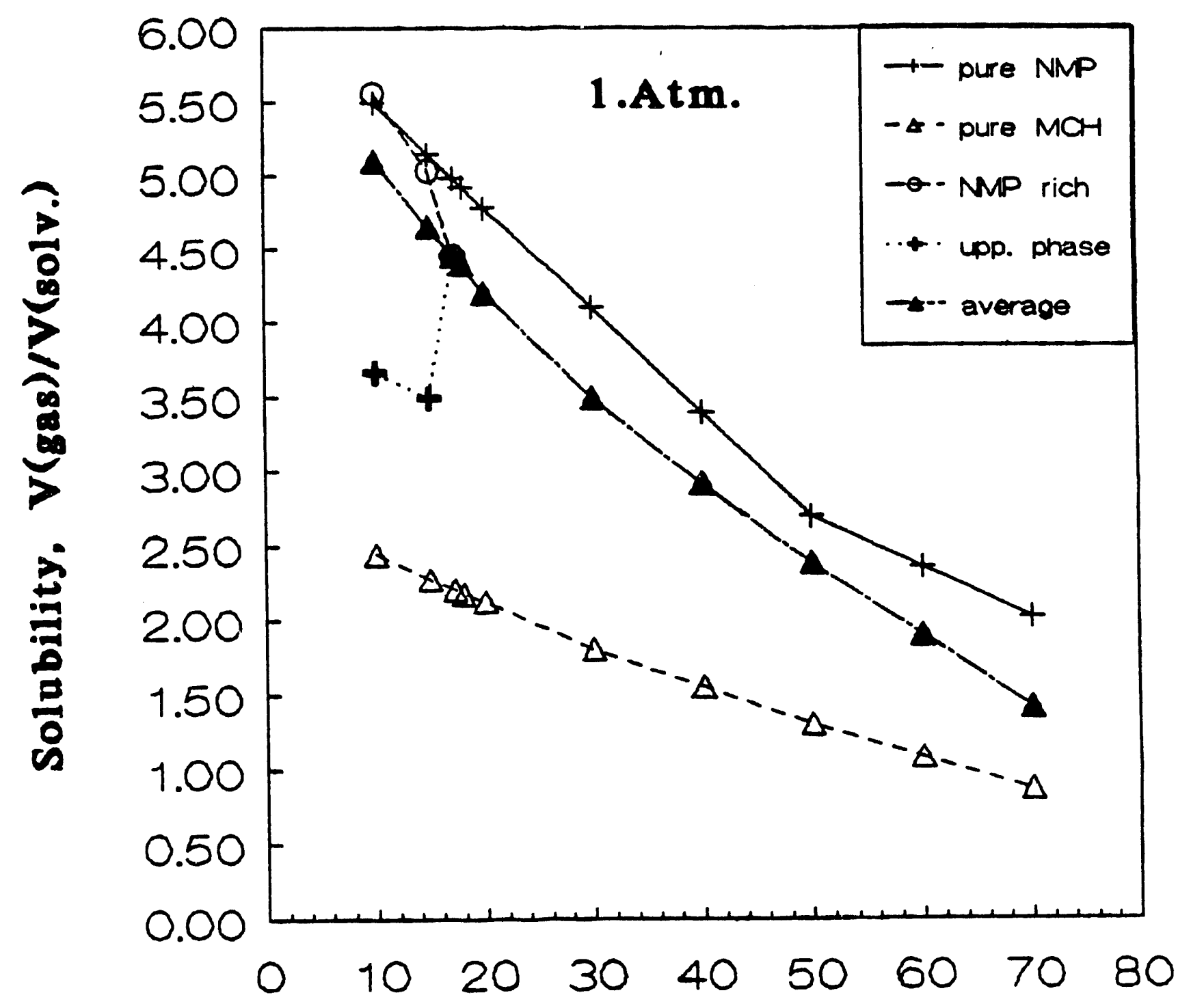

Temperature, c

Figure VI.21 $\begin{aligned} & \text { Solubility of carbon dioxide in pure NMP, pure } \\ & \text { methylcyclohexane, and in critical mixture as a function of } \\ & \text { temperature. }\end{aligned}$ 


\section{Solubility of $\mathrm{H} 2 \mathrm{~S}$ \\ in $\mathrm{NMP} / \mathrm{MCH}$}

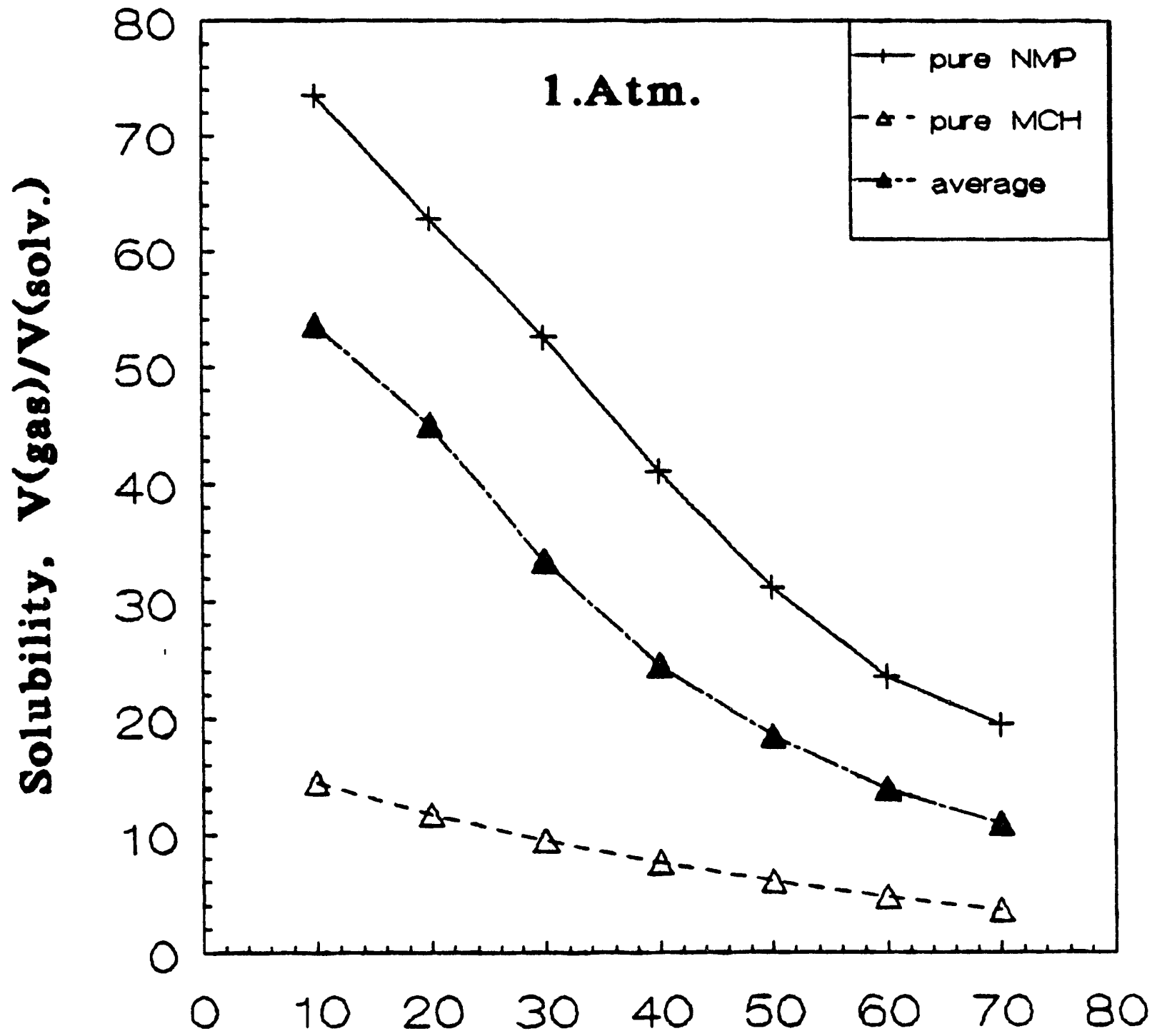

Temperature, c

Figure VI.22 Solubility of hydrogen sulfide in pure NMP, pure methylcyclohexane, and in critical mixture as a function of temperature. 


\section{SOLUBILITY OF CO2 METHANOL+TOLUENE}

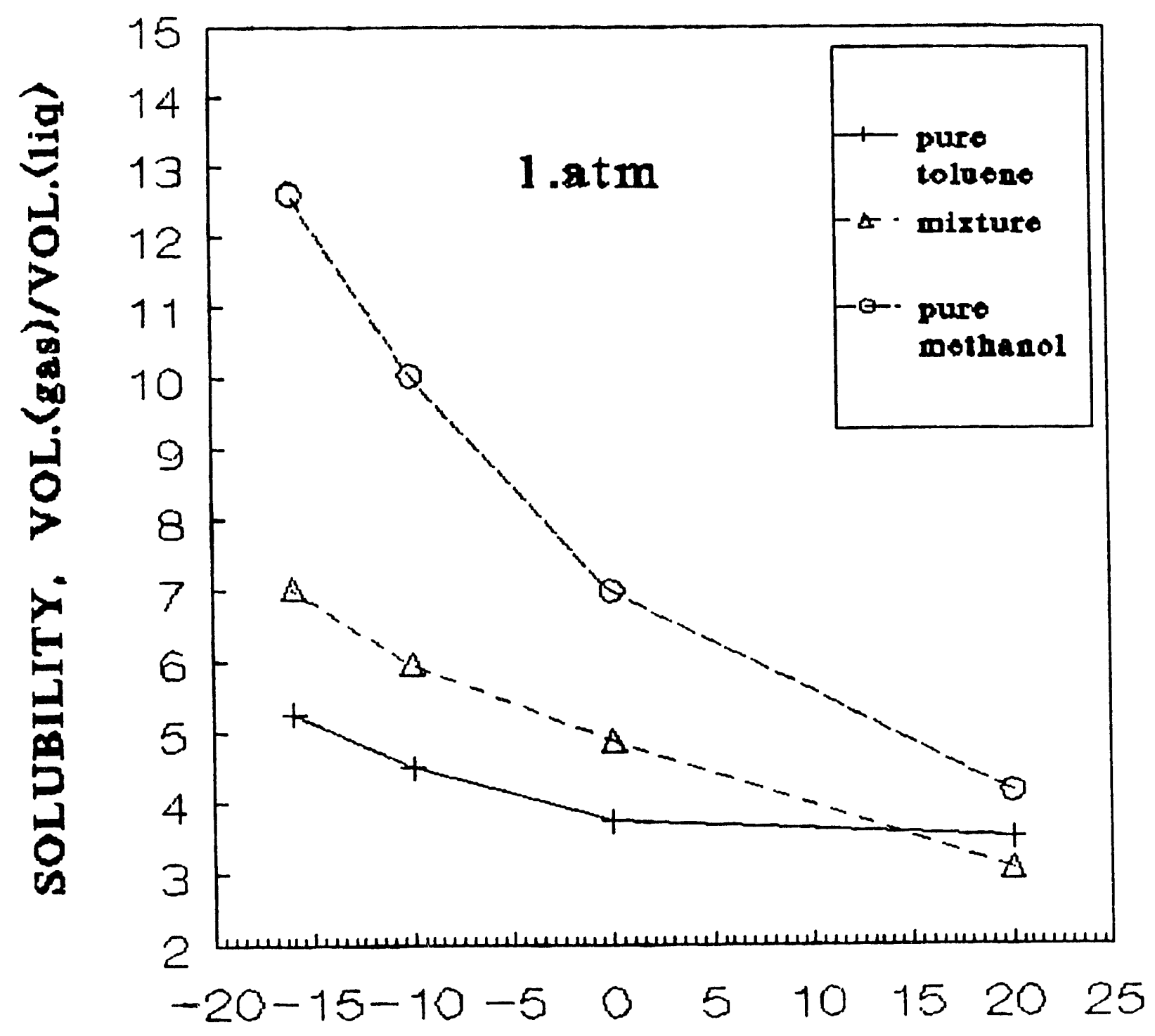

\section{TEMPERATURE， C}

Figure VI.23 Solubility of carbon dioxide in pure methanol, pure toluene, and in critical mixture as a function of temperature. 


\section{SOLUBILITY OF H2S METHANOL+TOLUENE}

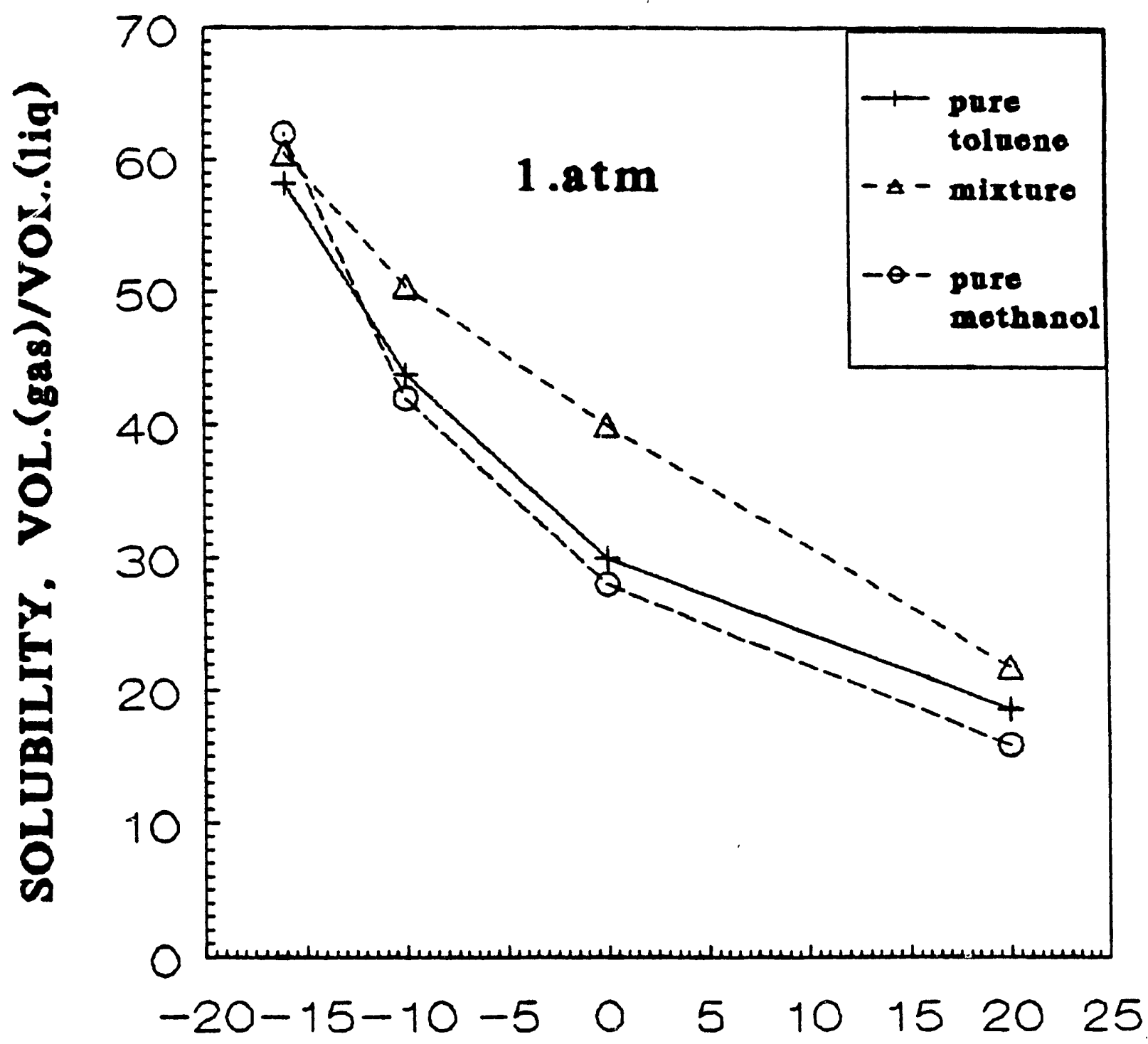

TEMPERATURE, C

Figure VI.24 Solubility of hydrogen sulfide in pure methanol, pure toluene, and in critical mixture as a function of temperature. 


\section{$\underline{\text { Selectivity }}$}

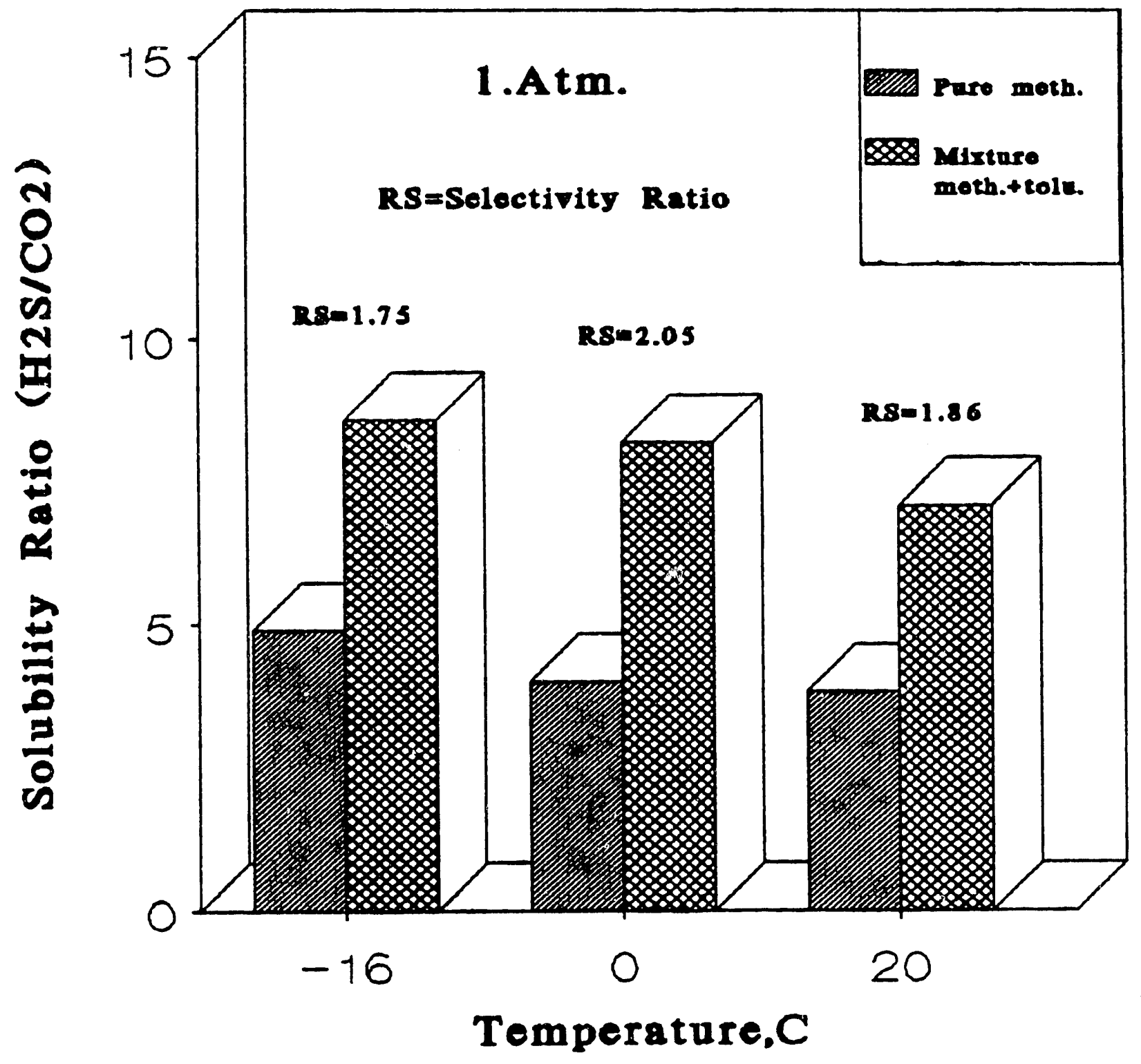

Figure VI.25 Selectivity of hydrogen sulfide with respect to carbon dioxide in methanol-toluene critical mixture. 
In some coal gasifiers, methane is proủced together with syngas and has to be separated from the hydrogen product. One way of doing so is cryogenic separation. Another is use of hydrocarbon solvents. Originally one of our goals was to find a better solvent for methane. Literature results for solubility of methane in. various solvents are given in Table VI.5. However, our search was not successful. What we hoped for is to find solvent pairs with strong maxima to increase the solubility of metnane which is low in all solvents (see table VI.5). As dodecane (or other high molecular weight paraffins) is a good solvent for methane we tried to improve it by adding NMP. Fig.' VI.26 gives the results. No strong nonlinear effects are noticed. This may be due to the chemical nature of methane which is a non-polar symmetric molecule with low interaction and low London forces. 
Equilibrium solubilities of methane in various solvents and conditions, literature data.

Solvent

$\bar{x} y$ lene
DEA
(Diethanolamine)

\section{Decane}

Benzene

Toluene

Hexane

Pentane

Hexadecane

Quinoline

Ethylene oxide

octacosane

Carbonyl sulfide

Hexatriacontane

NMP

Acetone

Chlorocyclohexane

Methylnapthalene

Diethyl ether

$$
\mathrm{V} \mathrm{cm}
$$$$
\text { cm }
$$

120.62

4.07

$\mathrm{P}$ atm. $\quad \mathrm{T}^{0} \mathrm{C}$

95.88

1.00

20.25

0.40

0.04

199.92

20.10

89.13

13.00

106.30

17.00

130.52

1.70

20.25

12.01

0.60

6.50

0.50

7.71

0.45

149.3

1.68

0.99

115.22

6.80

0.01

7.26

1.12

$292.84 \quad 20.00$

6.66

0.33

118.18

20.00

3.81

0.19

49.92

1.00

0.73

0.73

489.38

9.77

2.75

0.28

58.44

11.00

17.88

1.62

596.46

10.21

2.71

0.27

95.96

1.21

0.47

0.39

73.53

17.1

$20-25$

11.61

0.07

118.61

1.0

25

0.47

0.47

142.1

9.0

38

2.21

0.24

$103.81 \quad 20.7$

11.15

24.51

1.18
Ref.

$\mathrm{Ng}$ et al. (1982)

Gueuara et al. (1984) Lin et al. (1979)

Lin et al. (1979)

Lin et al. (1979)

Lin et al. (1977)

Le Roy

(1975)

Lin et al. (1980)

Simmick et al. (1979) Hwang et al. (1977)

Huang et al. (1988)

Sentark et al. (1979) Tsal et al. (1987)

Gueuara et al. (1984) $\mathrm{Ng}$ et al. (1982)

Lopez et al. (1987)

Li et al. (1981) Gueuara et al. (1987)

$\mathrm{V}$ - Molar Volume

S - Solubility, gas volume at standard condition over solute-free solvent volume

S* - Solubility Extrapolated to 1 atm. 


\section{Solubility of CH4 in M-Pyrol/Dodecane}



Figure VI.26 Solubility of methane in pure dodecane and in NMP-dodecane critical mixture as a function of temperature. 
VII. SOME THEORETICAL CONSIDERATIONS ON THE RESULTS

Despite extensive analysis of present theory on nonlinear effects on solubility of mixtures of solvents, we find no theory that allows a quantitative prediction of the effect. Nor can the theory predict what solvents to chose for a particular application. However we developed some ideas that could lead to at least semi-empirical predictions based on theory. However this would involve significant future work.

For a start let us review the theory of gas solubility in mixed solvents as discussed by O'Connell (O'Connell 1964, 1971).

\section{Free Energy And Activity Coefficient}

For a real solution, the molal free energy ( $g$ ) can be described as the sum of the molal free energy for an ideal solution and an excess molal free energy $\left(g^{E}\right)$ for non-ideal effects.

$$
g=\sum_{i=1}^{c} x_{i} g_{i}+R T \sum_{i=1}^{c} x_{i} \ln x_{i}+g^{E}=\sum_{i=1}^{c} x_{i}\left(g_{i}+R T \ln x_{i}+g_{i}^{E}\right)
$$

where the excess molal free energy is the sum of the partial excess molal free energies $\left(g_{i}{ }^{E}\right)$ which is related to the liquid-phase activity coefficient by

$$
\left.\frac{g_{i}^{E}}{R T}=\ln \gamma_{i}=\left[\frac{\partial\left(n_{T} g^{E} / R T\right)}{\partial n_{i}}\right]_{P, T, n_{j}}=\frac{g^{E}}{R T}-\sum x_{k}\left[\frac{\partial\left(g^{E} / R T\right)}{\partial x_{k}}\right]_{T, P, x_{x}} 0\right)
$$

where $j \neq i, r \neq k, r \neq i$ and $k \neq i$.

one can express the molal free energy as

$$
\frac{g^{E}}{R T}=\sum x_{i} g_{i}^{E}=\sum x_{i} \ln \gamma_{i}
$$

where $\gamma_{i}$, the activity coefficient, is defined by

$$
\gamma_{i}=\frac{a_{i}}{x_{i}} ; a_{i}=\frac{f_{i}(T, P, x)}{f_{i}\left(T, P^{0}, x^{\circ}\right)}
$$

Some empirical and semi-theoretical equations for correlating liquid phase activity coefficients and excess Gibbs energies of binary mixtures are given in Table VII.1.

The Van Laar interaction constants $A_{i j}$ and $A_{j i}$ are, in theory, only constant for a particular binary pair at a given temperature. In practice, they are frequently computed from isobaric data covering a range of temperature. The Van Laar theory expresses the temperature dependence of $A_{i j}$ to be

$$
A_{i j}=\frac{A_{i j}}{R T}
$$


Regular solution theory (Hildebrand) and Van Laar equation are equivalent for a binary solution and

$$
A_{i j}=\frac{V_{i j}}{R T}\left(\delta_{i}-\delta_{j}\right)^{2}
$$

The Van Laar equation can fit activity coefficient-composition curves corresponding to both positive $\left(\gamma_{i}>1\right)$, and negative $\left(\gamma_{i}<1\right)$ deviation from Raoult's Law.

\section{Predicting Binary Van Laar Constants}

For partially miscible pairs, the preferred procedure for obtaining Van Laar constants is the best fit of activity coefficient data for each species over the complete composition range. Frequently, only mutual solubility data for a binary pair are available. In this case, Van Laar constants can be computed directly from the liquid-liquid equilibrium condition

$f_{i L}^{1}-f_{i L}{ }^{11}$

(the same fugacities in the phases)

$$
\gamma_{i L}^{I} x_{i}^{I} f_{i L}^{O I}=\gamma_{i L}^{I I} x_{i}^{I I} f_{i L}^{O I I} \Rightarrow \gamma_{i L}^{I} X_{i}^{I}=\gamma_{i L}^{I I} X_{i}^{I I}
$$

Combining Eq. 15 with the Van Laar equations gives the Carlson and Colburn (Carlson and Colburn, 1949) equation

$$
\begin{gathered}
\frac{A_{12}}{A_{21}}=\frac{\left(x_{1}{ }^{I} / x_{2}{ }^{I}+x_{1}^{I I} / x_{2}^{I I}\right)\left[\frac{\ln x_{1}^{I I} / x_{1}{ }^{I}}{\ln \left(x_{2}{ }^{I} / x_{2}{ }^{I I}\right)}\right]-2}{\left(x_{1}{ }^{I} / x_{2}{ }^{I}+x_{1}{ }^{I} / x_{2}^{I I}\right)-\frac{2 x_{1}^{I} x_{1}^{I I} \ln \left(x_{1}^{I I} / x_{1}{ }^{I}\right)}{x_{2}{ }^{I} x_{2}^{I I} \ln \left(x_{2}{ }^{I} / x_{2}^{I I}\right)}} \\
A_{12}=\frac{\ln \left(x_{1}^{I I} / x_{1}{ }^{I}\right)}{\left(1+\frac{A_{12}}{A_{21}} \cdot \frac{x_{1}{ }^{I}}{x_{2}{ }^{I}}\right)^{-2}-\left(1+\frac{A_{12}}{A_{21}} \cdot \frac{x_{1}^{I I}}{x_{2}^{I I}}\right)^{-2}}
\end{gathered}
$$

At the critical solution temperature where $x_{1}{ }^{1}=x_{1}{ }^{11}$, Eqs. 16 and 17 become indeterminate. However, application of the instability conditions as discussed by Hildebrand and Scott (Hildebrand and Scott, 1950) leads to the expression

$$
\begin{gathered}
\frac{A_{12}}{A_{21}}=\frac{1-\left(x_{1}\right)^{2}}{2 x_{1}-\left(x_{1}\right)^{2}} \\
A_{12}=\frac{13.5\left(1-x_{1}\right)^{2}}{\left(2-x_{1}\right)^{2}\left[1-x_{1}^{2}\right]} \quad A_{21}=\frac{13.5\left(x_{1}\right)}{\left(2-x_{1}\right)\left(1+x_{1}\right)^{2}}
\end{gathered}
$$


Table VII.1 Binary Activity Coefficient And Excess Gibbs Energy Relations $\ln \gamma_{1} \ln \gamma_{2} \quad g^{E} / R T$

Symmetrical) Margules
$A x_{2}{ }^{2}$
$\mathrm{Ax}_{1}{ }^{2}$
$A x_{1} x_{2}$

Van Laar

$$
A_{12}\left(\frac{A_{21} X_{2}}{A_{12} X_{1}+A_{21} X_{2}}\right)^{2} \quad A_{21}\left(\frac{A_{12} X_{1}}{A_{12} X_{1}+A_{21} X_{2}}\right)^{2} \quad \frac{1}{\left(1 / A_{12} X_{1}+1 / A_{21} X_{2}\right)}
$$

Scatchord Hildebrand

$$
\frac{V_{1}}{R T}\left(1-\phi_{1}\right)^{2}\left(\delta_{1}-\delta_{2}\right)^{2} \quad \frac{V_{2}}{R T} \phi_{1}{ }^{2}\left(\delta_{1}-\delta_{2}\right)^{2}
$$$$
\frac{\left(\delta_{1}-\delta_{2}\right)^{2}}{R T\left(\frac{1}{V_{1} X_{1}}+\frac{1}{V_{2} X_{2}}\right)}
$$

$$
\phi=\frac{V_{1} X_{1}}{V_{1} X_{1}+V_{2} X_{2}}
$$


Spinodal Iine And Critical Point (case of regular solution).

A spinodal point is a point at which the second derivative of the Gibbs free energy with respect to composition is equal to zero. The second derivative of Eq (9) for binary mixture is given by

$$
\frac{\partial^{2} g / R T}{\partial x_{1}^{2}}=\left(\frac{1}{x_{1}}+\frac{1}{x_{2}}\right)+\frac{\partial g E / R T}{\partial x_{1}^{2}}
$$

Using Margules Eq. from Table VII.1

$$
\frac{\partial^{2} g / R T}{\partial x_{1}^{2}}=\left(\frac{1}{x_{1}}+\frac{1}{x_{2}}\right)-2 A
$$

the stability criteria is

$$
\frac{\partial^{2} g / R T}{\partial x_{1}^{2}} \geq 0
$$

For symmetrical Margules Eq., $x_{1}=x_{2}=0.5$ at the critical point and by Eq. 22 the constant A can be calculated using Table VII.1.

$$
\mathrm{A}=\mathrm{A} \cdot / \mathrm{RT}=2
$$

\section{Solubility of Gas In Solution Mixture}

It can be shown that an ideal solvent mixture $A$, with low gas solubility, obeys Henry's Law and its solubility in the mixture can be expressed as follows:

where 3 is the gas component.

$$
\ln \mathrm{H}_{3, m}=x_{1} \operatorname{lnH}_{3,1}+x_{2} \operatorname{lnH}_{3,2}
$$

O'connell (O'Connell, 1964) showed that for not ideal solution but symmetrical solution mixtures, Eq. 23 could be expanded to

$$
\text { In } \mathrm{H}_{3, \mathrm{~m}}=\mathrm{x}_{1} \operatorname{lnH}_{3,1}+\mathrm{x}_{2} \operatorname{lnH}_{3,2}-\mathrm{A}_{12} \mathrm{x}_{1} \mathrm{x}_{2}
$$

For an ideal gas, $\phi=1$, and with low gas solubility in liquid the fugacities of the gas obey

$$
f=y_{i} P=H_{i} x_{i, s} \text { and } x_{i, s}=P_{i} / H_{i}
$$

where $x_{i, s}$ is the mole fraction of the gas in the solution. Using Margules'Eq from Table VII.1, Eq. 24 becomes

$$
x_{i, m}=x_{i, 1}^{x_{1}} \cdot x_{i, 2}^{x_{2}} \cdot \exp \left(g_{1,2}^{E} / R T\right)
$$

(for ideal solution $g_{1,2}{ }^{E} / R T=0$ ).

In the original o'connell equ:ion the free energy was calculated using Margules Eq. (Table. I.I) neglecting the effect 
of the dissolved gas in the mixture. Thus, the free energy is only a function of the solvents. It was also suggested that the Scatchord Hildebrand Eq. (Table VII.1) with Hildebrand parameters $\left(\delta_{1}, \delta_{2}\right)$ for the pure solvents, can be used.

If the selectivity, the solubility ratio of two gases, has to be calculated, Eq. 26 can be used

$$
\frac{x_{A, m}}{x_{B, m}}=S_{A, B}=\left(\frac{x_{A, 1}}{x_{B, 1}}\right)^{x_{1}}\left(\frac{x_{A, 2}}{x_{B, 2}}\right)^{x_{2}} \exp \left(\frac{g_{A}^{E}}{R T}-\frac{g_{B}^{E}}{R T}\right)
$$

or

$$
S_{A, B}=\left(S_{A B, 1}\right)^{x_{1}}\left(S_{A B, 2}\right)^{x_{2}} \exp \left(\frac{g_{A}^{E}-g_{B}^{E}}{R T}\right)
$$

When using the original $E q, g_{A}{ }^{E}=g_{B}{ }^{E}$, and the selectivity is not a function of the free energy.

It is clear that this theory cannot explain our results as in Eq. 26 the effect of solubility is inoependent of the solute, whereas the most important feature of our results is the fact that the non-linear impact on solubility is strongly different for $\mathrm{CO}_{2}$ as compared to $\mathrm{H}_{2} \mathrm{~S}$.

We have as yet not developed a rigorous quantitative theory. However, there are indications that the nonlinear effects correlate with the impact of the solute on the critical point. Both $\mathrm{H}_{2} \mathrm{~S}$ and $\mathrm{CO}_{2}$ when dissolved change the critical temperature of some of the mixtures, indicating a strong interaction with the solvent. Now even if this is correct it will not lead to a prior prediction as to which solvents are suitable as we have no theory predicting the effect of solutes on the critical point, but it would help in screening.

What is interesting is that in all cases with strong nonlinear effects on upper critical point mixture the critical temperature changed, as can be seen from Table VII.2, where we gave data for several solvents. 
Solvent System

Acetonitrile
+
Water

NMP

Dodecane

NMP

$\stackrel{+}{\text { Heptane }}$

NMP

$\mathrm{MCH}$
Dissolved Gas

$\mathrm{CO}_{2}$

$\mathrm{H}_{2} \mathrm{~S}$

$\mathrm{CO}_{2}$

$\mathrm{H}_{2} \mathrm{~S}$

$\mathrm{CO}_{2}$

$\mathrm{H}_{2} \mathrm{~S}$

$\mathrm{CO}_{2}$

$\mathrm{H}_{2} \mathrm{~S}$
Temperature

Change of CST, ${ }^{\circ} \mathrm{C}$

$+5.5$

$+8.4$

$+0.3$

$+1.0$

$-4.3$

$-8.3$

$-2.0$

$-9.2$ 


\section{$\Gamma$}

VIII. TECHNICAL IMPLICATIONS OF THE RESULTS results

There are several important technical implications of our

one important result of our study that has direct economic value for improving hydrogen separation and would also be useful for syngas is the fact that the selectivity and temperature dependence of solvents can be significantly improved by adding a second solvent forming a critical mixture. Regretfully, we have as yet no reliable means to predict which solvent will improve selectivity, but the fact that our results show large improvements to be feasible opens new doors for new solvents and technology.

Two options are of interest. One is to use a critical one-phase mixture which in the vicinity of the critical point has either greater solvent power and/or selectivity. Another is to use the same effect below the critical point and add a partially miscible solvent such that the composition of the mixture is close to phase separation at that temperature. Thus, NMP which is the solvent for the Purisol process shows at $20^{\circ} \mathrm{C}$ a $35 \%$ higher selectivity for $\mathrm{H}_{2} \mathrm{~S}$ compared to $\mathrm{CO}_{2}$ when $20 \%$ dodecane is added. In an acetonitrile-water mixture the selectivity improvement is $60 \%$.

The temperature dependence of a solvent can also be drastically improved. Both effects are summarized in Fig. VI.12, VI.16 and S.2. This could have a significant economic impact on reducing the cost of hydrogen separation. This method would also be important in purification of natural gas and syngas for manufacture of methanol, Fisher-Tropsch, and petroleum oils from coal. These applications could have considerable economic significance.

b) Process Dependent on Phase Separation

One advantage of operating close to a critical point is the ability of achieving phase separations with relatively small energy expenditures. One way of using this effect is given in Fig. VIII.1. As an example of this method, we can discuss the removal of $\mathrm{CO}_{2}$ by a water- acetonitrile critical mixture.

The gas is contacted first at $0^{\circ} \mathrm{C}$ with a counter current mixture of acetonitrile-water rich in acetonitrile. The gas is then contacted with a mixture of acetonitrile-water rich in water. Each fraction has the composition obtained when a critical mixture of acetonitrile-water is cooled to $0^{0}$ and separated into two phases. The two fractions are then depressurized and heated to $30^{\circ} \mathrm{C}$ to release the $\mathrm{CO}_{2}$. The two fractions are then mixed which releases more $\mathrm{CO}_{2}$. This further release is due to the fact that the solubility of $\mathrm{CO}_{2}$ in the mixed single phase is less thar in the two fractions (see sections VI and VII). The mixture is ther cooled to $0^{\circ} \mathrm{C}$ 
and separated into two phases and reused. This has two advantages. It increases the temperature dependence of the solubility of $\mathrm{CO}_{2}$. Second, the amount of acetonitrile evaporated into the gas stream is reduced as the vapor pressure of acetonitrile in the water-rich fraction is much lower. This reduces the cooling requirement as the process operates with a lower vapor pressure compared to acetonitrile. Acetonitrile might not be the best solvent for this purpose and a higher boiling solvent forming a critical mixture with water would be desirable. A similar scheme might be used with NMP- dodecane for $\mathrm{H}_{2} \mathrm{~S}$.

For hydrogen production'from coal, we see our main achievement in the ability to increase selectivity by suitable solvent addition. This has been a goal of significant research efforts by many companies and here we have supplied a tool of significant economic value. Properly utilized after further research we estimate that this will reduce the cost of separation by $30 \%$, mainly by reducing the large energy requirements. This reduction is due to higher selectivity and increased temperature gradients. 


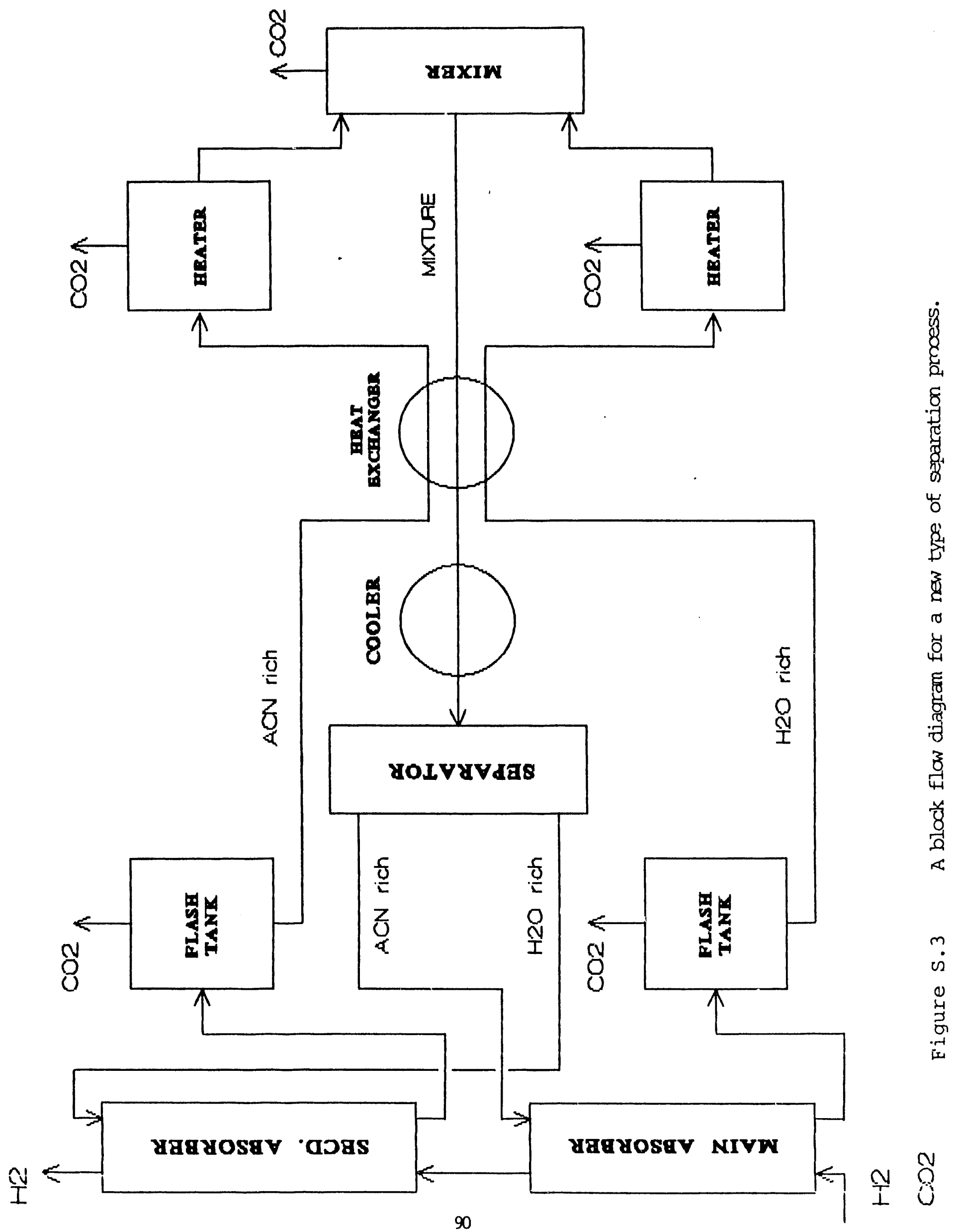


Anon., Hydro. Process. - Gas Processing Handbook, Issue 54, pp. 79-138, 1975 .

Barsem, R.L., et al., "Cryogenic Methane Separation/Catalytic Hydro-gasification Process Analysis," Final Report, DOE Contract ET-78-C-01-3044 by Air Products and Chemicals, Inc., 1980 .

Beacon, D.K., and Roszkowski, T.R., Oil Gas, J., 67, pp. 138$142,1969$.

Benson, H.E., Field, J.H., and Jimeson, R.M., Chem. Eng. Progr., 50, p. 356, 1954 .

Benson, H.E., Field, J.H., and Hagnes, W.P., Chem. Eng. Progr., 52, p. 433, 1956.

Benson, H.E., and Parrish, R.W., "HiPure Process Removes $\mathrm{CO}_{2} / \mathrm{H}_{2} \mathrm{~S}$," Hydrocarbon Processing, 53(4), pp. 81-82, 1974.

Blance, C., and Elgue, J., Hydrocarbon Processing, $60(8)$, p. 111,1981 .

Bottoms, R.R., U.S. Patent 2065112, 1936.

Bratzler, K., and Doerges, A., Hydrocarbon Processing, 53(4), pp. 78-80, 1974 .

Carlson, H.C., and Colburn, A.P., Ind. Eng. Chem., 34 , pp. $581-589,1942$.

Crow, J.H., and Baumann, J.C., Hydrocarbon Processing, 23 (10), p. 131, 1974 .

Franckowiak, S., and Nitscinke, E., Hydrocarbon Processing, 49, pp. 145-148, 1970 .

Garcia Sanches, F., Lauyier, S., and Richard, D., J. Chem. Eng. Data, 32, 211-215, 1987 .

Gueuara, F.M. and Rodriguez, H.T., J. Chem. Eng. Data, 29, $456-460,1984$.

Hegeuer, A.M., and Harris, R.A., Hydrocarbon Process, 49, pp. $54-56,1970$.

Hildebrand, J.H., and Scott, R.L., "The Solubility of Nonelectrolytes," 3rd ed., Reinhold Publishing Corp. New York, $1950 \ldots$

Hise, R.E., Massey, L.G., Adler, P.J., Brosilow, C.B., Gardner, N.C., Brown, W.R., Cook, W.J., and Petrik, M., "The CNG Process, A New Approach to Physical Absorption Acid Gas Removal" paper presented at AJChE Annual Meeting, Nov. 14-18, 1989 . 
Hochgesand, G., Ind. Eng. Chem. 62(7), pp. 37-43, 1970.

Hochgesand, G., "Rectisol and Purisol," European and Japanese Chemical Industries Symposium, Vol. 62, 37-43, 1970.

Hoogendoorn, J.C., and Solomon, J.M., Brit. Chem. Eng., 2, pp. 238-244, 1957 .

Huang, S.H., Lin, H.M. and Chao, K.C., J. Chem. Eng. Data, $143-145,1988$.

Hwang, S.C., and Robinson, R.L. Jr., J. Chem. Eng. Data, $\underline{22}$ 319,1977 .

Judd, D.K., Hydrocarbon Processing, 57(4), p. 122, 1978.

Klein, J.P., Oil and Gas Int., 10, pp. 109-112, 1970.

Kohl, A.L., Petrol. Processing, 6, pp. 26-31, 1953.

Kohl, A.L., and Buckingham, P.A., Petr. Refiner, 39, pp. 193196,1960 .

Kohl, A.L. and Riesenfeld, F.C., "Gas Purification," Fourth Ed., Gulf Publishing Co., Houston-London-Paris-Tokyo, 1985.

Le Roy, C.K., J. Chem. Eng. Data, 20, 463-467, 1975.

Li, Y.H., Dillard, K.H., and Rolinson, R.L. Jr., J. Chem. Eng. Data, 26, 200-204, 1981 .

Lin, H.M., Sebastian, H.M., Chao, K.C., J. Chem. Eng. Data, 24, 146-149, 1979 .

Iin, H.M., Sebastian, H.M., Simnick, J.J., and Chao, K.C., J. Chem. Eng. Data, 24, 146-149, 1979.

Lin, Y.N., Chen, R.J.J., Chappelear, P.S., and Kobayashi, R., J. Chem. Eng. Data, 22, 402-408, 1977 .

Lopez, M.C., Gallardo, M.A., Vrieta, J.S., and Losa, C.G., J. Chem. Eng. Data, 32, 472-471, 1987.

Ludmer, Z., shinnar, R. and Yakhot, V., "Solubility in Binary Mixtures at the Immiscibility Critical Point," AIChE J., Vol. $33,1776-1780,1987$.

Ng, H.J., Huang, S.S.S., and Robinson, P.B., J. Chem. Eng. Data, 30, 177-179, 1985 .

O'Connell, J.P., and Prausnitz, J.M., Ind. Eng. Chem. Found., 3 , pp. 347,1964 .

O'Connell, J.P., "Molecular Thermodynamics of Gases in Mixed Solvents," AIChE J., Vol. 17, 658-663, 1971.

Ohgaki, K., and Katagama, T., J. Chem. Eng. data, 21(53), 1976 . 
Paulaitis, M.E., et al., "Supercritical Fluid Extraction," Rev. Chem. Eng., Vol. 1, 179, 1983a.

Paulaitis, M.E., Penninger, M.L., Gray, R.D., Jr., and Phillips, D., eds., "Chemical Engineering at supercritical Fluid Conditions," Ann Arbor Sci. Pub., 1983b.

Penninger, Jr., M.L., et al., eds., "supercritical Fluid Technology," Elsevier, 1985.

Qader, S.A., "Natural Gas Substitutes from Coal and oil," Elsevier, Amsterdam-oxford-New York-Tokyo, 1985.

Rib, D.M., Kimure, S.G., and Smith, D.P., "Coal-Gas Clean-up Facility," Environmental Progress 2(2), pp. 86-90, 1983.

Sebastian, H.M., Lin, H.M., and Chao, K.C., J. Chem Eng. Data, $\underline{25}, 379-387,1980$.

Senturk, N.H., Kalra, H., and Robinson, D.B., J. Chem. Eng. Data, 24, 311-313, 1979 .

Shinnar, R., "Gas Purification," Literature survey, 1989.

Shinnar, R., "Hydrogen Recovery By Novel Solvent system," Topical Report DOE Contract DE-AC21-87MC23292, 1989.

Sigmund, P.W., Butwell, K.F., and Wassler, A.J., Hydrocarbon Processing, 60(5), p. 118, 1981.

Simnick, J.J., Sebastian, H.M., Lin, H.M. and Chao, K.C., J. Chem. Eng. Data, 24, 239-240, 1979.

Sweng, J.W., and Valentine, J.P., Chem. Eng., 49, pp. 54-56, 1970 .

Sweng, J.W., "The Selexol Process in Fuel Gas Treating," Paper presented at 31 st National Meeting of the AIChE, Missouri, April 11-14, 1976.

Tsal, F.N., Huang, S.H., Lin, H.M., and Chao, K.C., J. Chem. Eng. Data, 32, 467-469, 1987 .

Valentine, J.P., Die Gas J., 72(46), pp. 60-62, 1974 .

Walfer, W., Schwartz, E., Wodrazka, W., and Volkmer, K., Oil and Gas Journal, Jan 21, p. 66, 1980.

Walfer, W., Hydrocarbon Processing, 61(11), p. 193, 1982

Whyte, Jr., T.E., Yom, C.M. and Wagener, E.H., "Industrial Gas Separations," A.C.S., Washington, D.C. 1983.

Yokyoma, C., Mosuoka, H., Arai, K., and Saito, S., J. Chem. Eng. Data, 30, 177-179, 1985. 

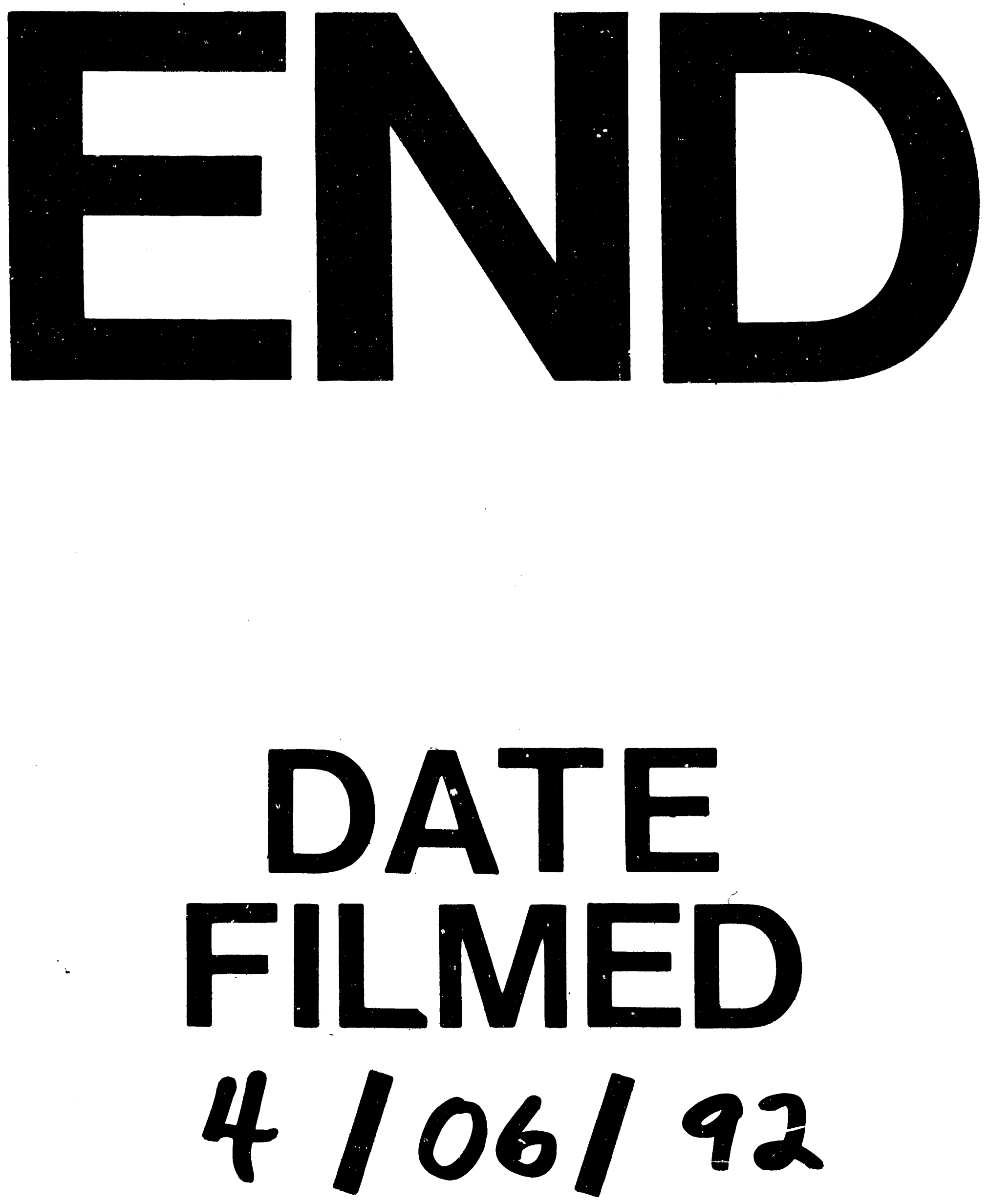
